\author{
UNIVERSIDADE DE SÃO PAULO \\ ESCOLA DE ENFERMAGEM
}

CAROLINA LUIZA BERNARDES

\title{
CONSTRUÇÃO E VALIDAÇÃO DE UMA ESCALA DE CRENÇAS DOS TRABALHADORES DA EQUIPE DE ENFERMAGEM FRENTE AO ACIDENTE DE TRABALHO COM FLUIDO BIOLÓGICO
}




\title{
CONSTRUÇÃO E VALIDAÇÃO DE UMA ESCALA DE CRENÇAS DOS TRABALHADORES DA EQUIPE DE ENFERMAGEM FRENTE AO ACIDENTE DE TRABALHO COM FLUIDO BIOLÓGICO
}

\author{
Versão corrigida da Tese apresentada ao \\ Programa de Pós-Graduação em Gerenciamento \\ em Enfermagem da Escola de Enfermagem da \\ Universidade de São Paulo para obtenção do título \\ de Doutora em Ciências
}

Área de concentração:

Fundamentos e Práticas de Gerenciamento em Enfermagem e em Saúde

Orientadora:

Prof ${ }^{a}$. Dr ${ }^{\text {a }}$. Patricia Campos Pavan Baptista

\begin{abstract}
VERSÃO CORRIGIDA
A versão original encontra-se disponível na Biblioteca da Escola de Enfermagem da Universidade de São Paulo e na Biblioteca Digital de Teses e Dissertações da Universidade de São Paulo.
\end{abstract}


AUTORIZO A REPRODUÇÃO E DIVULGAÇÃO TOTAL OU PARCIAL DESTE TRABALHO, POR QUALQUER MEIO CONVENCIONAL OU ELETRÔNICO, PARA FINS DE ESTUDO E PESQUISA, DESDE QUE CITADA A FONTE.

Assinatura:

Data:

Catalogação na Publicação (CIP)

Biblioteca "Wanda de Aguiar Horta"

Escola de Enfermagem da Universidade de São Paulo

\begin{abstract}
Bernardes, Carolina Luiza
Construção e validação de uma escala de crenças dos trabalhadores da equipe de enfermagem frente ao acidente de trabalho com fluido biológico / Carolina Luiza Bernardes. São Paulo, 2018.

$135 \mathrm{p}$.

Tese (Doutorado) - Escola de Enfermagem da Universidade de São Paulo.

Orientadora: Prof.. Dr. ㄹ. Patricia Campos Pavan Baptista

Área de concentração: Fundamentos e Práticas de Gerenciamento em Enfermagem e em Saúde

1. Enfermagem. 2. Exposição ocupacional. 3. Questionários. 4. Título.
\end{abstract}

Ficha catalográfica elaborada por Fabiana Gulin Longhi Palacio (CRB-8: 7257) 



\section{FOLHA DE APROVAÇÃO}

Nome: Carolina Luiza Bernardes

Título: Construção e Validação de uma Escala de Crenças dos trabalhadores da equipe de enfermagem frente ao acidente de trabalho com fluido biológico.

Tese apresentada ao Programa de Pós Graduação em Gerenciamento em Enfermagem da Escola de Enfermagem da Universidade de São Paulo para obtenção do título de Doutora em Ciências.

Aprovado em

\section{Banca Examinadora}

Orientador: Prof. Dr.

Instituição:

Assinatura:

Prof. Dr. Instituição:

Julgamento: Assinatura:

Prof. Dr. Instituição:

Julgamento: Assinatura:

Prof. Dr. Instituição:

Julgamento: Assinatura:

Prof. Dr. Instituição:

Julgamento: Assinatura:

Prof. Dr. Instituição: Julgamento: Assinatura: 


\section{Dedicatóría}

Ao Rafael, meu companheiro de todos os momentos, peta compreensão e carinho durante esta longa jornada.

Ao meu fitho João Lincoln, minha maior riqueza.

Aos mens pais Lincoln e Maria por terem me mostrado $\sigma$ caminho do saber.

As minhas Irmãs Amália e Natália e Tía Márcia pela amizade, força e por estarem sempre por perto. 


\section{AGRADECIMENTOS}

À orientadora, Prof ${ }^{a}$ Dr $^{a}$ Patricia Campos Pavan Baptista, pela competência, incentivo e parceria durante o desenvolvimento deste trabalho.

Aos colegas do grupo de pesquisa pelas considerações e parcerias.

À Mitti Koyama, por toda a estatística desenvolvida e suas contribuições. 
Bernardes CL. Construção e Validação de uma Escala de Crenças dos trabalhadores da equipe de enfermagem frente ao acidente de trabalho com fluido biológico [tese]. São Paulo: Escola de Enfermagem, Universidade de São Paulo; 2018.

\section{RESUMO}

Introdução: Os trabalhadores da equipe de enfermagem estão expostos as cargas de trabalho durante a realização de suas atividades no ambiente laboral. $O$ acidente de trabalho é a expressão do desgaste do trabalhador em que há exposição às cargas biológicas e mecânicas. Os fatores intrínsecos aos indivíduos, as crenças em relação aos acidentes, influenciam diretamente suas atitudes, favorecendo a ocorrência de exposições. Objetivo: Este estudo teve como objetivo construir e validar uma escala de medida de crenças de trabalhadores de enfermagem frente ao acidente de trabalho com fluido biológico. Método: Estudo metodológico, baseado na teoria de elaboração de instrumental psicológico. Para validação do instrumento foram realizados dois procedimentos: Procedimentos teóricos- composto pela validação de conteúdo por meio da submissão do questionário inicial de 51 itens, para a análise, por um painel de 7 juízes, cujas respostas foram analisadas segundo a relevância, precisão, clareza e objetividade dos itens, em seguida para validação semântica o questionário foi submetido a uma amostra de 40 trabalhadores da equipe de enfermagem de um Hospital Universitário localizado na cidade de São Paulo. Finalizada a validação de conteúdo, iniciou-se os procedimentos experimentais, em que a versão prévia do instrumento construído foi aplicada em uma amostra de 320 trabalhadores da equipe de enfermagem de um Hospital Universitário. Os procedimentos analíticos foram representados pela avaliação da validade de construto testada, e pela confiabilidade da escala, pelo alpha de Cronbach.Resultados: A análise fatorial indicou um instrumento composto por sete fatores e 27 itens com uma consistência interna, alpha de Cronbach, com um valor de alpha igual a 0,84. Conclusão: A versão final da escala apresenta propriedades psicométricas adequadas, revelando a possibilidade de sua utilização em estudos futuros para mensurar as crenças frente ao acidente com fluido biológico.

PALAVRAS-CHAVE: Enfermagem; Exposição ocupacional; Agentes biológicos; Questionário. 
Bernardes CL Construction and Validation of a Beliefs Scale of the nursing team workers against the biological fluid work accident [thesis]. São Paulo: School of Nursing, University of São Paulo; 2018.

\begin{abstract}
Introduction: Health workers are exposed to workloads while performing their activities in the work environment. The work accident is the expression of the wear and tear of the worker in which the biological and mechanical loads are exposed. The factors intrinsic to individuals, beliefs about accidents, directly influence their attitudes, favoring the occurrence of exposures. Objective: The purpose of this study was to construct and validate a nursing workforce belief scale in relation to the work accident with biological fluid. Method: Methodological study, based on the theory of psychological instrumentation. For the validation of the instrument, three procedures were performed: Theoretical Procedures - composed by the validation of content by means of the submission of the initial questionnaire of 51 items, for the analysis, by a panel of 7 judges, whose answers were analyzed according to relevance, precision, clarity and objectivity of the items, then for semantic validation the questionnaire was submitted to a sample of 40 workers of the nursing team of a University Hospital located in the city of São Paulo. After the validation of content, the experimental procedures were started, in which the previous version of the built instrument was applied to a sample of 320 workers of the nursing team of a University Hospital. The analytical procedures were represented by the evaluation of the tested construct validity and by the reliability of the scale by the cronbach alpha. Results: The factorial analysis indicated an instrument composed of seven dimensions and 27 items with an internal consistency, Cronbach's alpha, with a alpha value equal to 0.84 . Conclusion: The final version of the scale presents adequate psychometric properties, revealing the possibility of its use in future studies to measure the beliefs about the accident with biological fluid.
\end{abstract}

KEYWORDS: Nursing; Occupational exposure; Biological agentes; Questionnaire 


\section{SUMÁRIO}

1 INTRODUÇÃO

1.1 Os acidentes de trabalho com exposição aos fluidos biológicos .............. 14

1.2 As crenças dos trabalhadores da equipe de enfermagem relacionadas aos acidentes de trabalho com fluidos biológicos .....................................23

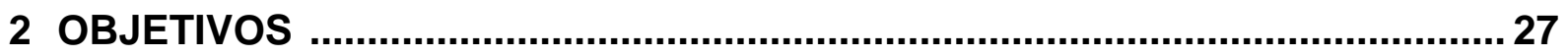

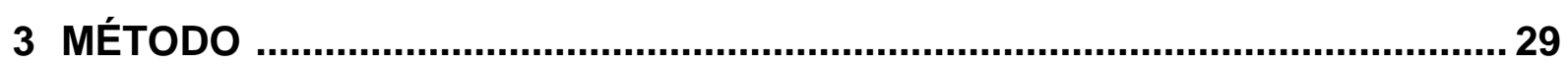

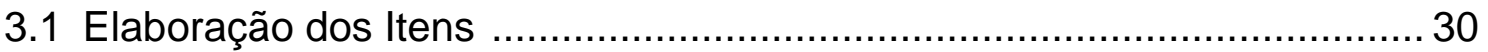

3.2 Validação de Conteúdo .................................................................... 32

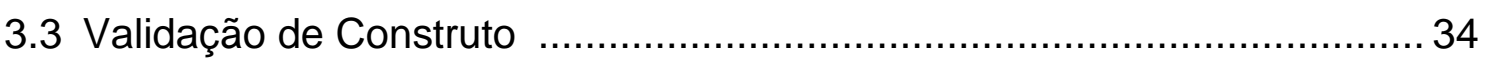

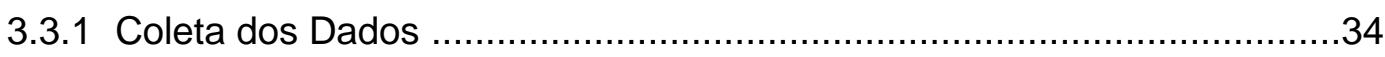

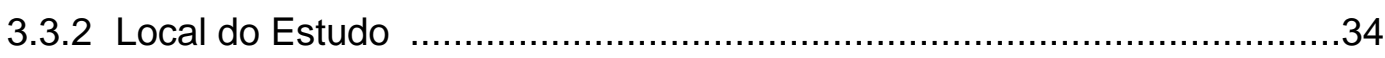

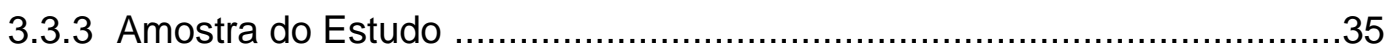

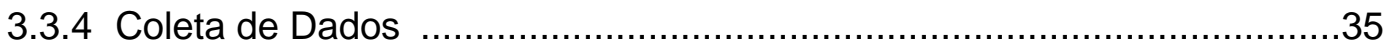

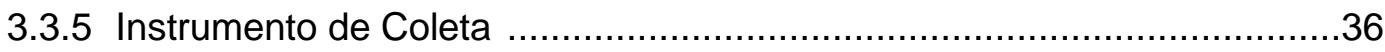

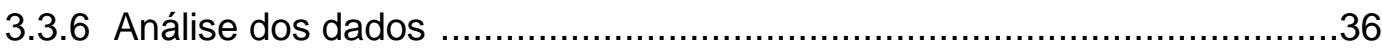

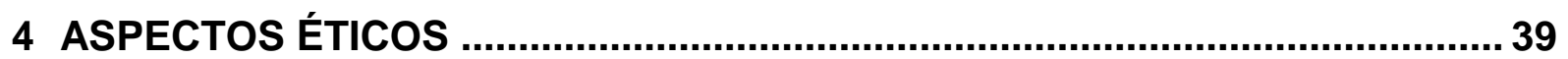

5 RESULTADOS

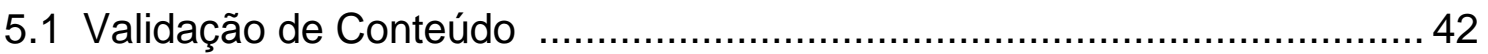

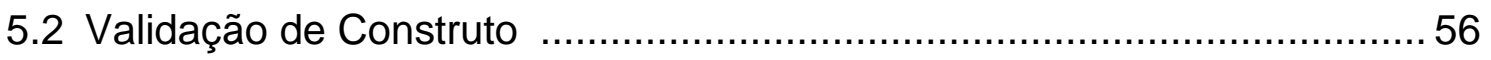

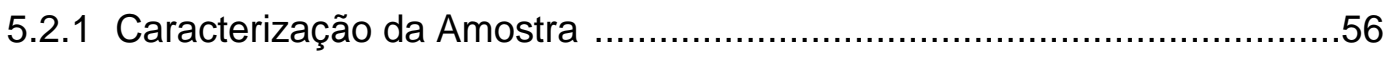

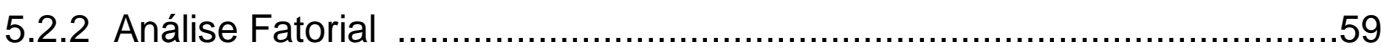

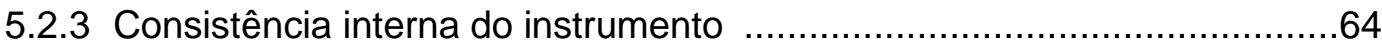

5.2.4 Versão Preliminar da Escala de Crenças dos trabalhadores da equipe de Enfermagem frente ao acidente de trabalho com fluido

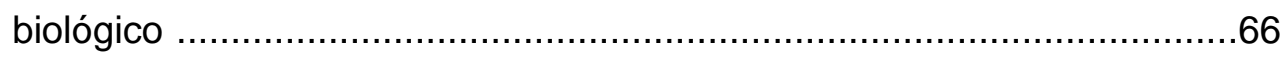

5.2.5 Escore da Escala de Crenças dos trabalhadores da equipe de Enfermagem frente ao acidente de trabalho com fluido biológico .............68

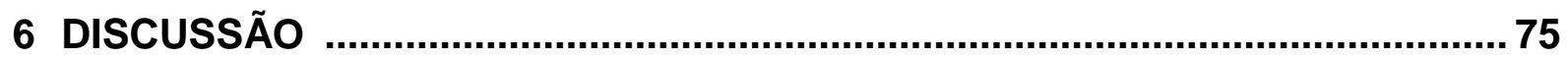

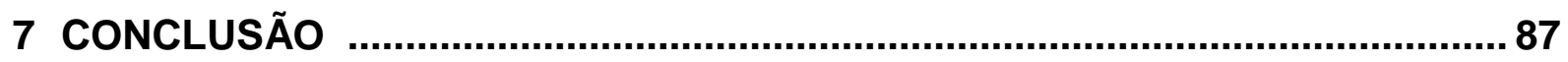

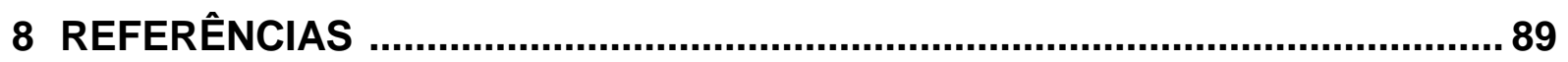

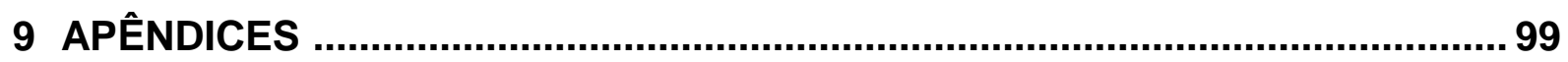

10 ANEXOS 


\section{LISTA DE TABELAS}

Tabela 1. Caracterização dos juízes segundo formação acadêmica, nível de formação, vínculo institucional e linha de pesquisa. São Paulo, SP, Brasil, 2018

Tabela 2. Distribuição das respostas dos juízes segundo a clareza dos itens. São Paulo, SP, Brasil, 2018

Tabela 3. Distribuição das respostas dos juízes segundo a relevância dos itens. São Paulo, SP, Brasil, 2018 46

Tabela 4. Distribuição das respostas dos juízes segundo a objetividade dos itens. São Paulo, SP, Brasil, 2018 48

Tabela 5. Distribuição das respostas dos juízes segundo a precisão dos itens. São Paulo, SP, Brasil, 2018 50

Tabela 6. Itens da Escala de Crenças dos trabalhadores da equipe de enfermagem relacionadas aos acidentes de trabalho com fluido biológico após análise de conteúdo. São Paulo, SP, Brasil, 2018 52

Tabela 7. Itens da Escala de Crenças dos Trabalhadores da Equipe de Enfermagem frente aos acidentes de trabalho com fluido biológico após análise semântica. São Paulo, SP, Brasil, 2018

Tabela 8. Caracterização dos trabalhadores de enfermagem. São Paulo, SP, Brasil, 2018

Tabela 9. Distribuição dos profissionais por resposta dos 37 itens da escala de crenças. São Paulo, SP, Brasil, 2018 58

Tabela 10. Distribuição dos Itens eliminados e respectivas comunalidades. São Paulo, SP, Brasil, 2018 59

Tabela 11. Cargas Fatoriais, porcentagem da variância explicada e coeficiente Alpha de Cronbach dos 10 fatores da escala de crenças. São Paulo, SP, Brasil, 2018 
Tabela 12. Correlação item-total corrigida, Alpha de Cronbach global e se o item for excluído. São Paulo, SP, Brasil, 2018

Tabela 13. Escala de Crenças em sua versão preliminar, após a validade de construto. São Paulo, SP, Brasil, 2018 66

Tabela 14. Distribuição da pontuação bruta e re-escalonada da Escala de Crenças segundo a dimensão 1. São Paulo, SP, Brasil, 2018 69

Tabela 15. Distribuição da pontuação bruta e reescalonada da Escala de Crenças segundo a dimensão 2. São Paulo, SP, Brasil, 2018 70

Tabela 16. Distribuição da pontuação bruta e reescalonada da Escala de Crenças segundo a dimensão 3 e 4. São Paulo, SP, Brasil, 2018 .70

Tabela 17. Distribuição da pontuação bruta e rescalonada da Escala de Crenças segundo a dimensão 1. São Paulo, SP, Brasil, 2018

Tabela 18. Distribuição da pontuação bruta e rescalonada da Escala de Crenças segundo a dimensão 7. São Paulo, SP, Brasil, 2018

Tabela 19. Distribuição total da pontuação bruta e reescalonada da Escala de Crenças dos Trabalhadores da Equipe de Enfermagem frente ao acidente de trabalho com fluido biológico. São Paulo, SP, Brasil, 2018 


\section{INTRODUÇÃO}


Os trabalhadores da saúde estão expostos às cargas de trabalho durante a realização de suas atividades profissionais e os acidentes de trabalho são a expressão do desgaste do trabalhador (Laurell, Noriega, 1989).Tratando-se dos acidentes de trabalho entre os trabalhadores de enfermagem, destacam-se os acidentes com fluido biológico, em que há exposição as cargas biológicas e mecânicas. Essa exposição ocupacional pode colocar o trabalhador em risco de adquirir infecções como o HIV, Hepatite B e C.

Percebe-se o grande número de estudos relacionados aos acidentes, bem como o incentivo à adoção das práticas preventivas no ambiente laboral. Entretanto, os números dessas ocorrências ainda são alarmantes no cenário mundial.

Estudo realizado nos Estados Unidos que analisou as lesões ocupacionais entre os anos de 2002 e 2015 em um centro médico acadêmico demonstrou que de um total de 266 casos, a maioria foi causada por lesões percutâneas (52,6\%), 43,2\% de lesões mucocutâneas. Dessas lesões 52,6\% foram nas mãos e 33,5\% envolveram a face e o pescoço. Desses de casos, 64,3\% representaram exposição ao sangue e, dos trabalhadores acidentados, $21,1 \%$ receberam profilaxia pós exposição (Egro et al., 2017).

Em Massachusetts, um programa de vigilância implementado nos hospitais entre os anos de 2002 e 2012, envolvendo todos os trabalhadores de saúde licenciados pelo Departamento de Saúde Pública, registrou um total de 34.358 casos de ferimentos cortantes. Em relação às notificações, $38 \%$ dos acidentados eram enfermeiros, (24\%) envolveram o procedimento de injeção e o acidente ocorreu durante o uso do objeto (44\%); o setor com maior número de acidentes foi o centro cirúrgico e a sala de procedimentos (43\%); os dispositivos mais envolvidos nas exposições foram a agulha hipodérmica e seringa (30\%) e agulha de sutura (22\%) (OHSP,2015).

O presente estudo, surgiu a partir dos resultados obtidos com a pesquisa desenvolvida no curso de Mestrado, em que se buscou desvelar a vivência dos trabalhadores da equipe de enfermagem que sofreram acidente de trabalho com fluido biológico,evidenciando as causas dos acidentes, bem como as dificuldades encontradas pelos trabalhadores após a exposição ao fluido biológico. 
Os resultados desta pesquisa, aliados à experiência adquirida como enfermeira em uma Unidade de Emergência e como docente durante a supervisão de estágio em serviços de saúde, fizeram-me refletir sobre as crenças dos trabalhadores em relação aos acidentes, que podem estar associadas as suas atitudes e ao comportamento adotado em relação a adoção de medidas preventivas, favorecendo a ocorrência de exposições.

Desse modo, as crenças dos trabalhadores, construídas ao longo da vida profissional relacionadas aos acidentes de trabalho com fluidos biológicos interferem nas práticas seguras e podem estar associadas as suas atitudes e o comportamento adotado em relação a adoção de medidas preventivas, favorecendo a ocorrência de exposições, no seguimento clínico após o acidente e as recorrências.

Tratando-se das crenças em relação ao acidente com fluido biológico, existem diversos estudos que as identificam e descrevem, entretanto, não foi encontrado nenhum instrumento que identifique e mensure essas crenças. Tendo em vista esta lacuna no campo da saúde do trabalhador, surgiu a idéia de elaboração de um instrumento que pudesse identificar e mensurar, especificamente, as crenças dos trabalhadores frente aos acidentes de trabalho com fluido biológico, considerando que a aplicação de uma escala de crenças poderá fornecer às instituições de saúde, indicadores válidos acerca das atitudes dos trabalhadores em relação aos fluidos biológicos, para subsidiar o desenvolvimento de práticas preventivas e de vigilância em saúde do trabalhador. Considerando a importância das estratégias de gestão para transformação das crenças e à adoção de atitudes mais favoráveis. 


\subsection{Os acidentes de trabalho com exposição aos fluidos biológicos}

Entende-se por trabalho, a transformação de uma matéria-prima em um produto final a partir de uma necessidade comum. Para tanto, o homem é um ser capaz de se organizar para produzir algo voltado para uma finalidade específica. Assim, todo processo de trabalho é constituído por alguns elementos assim denominados: objeto de trabalho, os meios e instrumentos e a atividade adequada a um fim (Marx, 1994).

O processo de trabalho da equipe de enfermagem está inserido na prestação de serviços à saúde e tem como objetivos, a produção de saúde por meio do cuidado ao indivíduo e o atendimento de suas necessidades (Felli, Peduzzi, 2016). É um processo dinâmico, interativo, permeado por fatores extrínsecos e intrínsecos ao sujeito trabalhador e ao indivíduo que está sendo cuidado.

Trtando-se de exposição do trabalhador, o referencial teórico da Medicina Social incorpora o conceito "cargas de trabalho", constituindo-se elementos presentes no processo de trabalho que interagem entre si e com o corpo do trabalhador de maneira dinâmica, resultando em processos de adaptação denominados desgastes, e caracterizados pela perda ou diminuição da capacidade laboral. Essas cargas, por sua vez, são agrupadas em físicas, químicas, biológicas, mecânicas, fisiológicas e psíquicas (Laurell, Noriega, 1989).

As cargas físicas estão relacionadas aos elementos presentes no ambiente de trabalho externos ao corpo do trabalhador, assim como o ruído, o calor, a umidade e a radiação. As cargas químicas, são caracterizadas por agentes como a fumaça, o pó, os vapores; as cargas biológicas dizem respeito aos microrganismos presentes no ambiente de trabalho; as cargas mecânicas tratam da ruptura da solução de continuidade do corpo, como as fraturas, contusões, cortes, perfurações; as cargas fisiológicas, compreendem as posições inadequadas e incômodas e o trabalho em turnos; por fim, as cargas psíquicas são identificadas por meio do estresse, situações de tensão prolongada e cansaço (Laurell, Noriega, 1989). 
Nessa perspectiva, a partir do referencial da medicina social, em um acidente de trabalho ocorre a interação entre diferentes cargas devido à complexidade dos fatores envolvidos.

O acidente de trabalho com fluido biológico pode ser descrito como a expressão do desgaste do trabalhador, em decorrência da exposição às cargas biológicas e às cargas mecânicas. A exposição às cargas biológicas ocorre por meio da realização de procedimentos invasivos e contato direto com fluidos biológicos e as cargas mecânicas são decorrentes de lesões percutâneas em que há rompimento da solução de continuidade da pele. Durante o acidente, o trabalhador pode ser exposto a patógenos transmitidos pelo sangue entre eles os vírus HIV, Hepatite B e Hepatite C (OSHA, 2011).

No Brasil, segundo dados do Anuário da Saúde do Trabalhador, ocorreram 717.911 acidentes de trabalho no ano de 2013, sendo que a atividade econômica com maior número de exposições foram as atividades de atendimento hospitalar, com 56.854 casos. O número de notificações de acidentes de trabalho com exposição a material biológico foi de 47.292 em 2014 e a região Sudeste do país apresentou o maior número de notificações com 22.277 casos notificados (Dieese, 2016).

A caracterização desses acidentes demonstrou que dos trabalhadores DA área da saúde acidentados, 78,5\% são mulheres, a faixa etária que mais sofreu acidentes foi a de 20 a 29 anos (36,3\%); segundo a escolaridade $61,9 \%$ dos acidentados tinham o ensino médio completo ou superior incompleto (Dieese, 2016).

A distribuição das notificações por condição de ocupação apresentou que 56,0\% possuíam carteira de trabalho assinada; em relação ao tempo de permanência, 26,2\% tinham mais de 5 anos no trabalho e quanto à consequência do acidente, $87,7 \%$ tiveram alta ou cura do tratamento. No que se refere a distribuição das notificações com ou sem emissão da Comunicação de Acidente de Trabalho (CAT), 75,5\% dos acidentes de trabalho com exposição a material biológico tiveram a emissão da notificação (Dieese, 2016). 
Em relação à classificação das 20 ocupações com maiores ocorrências de notificações de acidentes de trabalho com exposição a material biológico no Brasil, a maior incidência está entre os Técnicos e auxiliares de enfermagem com $23.466(49,6 \%)$ casos, seguidos dos Enfermeiros e afins com $3.998(8,5 \%)$ notificações (Dieese, 2016).

Quando observados trabalhadores da área da saúde da Inglaterra, país de Gales e Irlanda do Norte, foram descritos 2947 acidentes, houve um aumento de $67 \%$ dos acidentes perfurocortantes em 2011 em relação a 2002, principalmente das exposições envolvendo pacientes portadores de HIV, Hepatite B e C (Rice, Tomkins, Ncube, 2015).

Jaramillo et al., (2010) demonstraram que no Equador entre 795 trabalhadores da área da saúde entrevistados, 53\% afirmaram terem tido mais de um acidente com fluido biológico; 70,2\% referiram ter recebido capacitação no serviço onde atuam.

Na Índia, Jain, Sabharwal, Srivastava (2016) entrevistaram 165 sujeitos e verificaram que a prevalência de exposição acidental foi de $49,7 \%$ no grupo estudado; $20 \%$ deste grupo não havia sendo imunizado para Hepatite B.

Percebe-se, que embora existam estratégias de prevenção, sendo desenvolvidas e implementadas em diferentes países do mundo, as questões referentes aos acidentes de trabalho são ainda subjugadas pelos próprios trabalhadores, nas discussões diárias, nos acordos de convenção coletiva e nas sociedades de classe. É como se tudo já houvesse sido dito, porém, ainda, restam inúmeras questões intrínsecas a serem trabalhadas nas equipes de enfermagem.

Tratando-se dos acidentes de trabalho com fluidos biológicos, estes podem ser classificados de acordo com o tipo de exposição em: percutâneos, onde há rompimento da solução de continuidade da pele por meio de um objeto pontiagudo, bisturi ou agulha; contato com mucosas, ou seja, respingos em boca, nariz, olhos e o contato de pele não íntegra com o sangue e outros fluidos. (Center for disease Control e Prevention, 2001). 
Pesquisadores apontam que a incidência de exposições é maior na equipe de Enfermagem e os setores de maior ocorrência são a clínica médica, bloco cirúrgico e a unidade de Terapia intensiva. O tipo de acidente mais frequente é aquele envolvendo agulhas com a presença de sangue e as exposições ainda ocorrem em situações onde houve o reencape das agulhas (Costa et al., 2015; Denic et al., 2015; Giancotti et al., 2014; Beltrame et al., 2015).

No que concerne ao tipo de exposição no Brasil, em 2013, dos acidentes registrados, 56,7\% foram percutâneos, 27,2\% envolveram pele íntegra, 10\% ocorreram em mucosas, 4,8\% em pele não íntegra e 1,3\% envolveram outros tipos de exposição (Dieese, 2016).

Na Colômbia, foram registradas 2403 exposições a material biológico durante o período de 2009 a 2014, destas, 82,4\% dos trabalhadores ocorreram em mulheres; 47,5\% trabalhadores de enfermagem; 53,0\% dos acidentes ocorreram com perfuração de agulhas ocas e houve um caso de soroconversão ao vírus HIV (Diaz et., 2015). Neste mesmo país, outro estudo apontou para a exposição de mucosas oculares como o segundo mecanismo reportado por $44 \%$ dos 780 estudantes da área da saúde entrevistados em uma instituição de ensino superior, entre 56 a 94\% procuraram o serviço de emergência após a exposição (Galindo et al., 2011).

Butsashvili et al. (2012) verificaram, no estado da Georgia- EUA, que dos 1386 trabalhadores entrevistados, 45\% relataram acidentes com agulhas; $38 \%$ envolvendo cortes com instrumentos contaminados, $46 \%$ respingos de sangue. Os acidentes com agulhas ocorreram em sua maioria entre os médicos (22\%) e enfermeiros (39\%) e estavam relacionados ao reencape de agulhas usadas.

Outra pesquisa, realizada no segundo maior estado dos Estados Unidos, o Texas, verificou-se 1447 acidentes de trabalho com objetos perfurocortantes. Destes acidentes, 81,7\% ocorreram em hospitais; 7,9\% em clínicas com serviços de emergência. Quanto aos trabalhadores, as enfermeiras com registro sofreram $24,5 \%$ dos acidentes, seguido de estagiários (19,8\%) e médicos residentes $(13,3 \%)$. Grande parte das lesões ocorreram após às $7 \mathrm{~h}$ e antes das $15 \mathrm{~h}$. Em 
relação ao sexo, 62,4\% dos acidentados eram do sexo feminino; 41,3\% tinham de 26 a 35 anos (Texas, 2016).

Os dados deste mesmo estudo foram categorizados nos cinco principais tipos de instrumentos que causaram as lesões. As agulhas envolvendo seringas foram responsáveis por $37,2 \%$ de todas as lesões. As agulhas de sutura foram 0 segundo maior, com $20,9 \%$. As lesões causadas por scalps foi menor que $10 \%$ e outros tipos de objetos cortantes, não incluídos nos cinco primeiros, representaram um total combinado de 19,8\% das lesões (Texas, 2016).

$\mathrm{Na}$ Tailândia, estudo retrospectivo realizado entre 2005 e 2010 identificou 1.611 casos registrados, os enfermeiros eram os mais frequentemente expostos (483 casos), a lesão percutânea por agulhas ocas foi o tipo mais comum de lesão 35,8\%, 142 trabalhadores foram expostos a fontes HIV positivo (Chaiwarith et al., 2013).

Samargandy et al (2016) verificou 326 exposições na Arábia Saudita em um Hospital de ensino entre 2007 e 2013 das quais, 302 (92,6\%) foram as exposições percutâneas, 21 (6,5\%), mucocutânea, e 3 (0,9\%), mordedura. A equipe de enfermagem teve maior taxa de exposição (149 ou 45,6\%), seguido por médicos (57 ou 17,5\%). A maioria dos acidentes foi ocasionado por agulhas ocas (216 ou $72,5 \%)$.

Malka et al. (2012) em estudo retrospectivo realizado na Romênia entre 2002 e 2011 investigou 60 trabalhadores, com idade média de 36 anos que relataram quase uma exposição ocupacional durante um período de 9 anos, 54 (90\%) eram do sexo feminino; 48 (80\%) eram enfermeiros; em 49 (81,6\%) dos casos, a exposição foi percutânea e em 11 (18,3\%) a exposição foi de mucosa.

Ao mesmo tempo em que o levantamento quantitativo destas exposições é realizado, torna-se necessária a identificação das causas e circunstâncias em que os acidentes ocorrem, visando a contextualização dos acidentes e reconhecimento dos comportamentos de risco, buscando estratégias de intervenção específicas voltadas, não apenas a Utilzação de Equipamentos de 
Proteção Individual, mas aos motivos pelos quais os trabalhadores deixam de utilizá-los em algumas situações de risco iminente.

Em 2013, 26,9\% dos acidentes notificados no Brasil, ocorreram durante o descarte inadequado de material perfurocortante, seguido de 19,4\% durante a punção venosa/arterial; 19,2\% durante a administração de medicação; 17,2\% em um procedimento cirúrgico, odontológico ou laboratorial e 6,9\% na realização de teste de glicemia capilar. Quanto à distribuição das notificações segundo a utilização de equipamento de proteção individual (EPI), 91,3\% ocorreram sem utilização de EPI e 8,7\% com a utilização de EPI (Dieese, 2016).

Entre as causas dos acidentes de trabalhos com fluidos biológicos e entre os fatores que favorecem a ocorrência das exposições, evidenciam-se as características do paciente ao qual se presta o cuidado e o trabalho a ser feito, desconhecimento e mau uso dos instrumentos de trabalho, a não utilização dos equipamentos de proteção individual, o reencape de agulhas, o descarte inadequado de materiais perfurocortantes, o preenchimento das caixas coletoras acima do recomendado, estrutura do ambiente de trabalho e fatores elencados como relevantes como o comportamento humano e a própria organização do processo de trabalho (Abad et al., 2012; Bernardes, 2014; Julio, Filardi, Marziale, 2014).

Outro estudo apontou para fatores psicossociais como preditores dos acidentes de trabalho. Entre esses fatores estão a idade, sexo, grau de instrução, estado civil, emprego, número de vínculos de trabalho, setor de trabalho, trabalho por turnos, treinamento no trabalho e nível de estresse (Mehrdad, 2014).

Após a exposição biológica, a possibilidade de soroconversão, dentre outros fatores, desencadeiam sentimentos e emoções promotores do sofrimento psíquico que sinalizam a urgência da transformação das práticas de proteção no trabalho (Magagnini, Rocha, Ayres, 2011). O atendimento ao trabalhador após exposição ocupacional é primordial para o acolhimento, desmistificação do acidente, orientações e seguimento após exposição. Nesse sentido, após o acidente, deve ocorrer a avaliação da exposição por um profissional médico especializado e deve contemplar o tipo de exposição; tipo e quantidade de fluido e tecido; "status" 
sorológico da fonte, "status" sorológico do acidentado e susceptibilidade do trabalhador exposto (Center for disease Control e Prevention, 2005).

No continente africano, na província de Limpopo na África do Sul, estudo conduzido em um hospital rural com 233 enfermeiros, identificou que $40 \%$ dos trabalhadores desconhecia o protocolo pós exposição e $22 \%$ não sabiam ou não tinham certeza se ele estava disponível no hospital; 54\% dos entrevistados não receberam o procedimento pós exposição quando necessitaram (Makhado, Davhana- Maselesele, 2016).

Ao mesmo tempo, na Tanzânia, de 401 trabalhadores entrevistados mais de um quarto não tinha conhecimento sobre a transmissão ocupacional de HIV e em quais circunstâncias a profilaxia pós exposição é indicada (Mashoto, Mubyasi, Mushi, 2015).

Durante o atendimento, o acidentado deve receber orientações e aconselhamento com relação ao risco de recorrência de acidente, possível uso de quimioprofilaxia, comprometimento com o tratamento durante seis meses após a exposição, suporte emocional, reeducação quanto aos princípios da biossegurança e notificação do acidente por meio do registro do acidente em Comunicação de Acidente de Trabalho e preenchimento da ficha de notificação compulsória do Sistema de Informação de Agravos de Notificação (Brasil, 2004; Brasil, 2006).

A literatura evidencia que as causas relacionadas ao não seguimento do tratamento profilático pelos trabalhadores de enfermagem pós-exposição estão associadas aos efeitos colaterais das drogas, a não conscientização, à falta de conhecimento sobre as condutas a serem realizadas após o acidente e à falta de preparo emocional relacionada ao medo e a angústia dos profissionais, frente à possibilidade de adquirir HIV-AIDS (Paiva, Oliveira, 2011).

Estudo realizado visando identificar a ocorrência e características dos acidentes do trabalho registrados no Sistema de Informação de Agravos de Notificação (SINAN) direcionadas ao Centro Regional de Saúde do Trabalhador (CEREST) de uma cidade do interior de São Paulo verificou que, o número de acidentes notificados é baixo se comparado ao número de trabalhadores expostos. 
Os autores apontam que dada à importância da notificação dos acidentes para o desenvolvimento de estratégias preventivas é necessário a conscientização dos trabalhadores quanto à importância da notificação e o treinamento e capacitação dos profissionais para melhor preenchimento dos registros, visando o aperfeiçoamento das informações contidas nos sistemas de informação (Valim, Marziale, 2012).

Estudo desenvolvido na perspectiva da fenomenologia, evidenciou que parte dos trabalhadores não notifica o acidente ou o fazem pela metade, devido à lentidão, burocracia, ausência de acolhimento e estrutura institucional. Os trabalhadores, também, relataram a negligência dos gestores em relação à exposição, falta de apoio e desconhecimento do fluxo de atendimento quanto aos cuidados subsequentes (Bernardes, 2014).

As questões relativas ao protocolo de atendimento ao trabalhador pós exposição ainda são problemáticas em muitas instituições de saúde. Por vezes, a rotina a ser seguida após uma exposição ocupacional está descrita mas não é incorporada por todos os trabalhadores, primordialmente pelos enfermeiros, líderes de equipes e que têm como função orientar e acolher os trabalhadores acidentados.

Como forma de prevenção dos acidentes de trabalho são utilizadas as precauções padrão que incorporaram o conceito das precauções universais e o isolamento para substâncias corporais. As precauções padrão se aplicam a todas as situações em que houver a possibilidade de exposição do trabalhador aos fluidos biológicos, sendo recomendado o uso de óculos, máscaras, luvas e aventais, como forma de barreira (Brasil, 2004).

Em relação ao uso dos EPS's, alguns autores internacionais identificaram que a principal razão para o descumprimento às precauções padrão é a indisponibilidade dos equipamentos, conhecimento, atitude, clima de segurança e carga de trabalho (Amoran, Onwube, 2013; Butsashvili et al., 2012; Quan et al., 2015).

Em Massachusets-, as análises demonstram que, nos hospitais de cuidados críticos, os ferimentos cortantes declinaram 17,8\%. Enquanto que, 0 relatório aponta como inaceitável o fato que em $55 \%$ dos acidentes não houve a 
utilização dos equipamentos de proteção individual que encontra-se disponível há quase duas décadas (OHSP, 2015).

Leow et al., (2012) estudaram alguns países de baixa e média renda (Afeganistão, Gambia, Gana, Liberia, Mongolia, Serra Leoa, Siri Lanka, Ilhas Salomão) em relação à oferta de equipamentos de proteção individual aos trabalhadores e observaram que nenhum dos países estudados tinha $100 \%$ de oferta de equipamentos de proteção individual aos trabalhadores; os óculos de proteção estavam disponíveis em apenas um hospital no Siri Lanka (4\%) e em maior quantidade na Libéria (56\%), enquanto que, a disponibilidade de luvas estéreis variou de $24 \%$ no Afeganistão e $94 \%$ em Gana.

Dessa forma, entende-se como necessário o desenvolvimento de um sistema efetivo de vigilância aos profissionais acidentados, no tocante à notificação, ferramenta fundamental para identificação de possíveis agravos decorrentes da exposição ocupacional. (Bahadori, Sadigh, 2010; Bernardes et al., 2014; Gessner et al., 2013; Silva et al., 2013).

Assim, é evidente o papel das instituições na prevenção dos acidentes no trabalho, paralelamente a existência de um comitê de biossegurança, de protocolos bem divulgados que podem favorecer o alcance de resultados favoráveis em relação ao uso dos equipamentos de proteção individual, notificação do acidente e profilaxia pós exposição (Lages et al., 2015, Magagnini et al., 2015).

Para que isto ocorra, torna-se perceptível a necessidade de estratégias que intensifiquem a notificação e o acompanhamento do trabalhador acidentado. Estudos apontam que os Centros de Referência em Saúde do Trabalhador presentes em nosso país são ferramentas fundamentais no atendimento às exposições ocupacionais e aspectos como a infraestrutura, capacitação de pessoal e quantidade adequada, bem como o atendimento a trabalhadores externos devem ser prioritários para a redução dos altos índices de subnotificação das exposições aos fluidos biológicos (Galdino, Santana, Ferrite, 2012). 


\subsection{As crenças dos trabalhadores da equipe de enfermagem relacionadas aos acidentes de trabalho com fluidos biológicos}

Como visto, a epidemiologia dos acidentes de trabalho com fluido biológico no Brasil e em diversos países no mundo demonstra a problemática dessas ocorrências para a saúde do trabalhador e para o processo de trabalho como um todo.

Sabe-se da importância do desenvolvimento de estratégias capazes de modificar as práticas dos trabalhadores no contexto organizacional e para o alcance dessas modificações torna-se importante identificar os fatores que influenciam as atitudes dos trabalhadores em relação aos acidentes no processo de trabalho.

É sabido, que esse processo é permeado por escolhas, ações, atitudes que são diretamente influenciados pelas crenças dos trabalhadores. As crenças são estruturas formadas a partir da visão de um sujeito sobre determinado objeto. Existem as crenças centrais e as periféricas, as crenças centrais ou também denominadas primitivas são aquelas mais resistentes a mudanças,como a identidade do indivíduo, enquanto que, as crenças periféricas são menos resistentes a mudanças, podem ser modificadas e estão relacionadas por exemplo, as práticas de trabalho (Ajzen, Fisbein, 1980).

Alguns estudos já foram realizados no Brasil com o objetivo de identificar as crenças presentes no contexto do trabalho que é o objetivo da presente pesquisa. Esses estudos investigaram as crenças dos trabalhadores sobre o sistema de treinamento e desenvolvimento de trabalhadores de duas organizações e apontaramm para a importância no desenvolvimento de ferramentas que possam identificar as crenças no contexto organizacional e assim contribuir para melhorias no processo de trabalho (Freitas, Borges-Andrade, 2004).

Existem alguns modelos que tentam explicar a adoção de medidas preventivas a partir da relação entre crenças individuais e comportamento. Um desses modelos é o Modelo de Crenças em Saúde, em que o comportamento preventivo está baseado em alguns fatores: a percepção da suscetibilidade, o indivíduo acredita no risco ao qual está exposto e a possibilidade de adoecimento, a 
Percepção de severidade caracterizada pela associação entre o problema de saúde a gravidade de suas consequências, a Percepção de benefícios em que há percepção de que o problema pode ser prevenido por meio de uma ação, mesmo que o desenvolvimento dessa ação possa gerar situações desconfortáveis, gastos financeiros, entre outros e a Percepção de barreiras ou seja, para que o sujeito desenvolva a percepção de suscetibilidade e severidade é importante a presença de estímulos para a ação, como forma de motivá-lo a agir (Rosenstock, 1990).

Nesta perspectiva, em pesquisa publicada sobre a aplicação do modelo de crenças em saúde na prevenção dos acidentes com agulha, verificou-se que, dos 319 trabalhadores entrevistados, 75\% relataram reencapar agulhas pelo menos alguma vez, enquanto que, aqueles que adotavam a recomendação de não reencape tinham menos de dois de experiência profissional, percebiam menos barreiras e mais benefícios na adoção da recomendação de não reencapar agulhas (Brevidelli, 2001).

Outro estudo, que analisou os depoimentos de trabalhadores, evidenciou que os mesmos não reconhecem o ambiente laboral como preditor potencial de acidentes ocupacionais, e também não observam o contexto da assistência antes de planejar e executar suas atividades. E ainda, ao reconhecerem os riscos aos quais estão expostos, não modificam o comportamento, não se sentem vulneráveis devido à autoconfiança adquirida com os anos de experiência e técnica profissional (Magagnini, Rocha, Ayres, 2011).

Ainda baseado no modelo de Crenças em Saúde, Sailer, Marziale (2007), verificaram as crenças significativas para a adesão dos trabalhadores ao tratamento antirretroviral. Entre aqueles que aderiram ao tratamento, apresentaram crença na suscetibilidade da ocorrência de acidentes, ou seja, podem sofrer o acidente; crença na severidade da doença, preocupação e medo em adquirir HIV/AIDS e o apego a vida diante da ameaça detectada. Quantos às crenças para o não seguimento do tratamento são relacionadas aos efeitos colaterais das drogas e às exigências de regularidade nos horários de tomada da medicação antirretroviral.

Percebe-se que o trabalhador acredita que pode sofrer 0 acidente, isso gera um impulso positivo para o uso dos Equipamentos de proteção individual, 
principalmente, ao refletir sobre as consequências para sua família, por outro lado também, existe a ausência de medo e a crença de que nada irá acontecer, que podem influenciar a desproteção (Neves et al., 2011).

As crenças dos trabalhadores de saúde em relação ao acidente impedem a adesão à profilaxia pós acidente e ao seguimento clínico do trabalhador acidentado pois, os trabalhadores têm conhecimento incipiente sobre a forma de contágio, apresentam crenças relacionadas à suscetibilidade ao acidente, gravidade das doenças que podem ser adquiridas e acreditam que o acompanhamento sorológico é um benefício, bem como a importância de comportamentos voltados para a prevenção das exposições aos fluidos biológicos (Wall et al., 2011).

Considerando que as crenças dos indivíduos geram consequências para o contexto organizacional Weiss (2002) e diante da escassez de uma escala de medida de crenças dos trabalhadores da equipe de enfermagem na literatura, tornase relevante a realização desta pesquisa cuja finalidade é elaborar uma escala de crenças dos trabalhadores da equipe de enfermagem frente ao acidente de trabalho com fluidos biológicos pois, acreditando que as crenças adquiridas durante a vida profissional influenciam no comportamento dos trabalhadores e na adoção de medidas preventivas no processo de trabalho.

A construção desta escala torna-se importante para a identificação das crenças dos trabalhadores frente ao acidente com fluido biológico, para o direcionamento de estratégias a serem implementadas como prevenção dos acidentes, possibilitando aos trabalhadores, a reflexão acerca de suas práticas, reduzindo a ocorrência dos acidentes de trabalho com fluidos biológicos. 
2 OBJETIVOS 
- Construir uma Escala de Crenças dos Trabalhadores de Enfermagem frente ao acidente de trabalho com fluido biológico.

- Validar a Escala de Crenças dos Trabalhadores de Enfermagem frente ao acidente de trabalho com fluido biológico. 
Trata-se de estudo metodológico de abordagem psicométrica que se propôs a construir e validar uma Escala de Crenças dos Trabalhadores de Enfermagem frente ao acidente de trabalho com fluido biológico.

O modelo teórico de construção do instrumento seguiu os pressupostos de (Pasquali, 1998), que preconiza três focos para criação e validação de um instrumento de medida baseado em constructos, a saber: procedimentos teóricos, que compreendem a teoria e a construção do instrumento, procedimentos empíricos (experimentais) e procedimentos analíticos (estatísticos), responsáveis pela validação do constructo por meio da análise fatorial.

\subsection{Elaboração dos itens}

Para a elaboração dos itens da escala, Pasquali (1998) preconiza a existência de três fontes: a literatura por meio de consulta a itens de outros instrumentos já construídos, entrevistas junto à população alvo e categorias comportamentais que englobam a literatura pertinente sobre o constructo, a opinião de peritos na área, a experiência do próprio pesquisador, bem como a análise de conteúdo do construto.

Nesta pesquisa, a fonte de itens do instrumento construído foram as categorias comportamentais (literatura pertinente e a experiência do próprio pesquisador em pesquisa realizada previamente). Dessa forma, inicialmente foi realizado um levantamento da literatura em artigos científicos, livros, teses e dissertações que apresentavam as crenças dos trabalhadores de enfermagem relacionadas aos acidentes de trabalho com fluido biológico, a descrição dessas crenças e suas características.

Após a realização desse levantamento iniciou-se a análise desse material para seleção dos itens a fim de compor o instrumento. Utilizou-se como critério para seleção dos itens, as seguintes questões norteadoras:

- Qual a opinião dos trabalhadores acerca dos acidentes de trabalho com fluido biológico? 
- O que os trabalhadores pensam em relação àqueles que já sofreram acidente de trabalho com fluido biológico?

- Os trabalhadores sabem o que fazer após a ocorrência de um acidente?

- Quais as causas dos acidentes de trabalho com fluido biológico?

Da análise das respostas a essas questões norteadoras foram elaborados 51 itens os quais foram analisados segundo os pressupostos de Pasquali (1998):

- Critério comportamental: O item deve expressar um comportamento e não uma abstração;

- Critério de objetividade: O indivíduo deve poder discordar ou concordar sobre o iem;

- Critério da simplicidade: O item deve expressar uma ideia única;

- Critério da clareza: o item deve ser inteligível para qualquer estrato da população;

- Critério da relevância: O item deve ser pertinente ao construto que se propõe medir;

- Critério da precisão: O item deve possuir uma posição definida no contínuo do atributo e ser distinta dos demais itens;

- Critério da variedade: Deve-se evitar o uso dos mesmos termos em todos os itens;

- Critério da modalidade: O item deve ser formulado com expressões de reação modal, isto é, não utilizar expressões extremadas;

- Critério da tipicidade: O item deve ser elaborado por meio de frases com expressões condizentes com o atributo. 
Desse modo, foram mantidos os 51 itens previamente selecionados conforme os critérios estabelecidos anteriormente, os quais deveriam ser valorados a partir de uma escala Likert, com 5 alternativas de resposta: Discordo Totalmente (1); Discordo parcialmente (2); Não concordo, nem discordo (3); Concordo parcialmente (4); Concordo totalmente (5). Os itens foram dispostos num quadro designado de escala de crenças dos trabalhadores da equipe de enfermagem frente ao acidente de trabalho com fluido biológico (Apêndice 1).

\subsection{Validação de conteúdo}

Para Sireci (1998), a análise de conteúdo é fundamental para a construção e adaptação de um instrumento de medida. Essa análise teórica é feita por juízes e ela comporta dois tipos distintos de juízes, segundo se a análise incide sobre a compreensão dos itens (análise semântica) ou sobre a pertinência dos itens ao construto que representam (propriamente chamada de análise dos juízes). Assim, antes de partir para a validação final do instrumento piloto, este é submetido a uma análise teórica dos itens por meio da análise dos juízes e análise semântica. Nessa análise, os juízes devem ser peritos na área do construto, pois sua tarefa consiste em ajuizar se os itens estão se referindo ou não ao traço em questão (Pasquali, 1998).

Com base no disposto, foram convidados sete juízes, previamente selecionados pela pesquisadora, todos com formação em enfermagem, doutores e que exercem a função de professores universitários com experiência na área de acidentes de trabalho com fluido biológico.

Os especialistas foram convidados via e-mail por meio de uma carta convite (Apêndice 2) explicando os objetivos da pesquisa e o motivo pelos quais eles haviam sido selecionados para participar do estudo. A partir do aceite, foi encaminhado para cada juiz, individualmente, o instrumento em desenvolvimento (Apêndice 3) e as instruções de como proceder na análise da Escala de Crenças dos Trabalhadores da Equipe de Enfermagem frente ao acidente de trabalho com fluido biológico. 
Os itens foram analisados por meio dos seguintes critérios propostos por Pasquali (1998): relevância, precisão, clareza e objetividade. Após o retorno da avaliação dos juízes via e-mail, as respostas foram digitadas em forma de um banco de dados no Programa Excel. Ao final desta etapa, foram mantidos no instrumento, os enunciados de acordo com a concordância entre os juízes, itens que não atingiram uma concordância de $70 \%$ ou mais foram descartados do instrumento, originando uma nova versão preliminar do instrumento onde 7 itens foram descartados.

Em seguida, procedeu-se à análise semântica dos itens, que teve como objetivo verificar se todos os itens eram compreensíveis para todos os membros da população à qual o instrumento se destina. Nela, duas preocupações foram relevantes: verificar se os itens eram inteligíveis para o estrato mais baixo (de habilidade) da população e, por isso, a amostra para essa análise deve ser feita com esse estrato; segundo, para evitar deselegância na formulação dos itens, a análise semântica deverá ser feita também com uma amostra mais sofisticada (de maior habilidade) da população (para garantir a chamada "validade aparente" do teste). Entende-se por estrato mais baixo, aquele segmento da população-meta que apresenta menor nível de habilidades.

Assim, foram convidados 40 trabalhadores da instituição pesquisada, e após o aceite, o instrumento foi, inicialmente, aplicado a uma amostra de 30 trabalhadores da equipe de enfermagem (auxiliares e técnicos de enfermagem) e em seguida foram discutidas as dúvidas que os itens suscitaram. Em um segundo momento, os itens foram submetidos ao estrato mais alto da população, 10 enfermeiros, com o objetivo de evitar que os itens se apresentassem demasiadamente primitivos para tais pessoas e assim perdessem a validade aparente. Foi entregue para cada trabalhador duas cópias do Termo de Consentimento Livre e Esclarecido referente a esta etapa do estudo (Apêndice 4)

A viabilidade de ajustes nos itens foi considerada quando $15 \%$ dos participantes apresentaram dificuldade de compreensão ou de preenchimento dos itens do instrumento, situação em que os trabalhadores foram orientados a não responder a pergunta (Beaton et al., 2000). Deixar claro que foram mais 7 retirados Portanto 7 itens foram eliminados, totalizando um instrumento com 37 itens. 


\subsection{Validação do construto}

Após a realização das etapas de validade do conteúdo do instrumento, foram realizadas as etapas de validade do construto, etapa que permite uma avaliação empírica da legitimidade da representação comportamental dos traços latentes. Torna-se possível verificar se os indivíduos com determinadas características agem conforme a teoria supõe e quais itens ou fatores são mais pertinentes ao construto (Cronbach, 1996, Pasquali, 2003; Sven, 1990). Na análise de construto o instrumento com 37 itens foi aplicado em uma amostra de trabalhadores da equipe de enfermagem de um Hospital Universitário, após a coleta de dados foi realizada a verificação das propriedades psicométricas do instrumento por meio da avaliação da confiabilidade e validade da escala de crenças por meio dos procedimentos descritos a seguir.

\subsubsection{Coleta dos dados}

A coleta de dados foi realizada de Janeiro a março de 2018.

\subsubsection{Local do Estudo}

O estudo foi realizado em um hospital público, localizado no campus da Universidade de São Paulo no Distrito do Butantã na região oeste do Município de São Paulo.

É um serviço de média complexidade que atende preferencialmente às populações do Distrito de Saúde do Butantã e da Comunidade Universitária da USP prestando um serviço diferenciado com atendimento de excelência.

Possuin atualmente, 178 leitos nas especialidades Médica, Cirúrgica, Ortopedia, Pediatria, Obstetrícia e Ginecologia envolvendo as unidades de ensino da área de saúde da Universidade de São de Paulo (Medicina, Enfermagem, Odontologia, Nutrição, Psicologia, Fisioterapia, Terapia Ocupacional, Fonoaudiologia, Ciências Farmacêuticas e Serviço Social). Os alunos realizam suas 
disciplinas de práticas clínicas e cirúrgicas dentro do Hospital. Em média, anualmente recebe cerca de 2500 alunos e produz cerca de 400 pesquisas.

O Departamento de Enfermagem (DE) está subordinado à Superintendência do Hospital Universitário da Universidade de São Paulo (HU-USP) e tem como finalidade coordenar, supervisionar e controlar as atividades desenvolvidas nas áreas do ensino, da pesquisa e da assistência de enfermagem.

\subsubsection{Amostra do Estudo}

A amostra do estudo foi composta por trabalhadores da equipe de enfermagem (enfermeiros, técnicos e auxiliares de enfermagem) da instituição pesquisada. Os cálculos do tamanho da amostra foram realizados com o software estatístico PASS 2008 (Power Analysis and Sample Size System) - NCSS.

Para a Análise Fatorial Exploratória foi necessária uma amostra de 320 trabalhadores de tal forma que para uma correlação de 0,30 (para itens que compõem uma mesma subescala) a sua estimativa não difira em mais de $0,10 \mathrm{com}$ uma confiança de $95 \%$.

\subsubsection{Coleta de dados}

Inicialmente foi entregue pela Diretoria de Enfermagem da instituição à pesquisadora, uma lista com o respectivo número de trabalhadores de enfermagem por setor. Em seguida, a pesquisadora percorreu os setores, convidando os trabalhadores a participarem do Estudo e explicando os objetivos do mesmo. E partindo do aceite dos mesmos, foram entregues duas cópias do Termo de Consentimento Livre e Esclarecido (Apêndice 5) e uma cópia do instrumento de coleta de dados. Foi tratado com os trabalhadores que a pesquisadora passaria novamente nos setores ao término da jornada, para o recolhimento dos instrumentos, respectivamente nos plantões da manhã, tarde e noite. 


\subsubsection{Instrumento de coleta}

O instrumento de coleta de dados foi a Escala de Crenças dos Trabalhadores da equipe de enfermagem frente ao acidente de trabalho com fluido biológico (Apêndice 6) composta por 37 itens, os quais deveriam ser respondidos por meio de uma escala do tipo Likert, em que o trabalhador tinha 5 opções de resposta: Discordo Totalmente, Discordo, Não discordo nem concordo, Concordo e Concordo Totalmente. Juntamente com os itens havia algumas questões relacionadas a caracterização do trabalhador.

\subsubsection{Análise dos dados}

Esta etapa envolveu a verificação das propriedades psicométricas do instrumento por meio da avaliação da confiabilidade e validade da escala de crenças.

Os dados foram analisados descritivamente. Para as variáveis categóricas foram apresentadas frequências absolutas e relativas e para as variáveis numéricas, medidas-resumo (média, quartis, mínimo, máximo e desvio padrão).

Para se avaliar a dimensionalidade da escala de crenças composta por 37 itens procedeu-se a análise fatorial exploratória, utilizando-se 0 método por componentes principais e rotação ortogonal VARIMAX.

O método de rotação ortogonal Varimax minimiza o número de variáveis que têm altas cargas em um fator, simplificando a interpretação dos fatores. Privilegia apenas alguns pesos significativos e todos os outros próximos de zero. É o mais utilizado. A matriz de componentes, após a rotação ortogonal, visa extremar os valores das cargas fatoriais (loadings), de modo que cada variável se associe a apenas um fator. Assim as variáveis com baixa carga fatorial foram eliminadas. Foram consideradas cargas fatoriais acima de 0,30 (nível mínimo), cargas acima de 0,40 são consideradas mais importantes e, se forem maiores que 0,50 são consideradas estatisticamente significativa. 
O critério para a seleção do número de fatores foi de autovalores acima do valor um. Foram utilizados como critério de exclusão dos itens, aqueles cujas comunalidade foram inferiores a 0,6. A análise fatorial permite a decomposição da variância de cada item em duas partes: parte comum e parte específica. A parcela da variância comum- devida a fatores comuns- é denominada de comunalidade. Dessa forma, itens cuja variância devido a fatores comuns foram inferiores a 50\% foram excluídos por estarem pouco representados na análise fatorial.

Foram apresentados coeficiente de adequação da amostra de KaiserMeyer-Olkin (KMO) e o teste de esfericidade Bartlett. Para se testar a adequação do modelo de análise fatorial geralmente utilizam-se a estatística de Kaiser-MeyerOlkin (KMO) e o teste de esfericidade de Bartlett. O KMO é um indicador que compara a magnitude dos coeficientes de correlação observados com as magnitudes dos coeficientes de correlação parcial, e varia entre 0 e 1. Pequenos valores de KMO (abaixo de 0,5 ) indicam que o uso da análise fatorial não é adequado. Por sua vez, o teste de esfericidade de Bartlett serve para testar a hipótese nula de que a matriz de correlação é uma significância global de todas as correlações entre os itens da escala considerados.

Os resultados obtidos para as duas medidas (Teste de esfericidade de Bartlett e Medida de adequacidade da amostra) indicaram que a análise fatorial era adequada.

As análises foram realizadas utilizando-se o pacote estatístico SPSS 20.0. Para todos os testes estatísticos foram adotados um nível de significância de 5\%. 
4 ASPECTOS ÉTICOS 
O projeto foi submetido e aprovado pela Comissão de Ética em Pesquisa da Escola de Enfermagem da Universidade de São Paulo sob o parecer 952.181 (ANEXO I) e da instituição co-participante sob o parecer 2.352.645 (ANEXO II), onde a pesquisa foi realizada. Foi apresentado para cada participante um Termo de Consentimento Livre e Esclarecido (TCLE) para cada etapa da pesquisa conforme descrito anteriormente. Este documento fornece explicações sobre a pesquisa e assegura o sigilo das informações fornecidas. Foi resguardado aos entrevistados 0 direito de interromper a participação no projeto quando lhe fosse conveniente. 
A análise dos dados consistiu na validação de conteúdo e validação do constructo. A validação do conteúdo foi composta pela avaliação dos juízes e análise semântica e na validação do constructo foram verificadas as propriedades psicométricas do instrumento por meio da análise fatorial que permitiu a construção de sete dimensões denominadas:

- Causas dos acidentes

- Uso dos Equipamentos de Proteção Individual

- Sobrecarga de Trabalho

- Experiência pós acidente

- Medo

- Minimização dos Riscos

- Interferências no processo de trabalho

Foi verificada a consistência interna do instrumento por meio do Alpha de Cronbach.

\subsection{Validação de conteúdo}

Com relação aos 7 juízes que participaram do estudo, todos eram enfermeiros doutores, a média de idade foi de 46 anos e o tempo de formação 21 anos. Quanto ao vínculo institucional todos eram professores de Universidades, 3 trabalham em Universidades Privadas e 4 em Universidades Públicas. Quanto à linha de pesquisa desenvolvida, 3 tinham como principal área o Ensino, cuidar e a gestão e 4 tinham como linha principal a saúde do trabalhador conforme apresentado na Tabela 1. 
Tabela 1. Caracterização dos juízes segundo formação acadêmica, nível de formação, vínculo institucional e linha de pesquisa. São Paulo, SP, Brasil, 2018

\begin{tabular}{llc}
\hline Características & N & $\%$ \\
\hline $\begin{array}{l}\text { Formação Acadêmica } \\
\quad \text { Enfermeiro }\end{array}$ & 7 & 100,0 \\
& & \\
Nível de Formação & 7 & 100,0 \\
$\quad$ Doutorado & & \\
& 7 & 100,0 \\
Vínculo Institucional & 3 & 42,9 \\
$\quad$ Privada & 4 & 57,1 \\
$\quad$ Pública & & \\
& 7 & 100,0 \\
Linhas de Pesquisa & 1 & 14,3 \\
$\quad$ Cuidar, ensino e gestão & 1 & 14,3 \\
$\quad$ Gestão em Enfermagem & 1 & 14,3 \\
$\quad$ Processo de Cuidar em Enfermagem & 1 & 14,3 \\
$\quad$ Risco Biológico & 3 & 42,9 \\
$\quad$ Saúde do Trabalhador &
\end{tabular}

Após o recebimento do instrumento enviado aos juízes, as respostas foram digitadas em um banco de dados no Programa Excel. Ao final desta etapa, foram mantidos no instrumento, os enunciados de acordo com a concordância entre os juízes, itens que não atingiram uma concordância de $70 \%$ ou mais foram descartados do instrumento. 
Tabela 2. Distribuição das respostas dos juízes segundo a clareza dos itens. São Paulo, SP, Brasil, 2018

\begin{tabular}{|c|c|c|c|c|c|}
\hline Itens & $\begin{array}{l}\text { Discordo } \\
\text { Totalmente }\end{array}$ & Discordo & $\begin{array}{l}\text { Não discordo } \\
\text { nem concordo }\end{array}$ & Concordo & $\begin{array}{l}\text { Concordo } \\
\text { Totalmente }\end{array}$ \\
\hline Q1 & $0(0)$ & $1(14,3)$ & $1(14,3)$ & $1(14,3)$ & $4(57,1)$ \\
\hline Q2 & $0(0)$ & $0(0)$ & $0(0)$ & $1(14,3)$ & $6(85,7)$ \\
\hline Q3 & $1(14,3)$ & $4(57,1)$ & $0(0)$ & $1(14,3)$ & $1(14,3)$ \\
\hline Q4 & $0(0)$ & $1(14,3)$ & $0(0)$ & $1(14,3)$ & $5(71,4)$ \\
\hline Q5 & $0(0)$ & $2(28,6)$ & $0(0)$ & $1(14,3)$ & $4(57,1)$ \\
\hline Q6 & $0(0)$ & $0(0)$ & $1(14,3)$ & $1(14,3)$ & $5(71,4)$ \\
\hline Q7 & $0(0)$ & $2(28,6)$ & $0(0)$ & $3(42,9)$ & $2(28,6)$ \\
\hline Q8 & $1(14,3)$ & $1(14,3)$ & $0(0)$ & $0(0)$ & $5(71,4)$ \\
\hline Q9 & $0(0)$ & $1(14,3)$ & $0(0)$ & $1(14,3)$ & $5(71,4)$ \\
\hline Q10 & $0(0)$ & $2(28,6)$ & $2(28,6)$ & $0(0)$ & $3(42,9)$ \\
\hline Q11 & $1(14,3)$ & $0(0)$ & $0(0)$ & $1(14,3)$ & $5(71,4)$ \\
\hline Q12 & $0(0)$ & $0(0)$ & $0(0)$ & $2(28,6)$ & $5(71,4)$ \\
\hline Q13 & $1(14,3)$ & $2(28,6)$ & $0(0)$ & $0(0)$ & $4(57,1)$ \\
\hline Q14 & $1(14,3)$ & $0(0)$ & $0(0)$ & $2(28,6)$ & $4(57,1)$ \\
\hline Q15 & $1(14,3)$ & $2(28,6)$ & $0(0)$ & $1(14,3)$ & $3(42,9)$ \\
\hline Q16 & $1(14,3)$ & $1(14,3)$ & $0(0)$ & $1(14,3)$ & $4(57,1)$ \\
\hline Q17 & $1(14,3)$ & $1(14,3)$ & $0(0)$ & $0(0)$ & $5(71,4)$ \\
\hline Q18 & $0(0)$ & $0(0)$ & $0(0)$ & $0(0)$ & $7(100)$ \\
\hline Q19 & $0(0)$ & $0(0)$ & $1(14,3)$ & $1(14,3)$ & $5(71,4)$ \\
\hline Q20 & $1(14,3)$ & $0(0)$ & $0(0)$ & $1(14,3)$ & $5(71,4)$ \\
\hline Q21 & $0(0)$ & $0(0)$ & $0(0)$ & $1(14,3)$ & $6(85,7)$ \\
\hline Q22 & $2(28,6)$ & $0(0)$ & $1(14,3)$ & $0(0)$ & $4(57,1)$ \\
\hline Q23 & $1(14,3)$ & $0(0)$ & $0(0)$ & $1(14,3)$ & $5(71,4)$ \\
\hline Q24 & $1(14,3)$ & $1(14,3)$ & $0(0)$ & $0(0)$ & $5(71,4)$ \\
\hline Q25 & $1(14,3)$ & $0(0)$ & $1(14,3)$ & $2(28,6)$ & $3(42,9)$ \\
\hline Q26 & $0(0)$ & $0(0)$ & $0(0)$ & $2(28,6)$ & $5(71,4)$ \\
\hline Q27 & $1(14,3)$ & $0(0)$ & $0(0)$ & $1(14,3)$ & $5(71,4)$ \\
\hline Q28 & $1(14,3)$ & $0(0)$ & $1(14,3)$ & $1(14,3)$ & $4(57,1)$ \\
\hline Q29 & $1(14,3)$ & $0(0)$ & $1(14,3)$ & $0(0)$ & $5(71,4)$ \\
\hline Q30 & $0(0)$ & $1(14,3)$ & $0(0)$ & $0(0)$ & $6(85,7)$ \\
\hline Q31 & $0(0)$ & $0(0)$ & $0(0)$ & $0(0)$ & $7(100)$ \\
\hline Q32 & $0(0)$ & $0(0)$ & $0(0)$ & $0(0)$ & $7(100)$ \\
\hline Q33 & $0(0)$ & $0(0)$ & $0(0)$ & $1(14,3)$ & $6(85,7)$ \\
\hline Q34 & $0(0)$ & $1(14,3)$ & $1(14,3)$ & $1(14,3)$ & $4(57,1)$ \\
\hline Q35 & $0(0)$ & $0(0)$ & $1(14,3)$ & $1(14,3)$ & $5(71,4)$ \\
\hline
\end{tabular}


continuação

\begin{tabular}{lccccc}
\hline Itens & $\begin{array}{c}\text { Discordo } \\
\text { Totalmente }\end{array}$ & Discordo & $\begin{array}{c}\text { Não discordo } \\
\text { nem concordo }\end{array}$ & Concordo & $\begin{array}{c}\text { Concordo } \\
\text { Totalmente }\end{array}$ \\
\hline Q36 & $1(14,3)$ & $2(28,6)$ & $1(14,3)$ & $0(0)$ & $3(42,9)$ \\
Q37 & $0(0)$ & $0(0)$ & $0(0)$ & $1(14,3)$ & $6(85,7)$ \\
Q38 & $1(14,3)$ & $0(0)$ & $0(0)$ & $0(0)$ & $6(85,7)$ \\
Q39 & $0(0)$ & $0(0)$ & $0(0)$ & $0(0)$ & $7(100)$ \\
Q40 & $0(0)$ & $0(0)$ & $1(14,3)$ & $0(0)$ & $6(85,7)$ \\
Q41 & $0(0)$ & $0(0)$ & $0(0)$ & $0(0)$ & $7(100)$ \\
Q42 & $0(0)$ & $0(0)$ & $0(0)$ & $0(0)$ & $7(100)$ \\
Q43 & $1(14,3)$ & $1(14,3)$ & $0(0)$ & $0(0)$ & $5(71,4)$ \\
Q44 & $0(0)$ & $0(0)$ & $0(0)$ & $1(14,3)$ & $6(85,7)$ \\
Q45 & $0(0)$ & $0(0)$ & $0(0)$ & $1(14,3)$ & $6(85,7)$ \\
Q46 & $0(0)$ & $1(14,3)$ & $0(0)$ & $1(14,3)$ & $5(71,4)$ \\
Q47 & $2(28,6)$ & $0(0)$ & $0(0)$ & $1(14,3)$ & $4(57,1)$ \\
Q48 & $1(14,3)$ & $0(0)$ & $0(0)$ & $0(0)$ & $6(85,7)$ \\
Q49 & $0(0)$ & $0(0)$ & $0(0)$ & $0(0)$ & $7(100)$ \\
Q50 & $0(0)$ & $0(0)$ & $0(0)$ & $0(0)$ & $7(100)$ \\
Q51 & $0(0)$ & $0(0)$ & $1(14,3)$ & $0(0)$ & $6(85,7)$ \\
\hline
\end{tabular}


Tabela 3. Distribuição das respostas dos juízes segundo a relevância dos itens. São Paulo, SP, Brasil, 2018

\begin{tabular}{|c|c|c|c|c|c|}
\hline Itens & $\begin{array}{l}\text { Discordo } \\
\text { Totalmente }\end{array}$ & Discordo & $\begin{array}{l}\text { Não discordo } \\
\text { nem concordo }\end{array}$ & Concordo & $\begin{array}{l}\text { Concordo } \\
\text { Totalmente }\end{array}$ \\
\hline Q1 & $0(0)$ & $0(0)$ & $0(0)$ & $2(28,6)$ & $5(71,4)$ \\
\hline Q2 & $0(0)$ & $0(0)$ & $0(0)$ & $1(14,3)$ & $6(85,7)$ \\
\hline Q3 & $2(28,6)$ & $1(14,3)$ & $1(14,3)$ & $2(28,6)$ & $1(14,3)$ \\
\hline Q4 & $0(0)$ & $0(0)$ & $0(0)$ & $2(28,6)$ & $5(71,4)$ \\
\hline Q5 & $0(0)$ & $0(0)$ & $1(14,3)$ & $0(0)$ & $6(85,7)$ \\
\hline Q6 & $0(0)$ & $0(0)$ & $0(0)$ & $2(28,6)$ & $5(71,4)$ \\
\hline Q7 & $1(14,3)$ & $1(14,3)$ & $0(0)$ & $2(28,6)$ & $3(42,9)$ \\
\hline Q8 & $1(14,3)$ & $0(0)$ & $0(0)$ & $1(14,3)$ & $5(71,4)$ \\
\hline Q9 & $0(0)$ & $0(0)$ & $0(0)$ & $2(28,6)$ & $5(71,4)$ \\
\hline Q10 & $0(0)$ & $1(14,3)$ & $1(14,3)$ & $0(0)$ & $5(71,4)$ \\
\hline Q11 & $1(14,3)$ & $0(0)$ & $0(0)$ & $1(14,3)$ & $5(71,4)$ \\
\hline Q12 & $0(0)$ & $0(0)$ & $0(0)$ & $3(42,9)$ & $4(57,1)$ \\
\hline Q13 & $1(14,3)$ & $0(0)$ & $1(14,3)$ & $1(14,3)$ & $4(57,1)$ \\
\hline Q14 & $1(14,3)$ & $0(0)$ & $0(0)$ & $1(14,3)$ & $5(71,4)$ \\
\hline Q15 & $0(0)$ & $1(14,3)$ & $1(14,3)$ & $2(28,6)$ & $3(42,9)$ \\
\hline Q16 & $0(0)$ & $0(0)$ & $0(0)$ & $2(28,6)$ & $5(71,4)$ \\
\hline Q17 & $1(14,3)$ & $1(14,3)$ & $0(0)$ & $0(0)$ & $5(71,4)$ \\
\hline Q18 & $0(0)$ & $0(0)$ & $0(0)$ & $0(0)$ & $7(100)$ \\
\hline Q19 & $0(0)$ & $0(0)$ & $1(14,3)$ & $1(14,3)$ & $5(71,4)$ \\
\hline Q20 & $1(14,3)$ & $0(0)$ & $0(0)$ & $1(14,3)$ & $5(71,4)$ \\
\hline Q21 & $0(0)$ & $0(0)$ & $0(0)$ & $1(14,3)$ & $6(85,7)$ \\
\hline Q22 & $1(14,3)$ & $0(0)$ & $1(14,3)$ & $0(0)$ & $5(71,4)$ \\
\hline Q23 & $1(14,3)$ & $0(0)$ & $0(0)$ & $1(14,3)$ & $5(71,4)$ \\
\hline Q24 & $1(14,3)$ & $1(14,3)$ & $0(0)$ & $0(0)$ & $5(71,4)$ \\
\hline Q25 & $0(0)$ & $0(0)$ & $1(14,3)$ & $1(14,3)$ & $5(71,4)$ \\
\hline Q26 & $0(0)$ & $0(0)$ & $0(0)$ & $2(28,6)$ & $5(71,4)$ \\
\hline Q27 & $1(14,3)$ & $0(0)$ & $0(0)$ & $1(14,3)$ & $5(71,4)$ \\
\hline Q28 & $1(14,3)$ & $0(0)$ & $1(14,3)$ & $1(14,3)$ & $4(57,1)$ \\
\hline Q29 & $1(14,3)$ & $0(0)$ & $1(14,3)$ & $0(0)$ & $5(71,4)$ \\
\hline Q30 & $0(0)$ & $1(14,3)$ & $0(0)$ & $0(0)$ & $6(85,7)$ \\
\hline Q31 & $0(0)$ & $0(0)$ & $0(0)$ & $0(0)$ & $7(100)$ \\
\hline Q32 & $0(0)$ & $0(0)$ & $1(14,3)$ & $0(0)$ & $6(85,7)$ \\
\hline Q33 & $0(0)$ & $0(0)$ & $0(0)$ & $1(14,3)$ & $6(85,7)$ \\
\hline Q34 & $0(0)$ & $0(0)$ & $1(14,3)$ & $2(28,6)$ & $4(57,1)$ \\
\hline Q35 & $0(0)$ & $0(0)$ & $1(14,3)$ & $1(14,3)$ & $5(71,4)$ \\
\hline
\end{tabular}


continuação

\begin{tabular}{lccccc}
\hline Itens & $\begin{array}{c}\text { Discordo } \\
\text { Totalmente }\end{array}$ & Discordo & $\begin{array}{c}\text { Não discordo } \\
\text { nem concordo }\end{array}$ & Concordo & $\begin{array}{c}\text { Concordo } \\
\text { Totalmente }\end{array}$ \\
\hline Q36 & $1(14,3)$ & $1(14,3)$ & $1(14,3)$ & $1(14,3)$ & $3(42,9)$ \\
Q37 & $0(0)$ & $0(0)$ & $0(0)$ & $1(14,3)$ & $6(85,7)$ \\
Q38 & $1(14,3)$ & $0(0)$ & $0(0)$ & $0(0)$ & $6(85,7)$ \\
Q39 & $0(0)$ & $0(0)$ & $0(0)$ & $0(0)$ & $7(100)$ \\
Q40 & $0(0)$ & $0(0)$ & $1(14,3)$ & $0(0)$ & $6(85,7)$ \\
Q41 & $0(0)$ & $0(0)$ & $0(0)$ & $0(0)$ & $7(100)$ \\
Q42 & $0(0)$ & $0(0)$ & $0(0)$ & $0(0)$ & $7(100)$ \\
Q43 & $1(14,3)$ & $0(0)$ & $0(0)$ & $0(0)$ & $6(85,7)$ \\
Q44 & $0(0)$ & $0(0)$ & $0(0)$ & $1(14,3)$ & $6(85,7)$ \\
Q45 & $0(0)$ & $0(0)$ & $0(0)$ & $1(14,3)$ & $6(85,7)$ \\
Q46 & $0(0)$ & $1(14,3)$ & $0(0)$ & $0(0)$ & $6(85,7)$ \\
Q47 & $2(28,6)$ & $0(0)$ & $0(0)$ & $1(14,3)$ & $4(57,1)$ \\
Q48 & $1(14,3)$ & $0(0)$ & $0(0)$ & $0(0)$ & $6(85,7)$ \\
Q49 & $0(0)$ & $0(0)$ & $0(0)$ & $0(0)$ & $7(100)$ \\
Q50 & $0(0)$ & $0(0)$ & $0(0)$ & $0(0)$ & $7(100)$ \\
Q51 & $0(0)$ & $0(0)$ & $1(14,3)$ & $0(0)$ & $6(85,7)$ \\
\hline
\end{tabular}


Tabela 4. Distribuição das respostas dos juízes segundo a objetividade dos itens. São Paulo, SP, Brasil, 2018

\begin{tabular}{|c|c|c|c|c|c|}
\hline Itens & $\begin{array}{l}\text { Discordo } \\
\text { Totalmente }\end{array}$ & Discordo & $\begin{array}{l}\text { Não discordo } \\
\text { nem concordo }\end{array}$ & Concordo & $\begin{array}{l}\text { Concordo } \\
\text { Totalmente }\end{array}$ \\
\hline Q1 & $0(0)$ & $1(14,3)$ & $1(14,3)$ & $1(14,3)$ & $0(0)$ \\
\hline Q2 & $0(0)$ & $0(0)$ & $0(0)$ & $2(28,6)$ & $0(0)$ \\
\hline Q3 & $2(28,6)$ & $4(57,1)$ & $0(0)$ & $0(0)$ & $2(28,6)$ \\
\hline Q4 & $0(0)$ & $1(14,3)$ & $0(0)$ & $1(14,3)$ & $0(0)$ \\
\hline Q5 & $0(0)$ & $2(28,6)$ & $0(0)$ & $1(14,3)$ & $0(0)$ \\
\hline Q6 & $0(0)$ & $0(0)$ & $1(14,3)$ & $1(14,3)$ & $0(0)$ \\
\hline Q7 & $0(0)$ & $3(42,9)$ & $0(0)$ & $2(28,6)$ & $0(0)$ \\
\hline Q8 & $1(14,3)$ & $1(14,3)$ & $0(0)$ & $0(0)$ & $1(14,3)$ \\
\hline Q9 & $0(0)$ & $1(14,3)$ & $0(0)$ & $1(14,3)$ & $0(0)$ \\
\hline Q10 & $0(0)$ & $2(28,6)$ & $2(28,6)$ & $0(0)$ & $0(0)$ \\
\hline Q11 & $1(14,3)$ & $0(0)$ & $0(0)$ & $1(14,3)$ & $1(14,3)$ \\
\hline Q12 & $0(0)$ & $0(0)$ & $0(0)$ & $2(28,6)$ & $0(0)$ \\
\hline Q13 & $1(14,3)$ & $2(28,6)$ & $0(0)$ & $0(0)$ & $1(14,3)$ \\
\hline Q14 & $2(28,6)$ & $0(0)$ & $0(0)$ & $1(14,3)$ & $2(28,6)$ \\
\hline Q15 & $1(14,3)$ & $1(14,3)$ & $1(14,3)$ & $1(14,3)$ & $1(14,3)$ \\
\hline Q16 & $1(14,3)$ & $1(14,3)$ & $0(0)$ & $1(14,3)$ & $1(14,3)$ \\
\hline Q17 & $1(14,3)$ & $1(14,3)$ & $0(0)$ & $0(0)$ & $1(14,3)$ \\
\hline Q18 & $0(0)$ & $0(0)$ & $0(0)$ & $0(0)$ & $0(0)$ \\
\hline Q19 & $0(0)$ & $0(0)$ & $1(14,3)$ & $1(14,3)$ & $0(0)$ \\
\hline Q20 & $1(14,3)$ & $0(0)$ & $0(0)$ & $1(14,3)$ & $1(14,3)$ \\
\hline Q21 & $0(0)$ & $0(0)$ & $0(0)$ & $1(14,3)$ & $0(0)$ \\
\hline Q22 & $2(28,6)$ & $0(0)$ & $1(14,3)$ & $0(0)$ & $2(28,6)$ \\
\hline Q23 & $1(14,3)$ & $1(14,3)$ & $0(0)$ & $0(0)$ & $1(14,3)$ \\
\hline Q24 & $1(14,3)$ & $0(0)$ & $1(14,3)$ & $2(28,6)$ & $1(14,3)$ \\
\hline Q25 & $0(0)$ & $0(0)$ & $0(0)$ & $2(28,6)$ & $0(0)$ \\
\hline Q26 & $1(14,3)$ & $0(0)$ & $0(0)$ & $1(14,3)$ & $1(14,3)$ \\
\hline Q27 & $1(14,3)$ & $0(0)$ & $1(14,3)$ & $1(14,3)$ & $1(14,3)$ \\
\hline Q28 & $1(14,3)$ & $0(0)$ & $1(14,3)$ & $0(0)$ & $1(14,3)$ \\
\hline Q29 & $1(14,3)$ & $1(14,3)$ & $0(0)$ & $0(0)$ & $1(14,3)$ \\
\hline Q30 & $0(0)$ & $0(0)$ & $0(0)$ & $0(0)$ & $0(0)$ \\
\hline Q31 & $0(0)$ & $0(0)$ & $0(0)$ & $0(0)$ & $0(0)$ \\
\hline Q32 & $0(0)$ & $0(0)$ & $0(0)$ & $1(14,3)$ & $0(0)$ \\
\hline Q33 & $0(0)$ & $1(14,3)$ & $1(14,3)$ & $1(14,3)$ & $0(0)$ \\
\hline Q34 & $0(0)$ & $0(0)$ & $1(14,3)$ & $1(14,3)$ & $0(0)$ \\
\hline Q35 & $1(14,3)$ & $1(14,3)$ & $0(0)$ & $0(0)$ & $1(14,3)$ \\
\hline
\end{tabular}


continuação

\begin{tabular}{lccccc}
\hline Itens & $\begin{array}{c}\text { Discordo } \\
\text { Totalmente }\end{array}$ & Discordo & $\begin{array}{c}\text { Não discordo } \\
\text { nem concordo }\end{array}$ & Concordo & $\begin{array}{c}\text { Concordo } \\
\text { Totalmente }\end{array}$ \\
\hline Q36 & $1(14,3)$ & $2(28,6)$ & $1(14,3)$ & $0(0)$ & $1(14,3)$ \\
Q37 & $0(0)$ & $0(0)$ & $0(0)$ & $1(14,3)$ & $0(0)$ \\
Q38 & $1(14,3)$ & $0(0)$ & $0(0)$ & $0(0)$ & $1(14,3)$ \\
Q39 & $0(0)$ & $0(0)$ & $0(0)$ & $0(0)$ & $0(0)$ \\
Q40 & $0(0)$ & $0(0)$ & $1(14,3)$ & $0(0)$ & $0(0)$ \\
Q41 & $0(0)$ & $0(0)$ & $0(0)$ & $0(0)$ & $0(0)$ \\
Q42 & $0(0)$ & $0(0)$ & $0(0)$ & $0(0)$ & $0(0)$ \\
Q43 & $1(14,3)$ & $1(14,3)$ & $0(0)$ & $0(0)$ & $1(14,3)$ \\
Q44 & $0(0)$ & $0(0)$ & $0(0)$ & $1(14,3)$ & $0(0)$ \\
Q45 & $0(0)$ & $0(0)$ & $0(0)$ & $1(14,3)$ & $0(0)$ \\
Q46 & $0(0)$ & $1(14,3)$ & $0(0)$ & $0(0)$ & $0(0)$ \\
Q47 & $2(28,6)$ & $0(0)$ & $0(0)$ & $1(14,3)$ & $2(28,6)$ \\
Q48 & $1(14,3)$ & $0(0)$ & $0(0)$ & $0(0)$ & $1(14,3)$ \\
Q49 & $0(0)$ & $0(0)$ & $0(0)$ & $0(0)$ & $0(0)$ \\
Q50 & $0(0)$ & $1(14,3)$ & $0(0)$ & $0(0)$ & $0(0)$ \\
Q51 & $0(0)$ & $0(0)$ & $1(14,3)$ & $0(0)$ & $0(0)$ \\
\hline
\end{tabular}


Tabela 5. Distribuição das respostas dos juízes segundo a precisão dos itens. São Paulo, SP, Brasil, 2018

\begin{tabular}{|c|c|c|c|c|c|}
\hline Itens & $\begin{array}{l}\text { Discordo } \\
\text { Totalmente }\end{array}$ & Discordo & $\begin{array}{l}\text { Não discordo } \\
\text { nem concordo }\end{array}$ & Concordo & $\begin{array}{l}\text { Concordo } \\
\text { Totalmente }\end{array}$ \\
\hline Q1 & $0(0)$ & $1(14,3)$ & $1(14,3)$ & $1(14,3)$ & $4(57,1)$ \\
\hline Q2 & $0(0)$ & $0(0)$ & $0(0)$ & $1(14,3)$ & $6(85,7)$ \\
\hline Q3 & $1(14,3)$ & $4(57,1)$ & $0(0)$ & $1(14,3)$ & $1(14,3)$ \\
\hline Q4 & $0(0)$ & $1(14,3)$ & $0(0)$ & $2(28,6)$ & $4(57,1)$ \\
\hline Q5 & $0(0)$ & $2(28,6)$ & $0(0)$ & $1(14,3)$ & $4(57,1)$ \\
\hline Q6 & $0(0)$ & $0(0)$ & $1(14,3)$ & $1(14,3)$ & $5(71,4)$ \\
\hline Q7 & $0(0)$ & $3(42,9)$ & $0(0)$ & $2(28,6)$ & $2(28,6)$ \\
\hline Q8 & $1(14,3)$ & $1(14,3)$ & $0(0)$ & $0(0)$ & $5(71,4)$ \\
\hline Q9 & $0(0)$ & $1(14,3)$ & $0(0)$ & $1(14,3)$ & $5(71,4)$ \\
\hline Q10 & $0(0)$ & $1(14,3)$ & $2(28,6)$ & $1(14,3)$ & $3(42,9)$ \\
\hline Q11 & $1(14,3)$ & $0(0)$ & $0(0)$ & $1(14,3)$ & $5(71,4)$ \\
\hline Q12 & $0(0)$ & $0(0)$ & $0(0)$ & $2(28,6)$ & $5(71,4)$ \\
\hline Q13 & $1(14,3)$ & $2(28,6)$ & $0(0)$ & $0(0)$ & $4(57,1)$ \\
\hline Q14 & $1(14,3)$ & $0(0)$ & $0(0)$ & $2(28,6)$ & $4(57,1)$ \\
\hline Q15 & $1(14,3)$ & $2(28,6)$ & $0(0)$ & $1(14,3)$ & $3(42,9)$ \\
\hline Q16 & $1(14,3)$ & $0(0)$ & $0(0)$ & $2(28,6)$ & $4(57,1)$ \\
\hline Q17 & $1(14,3)$ & $1(14,3)$ & $0(0)$ & $0(0)$ & $5(71,4)$ \\
\hline Q18 & $0(0)$ & $0(0)$ & $0(0)$ & $0(0)$ & $7(100)$ \\
\hline Q19 & $0(0)$ & $0(0)$ & $1(14,3)$ & $1(14,3)$ & $5(71,4)$ \\
\hline Q20 & $1(14,3)$ & $0(0)$ & $0(0)$ & $1(14,3)$ & $5(71,4)$ \\
\hline Q21 & $0(0)$ & $0(0)$ & $0(0)$ & $1(14,3)$ & $6(85,7)$ \\
\hline Q22 & $2(28,6)$ & $0(0)$ & $1(14,3)$ & $0(0)$ & $4(57,1)$ \\
\hline Q23 & $1(14,3)$ & $0(0)$ & $0(0)$ & $1(14,3)$ & $5(71,4)$ \\
\hline Q24 & $1(14,3)$ & $1(14,3)$ & $0(0)$ & $0(0)$ & $5(71,4)$ \\
\hline Q25 & $1(14,3)$ & $0(0)$ & $1(14,3)$ & $1(14,3)$ & $4(57,1)$ \\
\hline Q26 & $0(0)$ & $0(0)$ & $0(0)$ & $2(28,6)$ & $5(71,4)$ \\
\hline Q27 & $1(14,3)$ & $0(0)$ & $0(0)$ & $1(14,3)$ & $5(71,4)$ \\
\hline Q28 & $1(14,3)$ & $0(0)$ & $1(14,3)$ & $1(14,3)$ & $4(57,1)$ \\
\hline Q29 & $1(14,3)$ & $0(0)$ & $1(14,3)$ & $0(0)$ & $5(71,4)$ \\
\hline Q30 & $1(14,3)$ & $1(14,3)$ & $0(0)$ & $0(0)$ & $5(71,4)$ \\
\hline Q31 & $0(0)$ & $0(0)$ & $0(0)$ & $0(0)$ & $7(100)$ \\
\hline Q32 & $0(0)$ & $0(0)$ & $0(0)$ & $0(0)$ & $7(100)$ \\
\hline Q33 & $0(0)$ & $0(0)$ & $0(0)$ & $1(14,3)$ & $6(85,7)$ \\
\hline Q34 & $0(0)$ & $1(14,3)$ & $1(14,3)$ & $1(14,3)$ & $4(57,1)$ \\
\hline Q35 & $0(0)$ & $0(0)$ & $1(14,3)$ & $1(14,3)$ & $5(71,4)$ \\
\hline
\end{tabular}


continuação

\begin{tabular}{lccccc}
\hline Itens & $\begin{array}{c}\text { Discordo } \\
\text { Totalmente }\end{array}$ & Discordo & $\begin{array}{c}\text { Não discordo } \\
\text { nem concordo }\end{array}$ & Concordo & $\begin{array}{c}\text { Concordo } \\
\text { Totalmente }\end{array}$ \\
\hline Q36 & $1(14,3)$ & $2(28,6)$ & $1(14,3)$ & $0(0)$ & $3(42,9)$ \\
Q37 & $0(0)$ & $0(0)$ & $0(0)$ & $1(14,3)$ & $6(85,7)$ \\
Q38 & $1(14,3)$ & $0(0)$ & $0(0)$ & $0(0)$ & $6(85,7)$ \\
Q39 & $0(0)$ & $0(0)$ & $0(0)$ & $0(0)$ & $7(100)$ \\
Q40 & $0(0)$ & $0(0)$ & $1(14,3)$ & $0(0)$ & $6(85,7)$ \\
Q41 & $0(0)$ & $0(0)$ & $0(0)$ & $0(0)$ & $7(100)$ \\
Q42 & $0(0)$ & $0(0)$ & $0(0)$ & $0(0)$ & $7(100)$ \\
Q43 & $1(14,3)$ & $1(14,3)$ & $0(0)$ & $0(0)$ & $5(71,4)$ \\
Q44 & $0(0)$ & $0(0)$ & $0(0)$ & $1(14,3)$ & $6(85,7)$ \\
Q45 & $0(0)$ & $0(0)$ & $0(0)$ & $1(14,3)$ & $6(85,7)$ \\
Q46 & $0(0)$ & $1(14,3)$ & $0(0)$ & $0(0)$ & $6(85,7)$ \\
Q47 & $2(28,6)$ & $0(0)$ & $0(0)$ & $1(14,3)$ & $4(57,1)$ \\
Q48 & $1(14,3)$ & $0(0)$ & $0(0)$ & $0(0)$ & $6(85,7)$ \\
Q49 & $0(0)$ & $0(0)$ & $0(0)$ & $0(0)$ & $7(100)$ \\
Q50 & $0(0)$ & $0(0)$ & $0(0)$ & $0(0)$ & $7(100)$ \\
Q51 & $0(0)$ & $0(0)$ & $1(14,3)$ & $0(0)$ & $6(85,7)$ \\
\hline
\end{tabular}

O valor adotado aceitável foi $\geq 70 \%$ para a clareza, relevância, objetividade e precisão. Seguindo esses critérios foram eliminados 7 itens: Item 03 (Considero que o trabalhador que sofre acidente não tem capacidade para trabalhar na enfermagem), Item 07 (Acredito que o casamento pode acabar se 0 trabalhador sofrer um acidente com um paciente portador de HIV/AIDS), Item 10 (Acredito que os acidentes não acontecem quando temos autoconfiança), Item 13 (A falta de conhecimento contribui para o acidente), Item 15 (A desatenção do colega de trabalho favorece a ocorrência de acidentes), Item 22 (Os Conflitos na equipe favorecem a ocorrência de acidente), Item 36 (A remuneração influencia na proteção).

Ao final da avaliação dos juízes, a Escala de Crenças dos Trabalhadores da Equipe de Enfermagem estava composta por 44 itens, conforme apresentado pela Tabela 6. 
Tabela 6. Itens da Escala de Crenças dos trabalhadores da equipe de enfermagem relacionadas aos acidentes de trabalho com fluido biológico após análise de conteúdo. São Paulo, SP, Brasil, 2018

\section{Itens}

1. Pensar sobre 0 acidente me causa angústia

2. Tenho medo de sofrer acidente com fluido biológico no trabalho

4. Penso que o trabalhador que sofre acidente com fluido biológico poderá ter conflitos familiares

5. Acredito que a falta de conhecimento contribui para 0 acidente

6. Penso que 0 acidente com fluido biológico pode trazer graves consequências para a vida

8. Tenho medo de me contaminar após um acidente

9. Tenho medo de contaminar meus filhos após o acidente

11. Penso que 0 acidente pode fazer o trabalhador repensar sobre a própria vida

12. Vejo que os trabalhadores que sofrem acidente de trabalho com fluido biológico passam a repensar suas práticas de trabalho

14. O Estresse influencia a ocorrência de acidentes

16. As Interferências externas levam ao acidente

17. Os trabalhadores mais inexperientes não se acidentam mais

18. A não utilização dos equipamentos de proteção individual pelos trabalhadores favorece a ocorrência do acidente

19. O Descarte inadequado de materiais perfurocortantes favorece a ocorrência de acidentes

20. O preenchimento da caixa coletora de materiais perfurocortantes além do limite recomendado favorece a ocorrência de acidentes

21. A utilização de materiais e instrumentos inadequados para a realização dos procedimentos contribui para a exposição dos trabalhadores

23. Paciente agitado favorece a ocorrência do acidente

24. O trabalho em turno noturno contribui para a ocorrência de acidentes

25. O Desequilíbrio emocional favorece a ocorrência de acidentes

26. A Escassez de recursos humanos é responsável pelos acidentes

27. A dupla jornada favorece a ocorrência de acidentes

28. Dobrar o plantão favorece 0 acidente

29. A luva deve ser utilizada ao realizar uma punção venosa

30. Os óculos de proteção são importantes para o descarte de diurese

31. O uso de equipamentos de proteção individual favorece uma prática segura 
continuação

32. Os Equipamentos de proteção individual devem ser utilizados em todas as situações onde há risco de exposição a material biológico

33. O Trabalho em equipe favorece 0 uso de Epi's

34. Quando os trabalhadores conhecem o diagnóstico do paciente, não utilizam Epi's

35. Os trabalhadores não consideram importante utilizar Epi's

37. A Pressa influencia a não utilização dos Equipamentos de proteção individual

38. A instituição oferece treinamentos periódicos sobre acidentes de trabalho com material biológico

39. O fluxo de atendimento nesta instituição após o acidente é divulgado para todos os trabalhadores

40. Os trabalhadores não sabem o que fazer caso sofram um acidente com fluido biológico

41. $O$ acidente de trabalho com fluido biológico deve ser notificado

42. Os trabalhadores devem abrir uma CAT (Comunicação de Acidente de Trabalho) após sofrer o acidente

43. A burocracia é muito grande após a ocorrência de um acidente

44. A abertura da CAT (Comunicação de Acidente de Trabalho) não é importante

45. Existe apoio institucional para os trabalhadores acidentados

46. O Atendimento médico após o acidente é importante, traz alívio e conforto

47. A equipe tem preconceito com quem sofre acidente

48. Os trabalhadores conhecem 0 acompanhamento clínico e laboratorial após o acidente

49. O Atendimento psicológico é muito importante para o trabalhador acidentado

50. O suporte da chefia após o acidente é muito importante

51. Os trabalhadores têm medo de uma possível demissão em caso de acidentes

\section{Etapa II}

A Análise Semântica dos Itens teve como objetivo verificar se os itens eram inteligíveis para o estrato da população-meta que apresenta menor grau de habilidade (extrato mais baixo, nesta pesquisa composto pelos auxiliares de enfermagem; e por meio da consulta ao estrato de maior habilidade (mais sofisticado) da população-meta, neste estudo, os enfermeiros.

Para atingir o objetivo da Validação de Aparência foram utilizadas as informações contidas nos instrumentos avaliados pelo painel de juízes. Para verificar 
a inteligibilidade da escala, após a Validação de Conteúdo, o referido instrumento foi aplicado na forma de teste piloto a 30 Técnicos e Auxiliares de Enfermagem.

A primeira versão da escala de crenças foi aperfeiçoada com base nas respostas e sugestões levantadas no teste piloto e, a seguir, reaplicada (segundo teste piloto) a 10 Enfermeiros. Aos trabalhadores participantes do teste piloto, foi solicitada a autorização formal para participar do estudo, por meio da assinatura do Termo de Consentimento Livre e Esclarecido (TCLE), conforme determina a Resolução 196/1996.

Após este teste, os itens 5, 27, 28 e 46 tiveram alteração na grafia conforme ilustrado no quadro 1 e 7 itens foram eliminados: 12, 38, 39, 41, 42, 45, 48, por se tratarem de itens que segundo os trabalhadores expressavam conhecimento e não crenças, chegando a um instrumento final de 37 itens.

Quadro 1. Itens com modificação na grafia, após o teste piloto. São Paulo, SP, Brasil, 2018

\begin{tabular}{|c|c|}
\hline Itens antes da modificação & Itens modificados \\
\hline $\begin{array}{l}\text { 5. Acredito que a falta de conhecimento } \\
\text { contribui para o acidente. }\end{array}$ & $\begin{array}{l}\text { 5. Acredito que a falta de conhecimento dos } \\
\text { trabalhadores em relação aos acidentes de } \\
\text { trabalho com fluido biológico contribui para } \\
\text { o acidente. }\end{array}$ \\
\hline $\begin{array}{l}\text { 27. A dupla jornada favorece a ocorrência de } \\
\text { acidentes. }\end{array}$ & $\begin{array}{l}\text { 27. A dupla jornada em outra instituição } \\
\text { favorece a ocorrência de acidentes. }\end{array}$ \\
\hline 28. Dobrar o plantão favorece o acidente & $\begin{array}{l}\text { 28. Dobrar o plantão na mesma instituição } \\
\text { favorece o acidente }\end{array}$ \\
\hline $\begin{array}{l}\text { 46. O Atendimento médico após o acidente é } \\
\text { importante, traz alívio e conforto. }\end{array}$ & $\begin{array}{l}\text { 46. O Atendimento por profissional capacitado } \\
\text { após o acidente é importante, traz alívio e } \\
\text { conforto. }\end{array}$ \\
\hline
\end{tabular}

Ao concluir esse processo, a Escala de Crenças em sua versão pré-final ficou com 37 itens conforme apresentado na Tabela 7. 
Tabela 7. Itens da Escala de Crenças dos Trabalhadores da Equipe de Enfermagem frente aos acidentes de trabalho com fluido biológico após análise semântica. São Paulo, SP, Brasil, 2018

\section{Itens}

1. Pensar sobre 0 acidente me causa angústia

2. Tenho medo de sofrer acidente com fluido biológico no trabalho

4. Penso que o trabalhador que sofre acidente com fluido biológico poderá ter conflitos familiares

5. Acredito que a falta de conhecimento dos trabalhadores em relação aos acidentes de trabalho com fluido biológico contribui para o acidente

6. Penso que o acidente com fluido biológico pode trazer graves consequências para a vida

8. Tenho medo de me contaminar após um acidente

9. Tenho medo de contaminar meus filhos após o acidente

11. Penso que 0 acidente pode fazer 0 trabalhador repensar sobre a própria vida

14. O Estresse influencia a ocorrência de acidentes

16. As Interferências externas levam ao acidente

17. Os trabalhadores mais inexperientes não se acidentam mais

18. A não utilização dos equipamentos de proteção individual pelos trabalhadores favorece a ocorrência do acidente

19. O Descarte inadequado de materiais perfurocortantes favorece a ocorrência de acidentes

20. O preenchimento da caixa coletora de materiais perfurocortantes além do limite recomendado favorece a ocorrência de acidentes

21. A utilização de materiais e instrumentos inadequados para a realização dos procedimentos contribui para a exposição dos trabalhadores

23. Paciente agitado favorece a ocorrência do acidente

24. O trabalho em turno noturno contribui para a ocorrência de acidentes

25. O Desequilíbrio emocional favorece a ocorrência de acidentes

26. A Escassez de recursos humanos é responsável pelos acidentes

27. A dupla jornada em outra instituição favorece a ocorrência de acidentes

28. Dobrar o plantão na mesma instituição favorece 0 acidente

29. A luva deve ser utilizada ao realizar uma punção venosa

30. Os óculos de proteção são importantes para o descarte de diurese

31. O uso de equipamentos de proteção individual favorece uma prática segura

continua 
continuação

32. Os Equipamentos de proteção individual devem ser utilizados em todas as situações onde há risco de exposição a material biológico

33. O Trabalho em equipe favorece o uso de Equipamentos de proteção individual

34. Quando os trabalhadores conhecem o diagnóstico do paciente, não utilizam Equipamentos de proteção individual

35. Os trabalhadores não consideram importante utilizar equipamentos de proteção individual

37. A Pressa influencia a não utilização dos Equipamentos de proteção individual

40. Os trabalhadores não sabem o que fazer caso sofram um acidente com fluido biológico

43. A burocracia é muito grande após a ocorrência de um acidente

44. A abertura da CAT (Comunicação de Acidente de Trabalho) não é importante

46. O Atendimento por profissional capacitado após o acidente é importante, traz alívio e conforto

47. A equipe tem preconceito com quem sofre acidente

49. O Atendimento psicológico é muito importante para o trabalhador acidentado

50. O suporte da chefia após o acidente é muito importante

51. Os trabalhadores têm medo de uma possível demissão em caso de acidentes

\subsection{Validação de Construto}

\subsubsection{Caracterização da Amostra}

Após a validação de conteúdo procedeu-se a validação do constructo como forma de se verificar as propriedades psicométricas do instrumento.

O instrumento foi aplicado em uma amostra de 320 trabalhadores de enfermagem, a maioria do sexo feminino, $n=295$ (92,2\%), com idade compreendida entre os 26 e 71 anos e uma média de 45,6 anos ( $D P=8,9$ ). tempo médio de profissão foi de 20,5 anos $(D P=9,0)$. No que concerne a categoria profissional 131 ( $n=40,9 \%)$ eram enfermeiros, 51,3\% ( $n=164)$ técnicos de enfermagem e 7,8\% $(n=25)$ eram auxiliares de enfermagem. Dos trabalhadores entrevistados $51,6 \%(n=165)$ referiu nunca ter sofrido acidente de trabalho com fluido biológico e 48,4\% ( $n=155)$ já sofreram acidente de trabalho envolvendo fluido biológico, conforme demonstra a Tabela 8. 
Tabela 8. Caracterização dos trabalhadores de enfermagem. São Paulo, SP, Brasil, 2018

\begin{tabular}{lc}
\hline Sexo, N(\%) & \\
Masculino & $25(7,8)$ \\
Feminino & $295(92,2)$ \\
Categoria Profissional, N(\%) & \\
$\quad$ Enfermeiro & $131(40,9)$ \\
Técnico de Enfermagem & $164(51,3)$ \\
$\quad$ Auxiliar de Enfermagem & $25(7,8)$ \\
Já sofreu acidente com fluido & \\
Sim & $155(48,4)$ \\
$\quad$ Não & $165(51,6)$ \\
Idade (anos), média \pm DP & $45,6 \pm 8,9$ \\
Tempo de profissão (anos), média \pm DP & $20,5 \pm 9,0$ \\
\hline
\end{tabular}

Em relação a Dimensionalidade da escala de crenças, a Tabela 9 apresenta a distribuição dos trabalhadores por resposta aos 37 itens da escala de crenças. 
Tabela 9. Distribuição dos profissionais por resposta dos 37 itens da escala de crenças. São Paulo, SP, Brasil, 2018

\begin{tabular}{|c|c|c|c|c|c|}
\hline Itens & $\begin{array}{l}\text { Discordo } \\
\text { Totalmente }\end{array}$ & Discordo & $\begin{array}{c}\text { Não } \\
\text { discordo } \\
\text { nem } \\
\text { concordo }\end{array}$ & Concordo & $\begin{array}{l}\text { Concordo } \\
\text { Totalmente }\end{array}$ \\
\hline Q1 Pensar sobre 0 acidente me causa angústia & $31(9,7)$ & $85(26,6)$ & $74(23,1)$ & $88(27,5)$ & $42(13,1)$ \\
\hline $\begin{array}{l}\text { Q2 Tenho medo de sofrer acidente com fluido } \\
\text { biológico no trabalho }\end{array}$ & $9(2,8)$ & $45(14,1)$ & $30(9,4)$ & $172(53,8)$ & $64(20,0)$ \\
\hline $\begin{array}{l}\text { Q4 Penso que o trabalhador que sofre acidente } \\
\text { com fluido biológico poderá ter conflitos familiares }\end{array}$ & $19(5,9)$ & $86(26,9)$ & $93(29,1)$ & $92(28,8)$ & $30(9,4)$ \\
\hline $\begin{array}{l}\text { Q5 Acredito que a falta de conhecimento contribui } \\
\text { para o acidente }\end{array}$ & $16(5)$ & $88(27,5)$ & $29(9,1)$ & $125(39,1)$ & $62(19,4)$ \\
\hline $\begin{array}{l}\text { Q6 Penso que o acidente com fluido biológico } \\
\text { pode trazer graves consequências para a vida }\end{array}$ & $2(0,6)$ & $7(2,2)$ & $46(14,4)$ & $148(46,3)$ & $117(36,6)$ \\
\hline $\begin{array}{l}\text { Q8 Tenho medo de me contaminar após um } \\
\text { acidente }\end{array}$ & $2(0,6)$ & $7(2,2)$ & $27(8,4)$ & $185(57,8)$ & $99(30,9)$ \\
\hline $\begin{array}{l}\text { Q9 Tenho medo de contaminar meus filhos após o } \\
\text { acidente }\end{array}$ & $20(6,3)$ & $72(22,5)$ & $55(17,2)$ & $119(37,2)$ & $54(16,9)$ \\
\hline $\begin{array}{l}\text { Q11 Penso que o acidente pode fazer } 0 \\
\text { trabalhador repensar sobre a própria vida }\end{array}$ & $1(0,3)$ & $21(6,6)$ & $71(22,2)$ & $175(54,7)$ & $52(16,3)$ \\
\hline $\begin{array}{l}\text { Q14 O Estresse influencia a ocorrência de } \\
\text { acidentes }\end{array}$ & $1(0,3)$ & $1(0,3)$ & $26(8,1)$ & $170(53,1)$ & $122(38,1)$ \\
\hline Q16 As Interferências externas levam ao acidente & $1(0,3)$ & $53(16,6)$ & $71(22,2)$ & $123(38,4)$ & $72(22,5)$ \\
\hline $\begin{array}{l}\text { Q17 Os trabalhadores mais inexperientes se } \\
\text { acidentam mais }\end{array}$ & $49(15,3)$ & $138(43,1)$ & $68(21,3)$ & $42(13,1)$ & $23(7,2)$ \\
\hline $\begin{array}{l}\text { Q18 A não utilização dos equipamentos de } \\
\text { proteção individual pelos trabalhadores favorece a } \\
\text { ocorrência do acidente }\end{array}$ & $5(1,6)$ & $5(1,6)$ & $12(3,8)$ & $159(49,7)$ & $139(43,4)$ \\
\hline $\begin{array}{l}\text { Q19 O Descarte inadequado de materiais } \\
\text { perfurocortantes favorece a ocorrência de } \\
\text { acidentes }\end{array}$ & $0(0,0)$ & $10(3,1)$ & $1(0,3)$ & $137(42,8)$ & $172(53,8)$ \\
\hline $\begin{array}{l}\text { Q20 O preenchimento da caixa coletora de } \\
\text { materiais perfurocortantes além do limite } \\
\text { recomendado favorece a ocorrência de acidentes }\end{array}$ & $0(0,0)$ & $8(2,5)$ & $3(0,9)$ & $156(48,8)$ & $153(47,8)$ \\
\hline $\begin{array}{l}\text { Q21 A utilização de materiais e instrumentos } \\
\text { inadequados para a realização dos procedimentos } \\
\text { contribui para a exposição dos trabalhadores }\end{array}$ & $0(0,0)$ & $14(4,4)$ & $19(5,9)$ & $154(48,1)$ & $133(41,6)$ \\
\hline $\begin{array}{l}\text { Q23 Paciente agitado favorece a ocorrência do } \\
\text { acidente }\end{array}$ & $2(0,6)$ & $25(7,8)$ & $21(6,6)$ & $178(55,6)$ & $94(29,4)$ \\
\hline $\begin{array}{l}\text { Q24 O trabalho em turno noturno contribui para a } \\
\text { ocorrência de acidentes }\end{array}$ & $27(8,4)$ & $108(33,8)$ & $96(30)$ & $51(15,9)$ & $38(11,9)$ \\
\hline $\begin{array}{l}\text { Q25 O Desequilibrio emocional favorece a } \\
\text { ocorrência de acidentes }\end{array}$ & $2(0,6)$ & $35(10,9)$ & $62(19,4)$ & $152(47,5)$ & $69(21,6)$ \\
\hline $\begin{array}{l}\text { Q26 A Escassez de recursos humanos é } \\
\text { responsável pelos acidentes }\end{array}$ & $3(0,9)$ & $28(8,8)$ & $92(28,8)$ & $133(41,6)$ & $64(20,0)$ \\
\hline
\end{tabular}


continuação

\begin{tabular}{|c|c|c|c|c|c|}
\hline $\begin{array}{l}\text { Q27 A dupla jornada favorece a ocorrência de } \\
\text { acidentes }\end{array}$ & $7(2,2)$ & $45(14,1)$ & $80(25)$ & $135(42,2)$ & $53(16,6)$ \\
\hline Q28 Dobrar o plantão favorece o acidente & $9(2,8)$ & $71(22,2)$ & $71(22,2)$ & $107(33,4)$ & $62(19,4)$ \\
\hline $\begin{array}{l}\text { Q29 A luva deve ser utilizada ao realizar uma } \\
\text { punção venosa }\end{array}$ & $4(1,3)$ & $4(1,3)$ & $4(1,3)$ & $124(38,8)$ & $184(57,5)$ \\
\hline $\begin{array}{l}\text { Q30 Os óculos de proteção são importantes para o } \\
\text { descarte de diurese }\end{array}$ & $0(0,0)$ & $39(12,2)$ & $31(9,7)$ & $131(40,9)$ & $119(37,2)$ \\
\hline $\begin{array}{l}\text { Q31 O uso de equipamentos de proteção individual } \\
\text { favorece uma prática segura }\end{array}$ & $0(0,0)$ & $4(1,3)$ & $12(3,8)$ & $147(45,9)$ & $157(49,1)$ \\
\hline $\begin{array}{l}\text { Q32 Os Equipamentos de proteção individual } \\
\text { devem ser utilizados em todas as situações onde } \\
\text { há risco de exposição a material biológico }\end{array}$ & $1(0,3)$ & $5(1,6)$ & $12(3,8)$ & $136(42,5)$ & $166(51,9)$ \\
\hline 330 Trabalho em equipe favorece o uso de Epi's & $7(2,2)$ & $43(13,4)$ & $61(19,1)$ & $139(43,4)$ & $70(21,9)$ \\
\hline $\begin{array}{l}\text { Q34 Quando os trabalhadores conhecem o } \\
\text { diagnóstico do paciente, não utilizam Epi's }\end{array}$ & $33(10,3)$ & $134(41,9)$ & $68(21,3)$ & $65(20,3)$ & $20(6,3)$ \\
\hline $\begin{array}{l}\text { Q35 Os trabalhadores não consideram importante } \\
\text { utilizar Epi's }\end{array}$ & $35(10,9)$ & $135(42,2)$ & $70(21,9)$ & $69(21,6)$ & $11(3,4)$ \\
\hline $\begin{array}{l}\text { Q37 A Pressa influencia a não utilização dos } \\
\text { Equipamentos de proteção individual }\end{array}$ & $6(1,9)$ & $61(19,1)$ & $30(9,4)$ & $191(59,7)$ & $32(10,0)$ \\
\hline $\begin{array}{l}\text { Q40 Os trabalhadores sabem o que fazer caso } \\
\text { sofram um acidente com fluido biológico }\end{array}$ & $10(3,1)$ & $105(32,8)$ & $35(10,9)$ & $131(40,9)$ & $39(12,2)$ \\
\hline $\begin{array}{l}\text { Q43 A burocracia é muito grande após a } \\
\text { ocorrência de um acidente }\end{array}$ & $24(7,5)$ & $46(14,4)$ & $61(19,1)$ & $127(39,7)$ & $62(19,4)$ \\
\hline $\begin{array}{l}\text { Q44 A abertura da CAT (Comunicação de Acidente } \\
\text { de Trabalho) não é importante }\end{array}$ & $142(44,4)$ & $128(40)$ & $28(8,8)$ & $8(2,5)$ & $14(4,4)$ \\
\hline $\begin{array}{l}\text { Q46 O Atendimento médico após o acidente é } \\
\text { importante, traz alívio e conforto }\end{array}$ & $11(3,4)$ & $22(6,9)$ & $41(12,8)$ & $150(46,9)$ & $96(30,0)$ \\
\hline $\begin{array}{l}\text { Q47 A equipe tem preconceito com quem sofre } \\
\text { acidente }\end{array}$ & $38(11,9)$ & $157(49,1)$ & $79(24,7)$ & $20(6,3)$ & $26(8,1)$ \\
\hline $\begin{array}{l}\text { Q49 O Atendimento psicológico é muito importante } \\
\text { para o trabalhador acidentado }\end{array}$ & $1(0,3)$ & $2(0,6)$ & $38(11,9)$ & $187(58,4)$ & $92(28,8)$ \\
\hline $\begin{array}{l}\text { Q50 O suporte da chefia após o acidente é muito } \\
\text { importante }\end{array}$ & $4(1,3)$ & $13(4,1)$ & $31(9,7)$ & $165(51,6)$ & $107(33,4)$ \\
\hline
\end{tabular}

Conforme tabela 9, nota-se que com exceção dos itens Q1 (Pensar sobre o acidente me causa angústia), Q4 (Penso que o trabalhador que sofre acidente com fluido biológico poderá ter conflitos familiares), Q17 (Os trabalhadores mais inexperientes se acidentam mais), Q24 (O trabalho em turno noturno contribui para a ocorrência de acidentes), Q34 (Quando os trabalhadores conhecem o diagnóstico do paciente, não utilizam Epi's), Q35 (Os trabalhadores não consideram importante utilizar Epi's), Q37 (A Pressa influencia a não utilização dos Equipamentos de proteção individual), Q40 (Os trabalhadores sabem o que fazer caso sofram um acidente com fluido biológico), Q44 (A abertura da CAT não é importante), Q47 (A 
equipe tem preconceito com quem sofre acidente) e Q51 (Os trabalhadores têm medo de uma possível demissão em caso de acidentes), todos (23) apresentaram efeito teto (ceiling) - esses ocorrem quando mais do que $15 \%$ das respostas estão concentradas no máximo da escala "Concordo Totalmente" (Terwee et al.,2007). Por outro lado, verificaram-se para os itens Q17 (Os trabalhadores mais inexperientes se acidentam mais), Q44 (A abertura da CAT não é importante e Q51 (Os trabalhadores têm medo de uma possível demissão em caso de acidentes), o efeito chão (floor) - mais de 15\% das respostas concentrada em "Discordo totalmente".

\subsubsection{Análise Fatorial}

Para se avaliar a dimensionalidade da escala sugerida pelos dados, procedeu-se a análise fatorial exploratória. O coeficiente de adequação da amostra de Kaiser-Meyer-Olkin(KMO) foi calculado em 0,8 e o teste de esfericidade de Barlett ( $p$ menor 0,001 foi considerado significativo.

A Análise Fatorial inicial com os 37 itens apontou a existência de dez fatores que explicam $68,4 \%$ da variância total dos itens. Nas análises fatoriais subseqüentes, foram eliminados os itens cujas comunalidades, a parcela da variância do item explicado pelos fatores comuns, apresentaram-se inferiores a 0,6. A tabela 10 apresenta os itens eliminados em cada etapa.

Tabela 10. Distribuição dos Itens eliminados e respectivas comunalidades. São Paulo, SP, Brasil, 2018

\begin{tabular}{cclc}
\hline Etapa & \multicolumn{1}{c}{ Item eliminado } & Comunalidade \\
\hline 1 & Q6 & $\begin{array}{l}\text { Penso que o acidente com fluido biológico pode trazer graves } \\
\text { consequências para a vida }\end{array}$ & 0,546 \\
2 & Q11 & $\begin{array}{l}\text { Penso que o acidente pode fazer o trabalhador repensar sobre a } \\
\text { própria vida }\end{array}$ & 0,550 \\
3 & Q4 & $\begin{array}{l}\text { Penso que o trabalhador que sofre acidente com fluido biológico } \\
\text { poderá ter conflitos familiares }\end{array}$ & 0,576 \\
\hline
\end{tabular}


Aplicando-se a análise fatorial após a exclusão dos 3 itens (tabela 10), resultaram 10 fatores que explicam $70,4 \%$ da variância total dos dados (tabela 11). A escolha deste número de fatores deu-se a partir do número de autovalores da matriz de correlação maiores do que um, já que um autovalor pequeno sugere uma pequena contribuição do fator na explicação das variações das variáveis originais.

A análise dos componentes principais considera a variância total dos dados ou seja, é uma medida de dispersão estatística e indica o "quão longe" em geral os seus valores se encotram do valor esperado ou da média. Assim, quanto maior for a variância, mais distantes da média estarão os valores, e quanto menor for a variância, mais próximos os valores estarão da média. As comunalidades são quantidades das variâncias (correlações) de cada variável explicada pelos fatores. Quanto maior a comunalidade, maior será o poder de explicação daquela variável pelo fator, nesse estudo desejamos comunalidades superiores a 0,5.

Tabela 11. Cargas Fatoriais, porcentagem da variância explicada e coeficiente Alpha de Cronbach dos 10 fatores da escala de crenças. São Paulo, SP, Brasil, 2018

\begin{tabular}{|c|c|c|c|c|c|c|c|c|c|c|c|}
\hline & \multicolumn{10}{|c|}{ Fatores } & \multirow[b]{2}{*}{ Comunalidade } \\
\hline & 1 & 2 & 3 & 4 & 5 & 6 & 7 & 8 & 9 & 10 & \\
\hline $\begin{array}{l}\text { Q20 O preenchimento da caixa } \\
\text { coletora de materiais } \\
\text { perfurocortantes além do limite } \\
\text { recomendado favorece a } \\
\text { ocorrência de acidentes }\end{array}$ & 0,862 & 0,212 & $-0,023$ & 0,092 & 0,074 & $-0,052$ & 0,131 & 0,025 & 0,106 & 0,107 & 0,846 \\
\hline $\begin{array}{l}\text { Q19 O Descarte inadequado de } \\
\text { materiais perfurocortantes } \\
\text { favorece a ocorrência de } \\
\text { acidentes }\end{array}$ & 0,854 & 0,160 & $-0,048$ & 0,029 & 0,160 & $-0,064$ & 0,071 & 0,100 & 0,020 & 0,151 & 0,826 \\
\hline $\begin{array}{l}\text { Q18 A não utilização dos } \\
\text { equipamentos de proteção } \\
\text { individual pelos trabalhadores } \\
\text { favorece a ocorrência do } \\
\text { acidente }\end{array}$ & 0,785 & 0,110 & 0,103 & $-0,006$ & $-0,010$ & 0,001 & $-0,065$ & 0,071 & $-0,040$ & $-0,015$ & 0,651 \\
\hline $\begin{array}{l}\text { Q21 A utilização de materiais e } \\
\text { instrumentos inadequados para } \\
\text { a realização dos procedimentos } \\
\text { contribui para a exposição dos } \\
\text { trabalhadores }\end{array}$ & 0,726 & 0,245 & 0,170 & 0,056 & 0,003 & 0,027 & 0,165 & 0,154 & 0,160 & 0,035 & 0,697 \\
\hline $\begin{array}{l}\text { Q23 Paciente agitado favorece } \\
\text { a ocorrência do acidente }\end{array}$ & 0,549 & 0,249 & 0,012 & 0,403 & $-0,038$ & $-0,089$ & 0,248 & 0,078 & 0,044 & $-0,104$ & 0,616 \\
\hline
\end{tabular}


continuação

Q32 Os Equipamentos de proteção individual devem ser utilizados em todas as

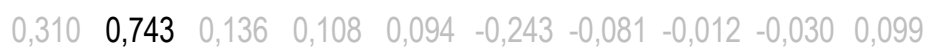
0,763 situações onde há risco de exposição a material biológico

Q29 A luva deve ser utilizada ao realizar uma punção venosa $\begin{array}{lllllllllll}0,292 & 0,696 & 0,040 & -0,035 & 0,162 & 0,027 & 0,127 & 0,052 & 0,065 & 0,036 & 0,624\end{array}$

Q31 0 uso de equipamentos de proteção individual favorece uma prática segura

Q33 O Trabalho em equipe favorece o uso de Epi's

$\begin{array}{llllllllll}-0,031 & 0,623 & 0,215 & 0,172 & -0,014 & -0,034 & 0,276 & 0,264 & 0,107 & 0,024\end{array}$

Q30 Os óculos de proteção são importantes para o descarte de diurese

Q50 0 suporte da chefia após 0 acidente é muito importante

$\begin{array}{llllllllll}0,084 & 0,433 & 0,102 & 0,334 & -0,066 & -0,318 & 0,231 & -0,084 & 0,324 & 0,349\end{array}$

Q27 A dupla jornada favorece a ocorrência de acidentes

$\begin{array}{llllllll}0,754 & 0,114 & 0,038 & 0,018 & 0,297 & 0,054 & 0,045 & 0,219\end{array}$

0,780

Q28 Dobrar o plantão favorece 0 acidente

$\begin{array}{lllllllllll}0,058 & 0,093 & 0,733 & -0,085 & 0,087 & 0,092 & 0,010 & 0,310 & 0,100 & 0,046 & 0,680\end{array}$

$\begin{array}{lllllllllll}0,058 & 0,093 & 0,733 & -0,085 & 0,087 & 0,092 & 0,010 & 0,310 & 0,100 & 0,046 & 0,680\end{array}$

Q26 A Escassez de recursos humanos é responsável pelos acidentes

Q24 O trabalho em turno noturno contribui para a ocorrência de acidentes

$\begin{array}{llllllllll}0,084 & 0,048 & 0,714 & 0,213 & -0,047 & 0,103 & 0,206 & 0,132 & 0,186 & 0,005\end{array}$

Q40 Os trabalhadores sabem o que fazer caso sofram um acidente com fluido biológico

Q43 A burocracia é muito grande após a ocorrência de um acidente

$\begin{array}{llllllllll}0,134 & 0,089 & 0,649 & -0,139 & 0,432 & -0,065 & -0,278 & -0,225 & 0,036 & -0,091\end{array}$

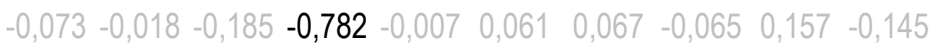

0,709

Q17 Os trabalhadores mais inexperientes se acidentam mais

Q46 O Atendimento médico após o acidente é importante, traz alívio e conforto

Q9 Tenho medo de contaminar meus filhos após 0 acidente

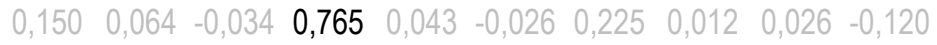

0,682

Q8 Tenho medo de me contaminar após um acidente

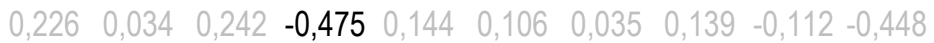

0,602

Q2 Tenho medo de sofrer acidente com fluido biológico no trabalho

Q35 Os trabalhadores não consideram importante utilizar Epi's

Q44 A abertura da CAT Trabalho) não é importante

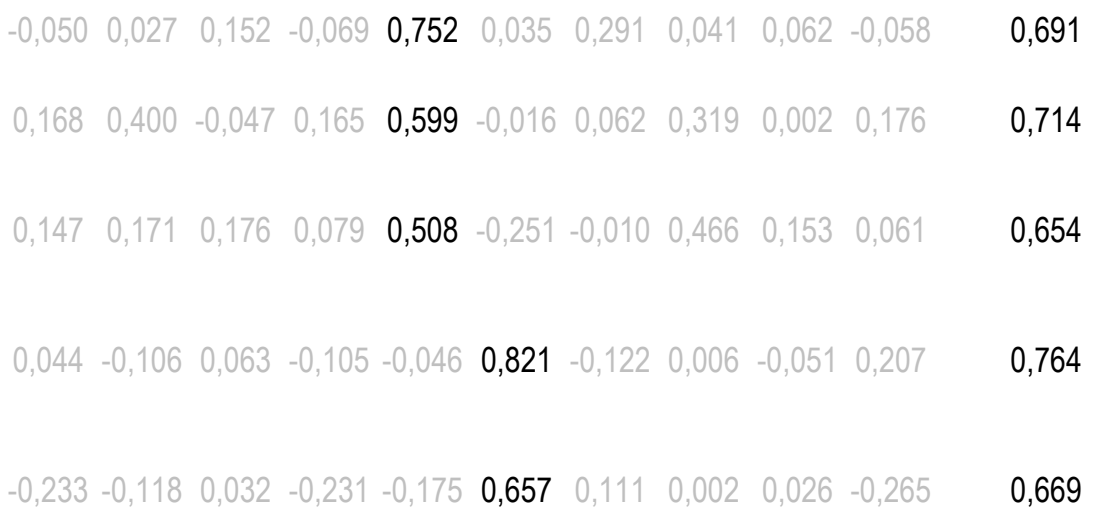


continuação

Q34 Quando os trabalhadores conhecem o diagnóstico do

$\begin{array}{llllllllll}0,026 & 0,001 & 0,219 & 0,290 & 0,316 & 0,632 & -0,029 & -0,232 & 0,268 & 0,151\end{array}$

paciente, não utilizam Epi's

$\begin{array}{lllllllllll}0,126 & 0,154 & 0,104 & 0,210 & 0,184 & -0,093 & 0,763 & 0,140 & 0,020 & 0,101 & 0,749\end{array}$

Q16 As Interferências externas

levam ao acidente

Q25 0 Desequilíbrio emocional

favorece a ocorrência de

$\begin{array}{llllllllll}0,469 & 0,096 & 0,354 & -0,029 & 0,116 & 0,076 & 0,660 & 0,030 & 0,037 & -0,037\end{array}$

0,814

acidentes

Q14 O Estresse influencia a

ocorrência de acidentes

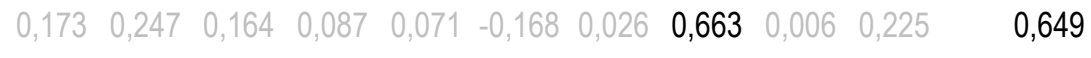

Q5 Acredito que a falta de

conhecimento contribui para 0

acidente

Q47 A equipe tem preconceito com quem sofre acidente

Q49 0 Atendimento psicológico

é muito importante para 0

\section{(1)}

Q1 Pensar sobre 0 acidente me causa angústia

$\begin{array}{lllllllllllll}0,111 & 0,128 & 0,008 & 0,035 & 0,464 & -0,070 & -0,128 & 0,327 & 0,509 & 0,099 & 0,643\end{array}$

Q51 Os trabalhadores têm medo de uma possível demissão em caso de

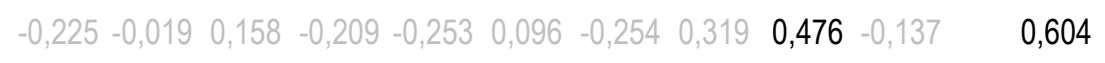
acidentes

Q37 A Pressa influencia a não utilização dos Equipamentos de proteção individual

$\begin{array}{lcccccccccc}\text { Autovalores } & 4,06 & 3,21 & 2,69 & 2,39 & 2,17 & 2,13 & 2,04 & 1,80 & 1,80 & 1,64 \\ \begin{array}{l}\text { Porcentagem (\%) da variância } \\ \text { total explicada }\end{array} & 11,95 & 9,43 & 7,92 & 7,04 & 6,40 & 6,25 & 6,00 & 5,30 & 5,29 & 4,83 \\ \begin{array}{l}\text { Porcentagem acumulada (\%) } \\ \text { da variância total explicada }\end{array} & 11,95 & 21,38 & 29,30 & 36,34 & 42,74 & 48,99 & 54,99 & 60,29 & 65,57 & 70,40 \\ \text { Alpha de Cronbach } & 0,865 & 0,781 & 0,753 & 0,659 & 0,648 & 0,601 & 0,745 & 0,405 & 0,520 & \text { - }\end{array}$

De acordo com a tabela 11, a análise fatorial resultou em dez fatores que explicam $70,4 \%$ da variância total dos 34 itens. Os resultados da análise fatorial podem ser interpretados através das "cargas fatoriais". Cada uma das "cargas fatoriais" representa a medida de correlação entre o fator derivado da análise e os itens originais.

Apesar da análise fatorial apontar a existência de 10 fatores, os fatores 8 e 9 apresentaram baixa consistência interna (abaixo de 0,520) e o último fator apresentou carga fatorial fortemente associada com apenas com 1 item.

Dessa forma, ao término da análise fatorial, o instrumento contava com 27 itens divididos em 7 dimensões, assim denominadas: Dimensão 1 "Causas dos 
acidentes"; Dimensão 2: Uso de Equipamentos de Proteção Individual"; Dimensão 3: "Sobrecarga de Trabalho"; Dimensão 4: "Experiência pós acidente; Dimensão 5: "Medo"; Dimensão 6: "Minimização dos fatores de risco e consequências pós acidente"; Fator 7: "Interferências".

\subsubsection{Consistência interna do instrumento}

A análise da consistência interna foi realizada por meio do cálculo do alpha de Cronbach, que apresentou o valor de alpha 0,84 tendo como valor mínimo 0,6 e máximo 0,86 . O alpha de Cronbach avalia a magnitude em que os itens de um instrumento estão correlacionados. Assim quanto maior a correlação média entre os itens, maior também o alpha de Cronbach.

Logo, por meio da análise item a item observou-se que os itens 17 (Os trabalhadores mais experientes não se acidentam mais); item 35 (Os trabalhadores não consideram importante utilizar Equipamentos de Proteção Individual); item 44 (A abertura da Comunicação de acidente de trabalho não é importante); item 51 (os trabalhadores têm medo de uma possível demissão em caso de acidentes) possuíam um baixo valor da correlação média intraclasse resultando em um alpha menor, caso esses mesmos itens fossem excluídos aumentariam o coeficiente alpha da escala como apresentado na Tabela 12.

Tabela 12. Correlação item-total corrigida, Alpha de Cronbach global e se $o$ item for excluído. São Paulo, SP, Brasil, 2018

\begin{tabular}{lcc}
\hline Itens & $\begin{array}{c}\text { Clpha de } \\
\text { Correlação } \\
\text { Item - Total } \\
\text { Cronbach } \\
\text { corrigida }\end{array}$ & $\begin{array}{c}\text { item for } \\
\text { excluído }\end{array}$ \\
\hline Alpha de Cronbach= $\mathbf{0 , 8 4 4}$ & & \\
Q1 Pensar sobre o acidente me causa angústia & 0,394 & 0,838 \\
Q2 Tenho medo de sofrer acidente com fluido biológico no trabalho & 0,477 & 0,836 \\
\hline
\end{tabular}


continuação

\begin{tabular}{|c|c|c|c|}
\hline Q5 & Acredito que a falta de conhecimento contribui para o acidente & 0,313 & 0,841 \\
\hline Q8 & Tenho medo de me contaminar após um acidente & 0,541 & 0,836 \\
\hline Q9 & Tenho medo de contaminar meus filhos após o acidente & 0,316 & 0,841 \\
\hline Q14 & O Estresse influencia a ocorrência de acidentes & 0,448 & 0,838 \\
\hline Q16 & As Interferências externas levam ao acidente & 0,482 & 0,836 \\
\hline Q17 & Os trabalhadores mais inexperientes não se acidentam mais & $-0,121$ & 0,855 \\
\hline Q18 & $\begin{array}{l}\text { A não utilização dos equipamentos de proteção individual pelos } \\
\text { trabalhadores favorece a ocorrência do acidente }\end{array}$ & 0,368 & 0,840 \\
\hline Q19 & $\begin{array}{l}\text { O Descarte inadequado de materiais perfurocortantes favorece a } \\
\text { ocorrência de acidentes }\end{array}$ & 0,486 & 0,838 \\
\hline Q20 & $\begin{array}{l}\text { O preenchimento da caixa coletora de materiais perfurocortantes além do } \\
\text { limite recomendado favorece a ocorrência de acidentes }\end{array}$ & 0,533 & 0,837 \\
\hline Q21 & $\begin{array}{l}\text { A utilização de materiais e instrumentos inadequados para a realização } \\
\text { dos procedimentos contribui para a exposição dos trabalhadores }\end{array}$ & 0,605 & 0,834 \\
\hline Q23 & Paciente agitado favorece a ocorrência do acidente & 0,456 & 0,837 \\
\hline Q24 & O trabalho em turno noturno contribui para a ocorrência de acidentes & 0,275 & 0,842 \\
\hline Q25 & O Desequilíbrio emocional favorece a ocorrência de acidentes & 0,576 & 0,833 \\
\hline Q26 & A Escassez de recursos humanos é responsável pelos acidentes & 0,505 & 0,835 \\
\hline Q27 & A dupla jornada favorece a ocorrência de acidentes & 0,559 & 0,833 \\
\hline Q28 & Dobrar o plantão favorece 0 acidente & 0,443 & 0,837 \\
\hline Q29 & A luva deve ser utilizada ao realizar uma punção venosa & 0,518 & 0,837 \\
\hline Q30 & Os óculos de proteção são importantes para o descarte de diurese & 0,410 & 0,838 \\
\hline Q31 & $\begin{array}{l}\text { O uso de equipamentos de proteção individual favorece uma prática } \\
\text { segura }\end{array}$ & 0,509 & 0,837 \\
\hline Q32 & $\begin{array}{l}\text { Os Equipamentos de proteção individual devem ser utilizados em todas as } \\
\text { situações onde há risco de exposição a material biológico }\end{array}$ & 0,481 & 0,838 \\
\hline Q33 & O Trabalho em equipe favorece o uso de Epi's & 0,503 & 0,835 \\
\hline Q34 & $\begin{array}{l}\text { Quando os trabalhadores conhecem o diagnóstico do paciente, não } \\
\text { utilizam Epi's }\end{array}$ & 0,309 & 0,841 \\
\hline Q35 & Os trabalhadores não consideram importante utilizar Epi's & $-0,032$ & 0,851 \\
\hline Q37 & $\begin{array}{l}\text { A Pressa influencia a não utilização dos Equipamentos de proteção } \\
\text { individual }\end{array}$ & 0,362 & 0,839 \\
\hline Q40 & $\begin{array}{l}\text { Os trabalhadores não sabem o que fazer caso sofram um acidente com } \\
\text { fluido biológico }\end{array}$ & 0,230 & 0,844 \\
\hline Q43 & A burocracia é muito grande após a ocorrência de um acidente & 0,266 & 0,843 \\
\hline Q44 & $\begin{array}{l}\text { A abertura da CAT (Comunicação de Acidente de Trabalho) não é } \\
\text { importante }\end{array}$ & $-0,235$ & 0,856 \\
\hline
\end{tabular}


continuação

\begin{tabular}{lcc}
\hline Q46 O Atendimento médico após o acidente é importante, traz alívio e conforto & 0,443 & 0,837 \\
Q47 A equipe tem preconceito com quem sofre acidente & 0,359 & 0,839 \\
$\begin{array}{l}\text { Q49 O Atendimento psicológico é muito importante para o trabalhador } \\
\text { acidentado }\end{array}$ & 0,356 & 0,840 \\
$\begin{array}{l}\text { Q50 O suporte da chefia após o acidente é muito importante } \\
\text { Q51 Os trabalhadores têm medo de uma possível demissão em caso de } \\
\quad \text { acidentes }\end{array}$ & 0,444 & 0,837 \\
\hline
\end{tabular}

\subsubsection{Versão Preliminar da Escala de Crenças dos Trabalhadores da Equipe de Enfermagem frente ao acidente de Trabalho com Fluido Biológico}

Ao final da validação de conteúdo e de construto, a Escala de Crenças dos Trabalhadores da Equipe de Enfermagem frente ao acidente de Trabalho com Fluido Biológico, se apresentou como uma escala de 34 itens, em que os respondentes possuem cinco opções de resposta para cada item: 1- Discordo Totalmente, 2- Discordo, 3- Não discordo nem concordo, 4- Concordo, 5- Concordo Totalmente, conforme apresentado na Tabela 13.

Tabela 13. Escala de Crenças em sua versão preliminar, após a validade de construto. São Paulo, SP, Brasil, 2018

\begin{tabular}{llcccc}
\hline & \multicolumn{4}{c}{ Não } \\
Itens & $\begin{array}{c}\text { Discordo } \\
\text { Totalmente } \\
\text { (1) }\end{array}$ & $\begin{array}{c}\text { Discordo } \\
\text { (2) }\end{array}$ & $\begin{array}{c}\text { concordo } \\
\text { (3) }\end{array}$ & $\begin{array}{c}\text { Concordo } \\
\text { (4) }\end{array}$ & $\begin{array}{c}\text { Concordo } \\
\text { Totalmente } \\
\text { (5) }\end{array}$ \\
\hline $\begin{array}{l}\text { Dimensão 1 - Causas dos Acidentes } \\
\text { 18. A não utilização dos equipamentos }\end{array}$ & & & & \\
de proteção individual pelos \\
trabalhadores favorece a ocorrência do \\
acidente \\
$\begin{array}{l}\text { 19.0 Descarte inadequado de materiais } \\
\text { perfurocortantes favorece a ocorrência } \\
\text { de acidentes }\end{array}$ \\
\hline
\end{tabular}

continua 
continuação

20.0 preenchimento da caixa coletora acima do limite recomendado favorece a ocorrência de acidentes

21. A utilização de materiais e instrumentos inadequados para a realização dos procedimentos contribui para a exposição dos trabalhadores

23. Paciente agitado favorece a ocorrência do acidente

Dimensão 2 - Uso dos Equipamentos de Proteção Individual

29. A luva deve ser utilizada ao realizar uma punção venosa

30. Os óculos de proteção são importantes para o descarte de diurese

31. 0 uso de equipamentos de proteção individual favorece uma prática segura

32. Os Equipamentos de proteção individual devem ser utilizados em todas as situações onde há risco de exposição a material biológico

33. 0 trabalho em equipe favorece 0 uso de Epi's

50. O suporte da chefia após 0 acidente é muito importante

Dimensão 3 - Sobrecarga de Trabalho

24. O trabalho em turno noturno contribui para a ocorrência de acidentes

26. A Escassez de recursos humanos é responsável pelos acidentes

27. A dupla jornada favorece a ocorrência de acidentes

28. Dobrar o plantão favorece 0 acidente

Dimensão 4 - Experiência e pós-acidente

17. Os trabalhadores mais inexperientes não se acidentam mais 40. Os trabalhadores não sabem o que fazer caso sofram um acidente com fluido biológico

43. A burocracia é muito grande após a ocorrência de um acidente 
continuação

46. 0 Atendimento médico após o

acidente é importante, traz alívio e

conforto

Dimensão 5 - Medo

2.Tenho medo de sofrer acidente com

fluido biológico no trabalho

8. Tenho medo de me contaminar após

um acidente

9. Tenho medo de contaminar meus

filhos após 0 acidente

Dimensão 6 - Minimização dos Riscos

34. Quando os trabalhadores

conhecem o diagnóstico do paciente,

não utilizam Epi's

35. Os trabalhadores não consideram

importante utilizar Epi's

44. A abertura da CAT não é

importante

Dimensão 7 - Interferências

16. As Interferências externas levam ao acidente

25. O Desequilíbrio emocional favorece a ocorrência de acidentes

\subsubsection{Escore da Escala de Crenças dos Trabalhadores da Equipe de Enferagem frente aos acidentes de trabalho com fluido biológico}

Em relação ao Escore da Escala de Crenças, a pontuação varia entre 1 ponto (Discordo Totalmente) e 5 pontos (Concordo Totalmente), entretanto não existe o mínimo teórico pois durante a validação do construto nenhum trabalhador pontuou 1, logo o nível de crenças inicial foi de 10 pontos. O reescalonamento de 0 a 100 foi realizado pois cada dimensão possui um número diferente de itens e portanto não são comparáveis. Assim, após o re-escalonamento 5 pontos corresponde ao 0 e 25 pontos corresponde a 100.

Ainda, dividindo a pontuação em tercis tem-se que até 33 pontos as crenças são médias, abaixo de 33 são fracas e acima de 33 são fortes. 
A Dimensão 1 contém 5 itens, logo a pontuação bruta mínima é 5 e o máximo 25. A tabela 14 apresenta os valores rescalonados de 0 a 100 pontos.

Tabela 14. Distribuição da pontuação bruta e re-escalonada da Escala de Crenças segundo a dimensão 1. São Paulo, SP, Brasil, 2018

\begin{tabular}{cc}
\hline \multicolumn{2}{c}{ Pontuação } \\
\hline Bruta & Re-escalonada \\
\hline 5 & 0,00 \\
6 & 5,00 \\
7 & 10,00 \\
8 & 15,00 \\
9 & 20,00 \\
10 & 25,00 \\
11 & 30,00 \\
12 & 35,00 \\
13 & 40,00 \\
14 & 45,00 \\
15 & 50,00 \\
\hline
\end{tabular}

\begin{tabular}{cc}
\hline \multicolumn{2}{c}{ Pontuação } \\
\hline Bruta & Re-escalonada \\
\hline 16 & 55,00 \\
17 & 60,00 \\
18 & 65,00 \\
19 & 70,00 \\
20 & 75,00 \\
21 & 80,00 \\
22 & 85,00 \\
23 & 90,00 \\
24 & 95,00 \\
25 & 100,00 \\
\hline
\end{tabular}

A Dimensão 2 apresenta 6 itens logo a pontuação bruta mínima é 6 pontos e o máximo 30 pontos. A tabela 15 apresenta a pontuação bruta e reescalonada da Dimensão 2.

As Dimensões 3 e 4 apresentam 4 itens, logo a pontuação bruta mínima nessa dimensão são 5 pontos e o máximo 20 pontos. A tabela 16 apresenta a pontuação bruta e reescalonada das Dimensões 3 e 4. 
Tabela 15. Distribuição da pontuação bruta e reescalonada da Escala de Crenças segundo a dimensão 2. São Paulo, SP, Brasil, 2018

\begin{tabular}{cc}
\hline \multicolumn{2}{c}{ Pontuação } \\
\hline Bruta & Re-escalonada \\
\hline 6 & 0,00 \\
7 & 4,17 \\
8 & 8,33 \\
9 & 12,50 \\
10 & 16,67 \\
11 & 20,83 \\
12 & 25,00 \\
13 & 29,17 \\
14 & 33,33 \\
15 & 37,50 \\
16 & 41,67 \\
17 & 45,83 \\
18 & 50,00 \\
\hline
\end{tabular}

\begin{tabular}{cc}
\hline \multicolumn{2}{c}{ Pontuação } \\
\hline Bruta & Re-escalonada \\
\hline 19 & 54,17 \\
20 & 58,33 \\
21 & 62,50 \\
22 & 66,67 \\
23 & 70,83 \\
24 & 75,00 \\
25 & 79,17 \\
26 & 83,33 \\
27 & 87,50 \\
28 & 91,67 \\
29 & 95,83 \\
30 & 100,00 \\
\hline
\end{tabular}

Tabela 16. Distribuição da pontuação bruta e reescalonada da Escala de Crenças segundo a dimensão 3 e 4. São Paulo, SP, Brasil, 2018

\begin{tabular}{cc}
\hline \multicolumn{2}{c}{ Pontuação } \\
\hline Bruta & Re-escalonada \\
\hline 4 & 0,00 \\
5 & 6,25 \\
6 & 12,5 \\
7 & 18,75 \\
8 & 25,00 \\
9 & 31,25 \\
10 & 37,50 \\
11 & 43,75 \\
12 & 50,00 \\
\hline
\end{tabular}

\begin{tabular}{cc}
\hline \multicolumn{2}{c}{ Pontuação } \\
\hline Bruta & Re-escalonada \\
\hline 13 & 56,25 \\
14 & 62,50 \\
15 & 68,75 \\
16 & 75,00 \\
17 & 81,25 \\
18 & 87,50 \\
19 & 93,75 \\
20 & 100,00 \\
\hline
\end{tabular}


As Dimensões 5 e 6 apresentam 3 itens, logo a pontuação bruta mínima nessa dimensão são 3 pontos e o máximo 15 pontos. A tabela 17 apresenta a pontuação bruta e reescalonada das Dimensões 5 e 6.

Tabela 17. Distribuição da pontuação bruta e rescalonada da Escala de Crenças segundo as dimensões 5 e 6. São Paulo, SP, Brasil, 2018

\begin{tabular}{cc}
\hline \multicolumn{2}{c}{ Pontuação } \\
\hline Bruta & Re-escalonada \\
\hline 3 & 0,00 \\
4 & 8,33 \\
5 & 16,67 \\
6 & 25,00 \\
7 & 33,33 \\
8 & 41,67 \\
9 & 50,00 \\
\hline
\end{tabular}

\begin{tabular}{cc}
\hline \multicolumn{2}{c}{ Pontuação } \\
\hline Bruta & Re-escalonada \\
\hline 10 & 58,33 \\
11 & 66,67 \\
12 & 75,00 \\
13 & 83,33 \\
14 & 91,67 \\
15 & 100,00 \\
\hline
\end{tabular}

A Dimensão 7 possui 2 itens, logo a pontuação mínima nessa dimensão são 2 pontos e o máximo 10 pontos. A tabela 18 apresenta a pontuação bruta e rescalonada da Dimensões 7.

Tabela 18. Distribuição da pontuação bruta e rescalonada da Escala de Crenças segundo a dimensão 7. São Paulo, SP, Brasil, 2018

\begin{tabular}{cc}
\hline \multicolumn{2}{c}{ Pontuação } \\
\hline Bruta & Re-escalonada \\
\hline 2 & 0,00 \\
3 & 12,50 \\
4 & 25,0 \\
5 & 37,50 \\
6 & 50,00 \\
\hline
\end{tabular}

\begin{tabular}{cc}
\hline \multicolumn{2}{c}{ Pontuação } \\
\hline Bruta & Re-escalonada \\
\hline 7 & 62,50 \\
8 & 75,00 \\
9 & 87,50 \\
10 & 100,00 \\
\hline
\end{tabular}


A versão final da Escala de Crenças dos Trabalhadores da Equipe de Enfermagem apresenta 27 itens. Logo sua pontuação mínima são 27 pontos e 0 máximo 135 pontos. A tabela 19 apresenta a pontuação bruta total e reescalonada da Escala de Crenças.

Tabela 19. Distribuição total da pontuação bruta e reescalonada da Escala de Crenças dos Trabalhadores da Equipe de Enfermagem frente ao acidente de trabalho com fluido biológico. São Paulo, SP, Brasil, 2018

\begin{tabular}{cc}
\hline \multicolumn{2}{c}{ Pontuação } \\
\hline Bruta & Re-escalonada \\
\hline 34 & 0,00 \\
35 & 0,74 \\
36 & 1,47 \\
37 & 2,21 \\
38 & 2,94 \\
39 & 3,68 \\
40 & 4,41 \\
41 & 5,15 \\
42 & 5,88 \\
43 & 6,62 \\
44 & 7,35 \\
45 & 8,09 \\
46 & 8,82 \\
47 & 9,56 \\
48 & 10,29 \\
49 & 11,03 \\
50 & 11,76 \\
51 & 12,50 \\
52 & 13,24 \\
53 & 13,97 \\
54 & 14,71 \\
55 & 15,44 \\
56 & 16,18 \\
57 & 16,91 \\
58 & 17,65 \\
\hline &
\end{tabular}

\begin{tabular}{cc}
\hline \multicolumn{2}{c}{ Pontuação } \\
\hline Bruta & Re-escalonada \\
\hline 59 & 18,38 \\
60 & 19,12 \\
61 & 19,85 \\
62 & 20,59 \\
63 & 21,32 \\
64 & 22,06 \\
65 & 22,79 \\
66 & 23,53 \\
67 & 24,26 \\
68 & 25,00 \\
69 & 25,74 \\
70 & 26,47 \\
71 & 27,21 \\
72 & 27,94 \\
73 & 28,68 \\
74 & 29,41 \\
75 & 30,15 \\
76 & 30,88 \\
77 & 31,62 \\
78 & 32,35 \\
79 & 33,09 \\
80 & 33,82 \\
81 & 34,56 \\
82 & 35,29 \\
83 & 36,03 \\
\hline &
\end{tabular}


continuação

\begin{tabular}{|c|c|}
\hline 84 & 36,76 \\
\hline 85 & 37,50 \\
\hline 86 & 38,24 \\
\hline 87 & 38,97 \\
\hline 88 & 39,71 \\
\hline 89 & 40,44 \\
\hline 90 & 41,18 \\
\hline 91 & 41,91 \\
\hline 92 & 42,65 \\
\hline 93 & 43,38 \\
\hline 94 & 44,12 \\
\hline 95 & 44,85 \\
\hline 96 & 45,59 \\
\hline 97 & 46,32 \\
\hline 98 & 47,06 \\
\hline 99 & 47,79 \\
\hline 100 & 48,53 \\
\hline 101 & 49,26 \\
\hline 102 & 50,00 \\
\hline 103 & 50,74 \\
\hline 104 & 51,47 \\
\hline 105 & 52,21 \\
\hline 106 & 52,94 \\
\hline 107 & 53,68 \\
\hline 108 & 54,41 \\
\hline 109 & 55,15 \\
\hline 110 & 55,88 \\
\hline 111 & 56,62 \\
\hline 112 & 57,35 \\
\hline 113 & 58,09 \\
\hline 114 & 58,82 \\
\hline 115 & 59,56 \\
\hline 116 & 60,29 \\
\hline 117 & 61,03 \\
\hline 118 & 61,76 \\
\hline 119 & 62,50 \\
\hline 120 & 63,24 \\
\hline
\end{tabular}

\begin{tabular}{|c|c|}
\hline 121 & 63,97 \\
\hline 122 & 64,71 \\
\hline 123 & 65,44 \\
\hline 124 & 66,18 \\
\hline 125 & 66,91 \\
\hline 126 & 67,65 \\
\hline 127 & 68,38 \\
\hline 128 & 69,12 \\
\hline 129 & 69,85 \\
\hline 130 & 70,59 \\
\hline 131 & 71,32 \\
\hline 132 & 72,06 \\
\hline 133 & 72,79 \\
\hline 134 & 73,53 \\
\hline 135 & 74,26 \\
\hline 136 & 75,00 \\
\hline 137 & 75,74 \\
\hline 138 & 76,47 \\
\hline 139 & 77,21 \\
\hline 140 & 77,94 \\
\hline 141 & 78,68 \\
\hline 142 & 79,41 \\
\hline 143 & 80,15 \\
\hline 144 & 80,88 \\
\hline 145 & 81,62 \\
\hline 146 & 82,35 \\
\hline 147 & 83,09 \\
\hline 148 & 83,82 \\
\hline 149 & 84,56 \\
\hline 150 & 85,29 \\
\hline 151 & 86,03 \\
\hline 152 & 86,76 \\
\hline 153 & 87,50 \\
\hline 154 & 88,24 \\
\hline 155 & 88,97 \\
\hline 156 & 89,71 \\
\hline 157 & 90,44 \\
\hline
\end{tabular}


continuação

\begin{tabular}{ll}
\hline 158 & 91,18 \\
159 & 91,91 \\
160 & 92,65 \\
161 & 93,38 \\
162 & 94,12 \\
163 & 94,85 \\
164 & 95,59 \\
\hline
\end{tabular}

\begin{tabular}{cc}
\hline 165 & 96,32 \\
166 & 97,06 \\
167 & 97,79 \\
168 & 98,53 \\
169 & 99,26 \\
170 & 100,00 \\
\hline
\end{tabular}

Lembrando que, a Escala de Crenças possui dois itens que devem ser revertidos: O item 40 "Os trabalhadores NÃO sabem o que fazer caso sofram um acidente com fluido biológico e o item 17 "Os trabalhadores mais inexperientes NÃO se acidentam mais. Dessa forma, ao serem lançados no banco de Dados, a pontuação desses itens deve ser invertida. Ou seja, Discordo Totalmente passa a valer 5 pontos e Concordo Totalmente passa a valer 1 ponto. 
6 DISCUSSÃo 
Essa pesquisa teve como objetivo a construção e validação de uma escala de crenças dos trabalhadores da equipe de enfermagem frente ao acidente de trabalho com fluido biológico, que fosse capaz de identificar essas crenças apartir de afirmativas relacionadas as causas dos acidentes, percepção dos trabalhadores, apoio institucional, uso dos equipamentos de proteção individual.

Quanto à validade de conteúdo, os itens foram avaliados por um grupo de juízes segundo os critérios de clareza, relevância, objetividade e precisão. Segundo Wynd, Schmidt, Schaefer (2003) a validação de conteúdo é uma etapa crucial no desenvolvimento de instrumentos de medida pois representa o início de procedimentos para associar conceitos abstratos com indicadores observáveis e mensuráveis.

Ao final desta etapa, foram mantidos no instrumento, os enunciados de acordo com a concordância entre os juízes, itens que não atingiram uma concordância de $70 \%$ ou mais foram descartados do instrumento. A literatura aponta que a taxa de concordância aceitável deve ser considerada de acordo com o número de juízes, com a participação de seis ou mais sujeitos recomenda-se uma taxa entre 0,7 e 0,8 , não inferior a 0,7 (Davis, 1992, Pasquali, 2003; Polit, Beck, 2006).

Em seguida deu-se a aplicação do teste piloto nos trabalhadores da equipe de enfermagem para a verificação da análise semântica dos itens. Essa análise tem como objetivo essencial, verificar se todos os itens são compreensíveis para todos os membros da população a que se destina (Pasquali, 1998). Assim, o instrumento foi aplicado nas três categorias de trabalhadores de enfermagem presentes na instituição, enfermeiros, técnicos e auxiliares de enfermagem.

Ao final do teste piloto alguns itens tiveram alteração em sua grafia, pois percebeu-se durante o teste, que alguns trabalhadores não compreenderam o significado de algumas expressões utilizadas, assim algumas afirmativas foram modificadas, como a palavra "instituição", que foi incluída nos itens 27 e 28 para dar mais sentido a frase, a expressão "acidentes de trabalho com fluido biológico" incluída no item 5 e a expressão "atendimento por profissional capacitado" ao invés de "atendimento médico" no item 46. 
Ainda, segundo os trabalhadores, os itens 12 (Vejo que os trabalhadores que sofrem acidente de trabalho com fluido biológico passam a repensar suas práticas de trabalho), item 38 (A instituição oferece treinamentos periódicos sobre acidentes de trabalho com material biológico), item 39 (O fluxo de atendimento nesta instituição após o acidente é divulgado para todos os trabalhadores), item 41 ( $O$ acidente de trabalho com fluido biológico deve ser notificado), item 42 (os trabalhadores devem abrir uma Comunicação de Acidente de Trabalho após sofrer o acidente, item 45 (Existe apoio institucional para os trabalhadores acidentados), não expressavam suas crenças e sim um fato ou o conhecimento em relação aos acidentes e item 48 (Os trabalhadores conhecem o acompanhamento clínico e laboratorial após o acidente).

Portanto esses itens foram eliminados, considerando que segundo a literatura, a possibilidade de ajustes nos itens do questionário pode ser considerada quando $15 \%$ dos participantes apresentam dificuldade de compreensão ou de preenchimento dos itens do instrumento, situação em que são orientados a não responder a pergunta (Beaton, 2000).

Em relação as categorias de resposta (Discordo totalmente, Discordo, Não discordo nem concordo, concordo, concordo totalmente) observou-se os efeitos teto em 23 itens ( porcentagem das respostas concentradas no máximo da escala) e efeito chão em 3 itens (porcentagem das respostas concentradas no mínimo da escala) (Hays, Anderson, Revick, 1993). A ocorrência desses efeitos pode indicar comprometimento de propriedades psicométricas como a sensibilidade e capacidade do instrumento para medir as crenças dos trabalhadores ou porque as perguntas eram não pertinentes ou óbvias.

Entretanto se analisarmos os itens que apresentaram efeito teto mais alto, item19 53,8\% (O Descarte inadequado de materiais perfurocortantes favore a ocorrência dos acidentes), item 29 57,5\% (A luva deve ser utilizada ao realizar uma punção venosa), item 32 51,9\%(Os equipamentos de proteção individual devem ser utilizadas em todas as situações onde há risco de exposição a material biológico), esses referem-se a questões já muito discutidas e incorporadas no processo de trabalho da equipe de enfermagem como comportamentos para a 
prevenção de acidentes e por esse motivo podemos inferir um efeito teto alto (Wall, Miranda, Sarquis et al., 2011).

Quando observamos o efeito chão, nos itens 17 13,3\% (Os trabalhadores mais inexperientes se acidentam mais), item 44 44,4\% (A abertura da Comunicação de Acidente de Trabalho não é importante) e item 51 17,5\% (Os trabalhadores têm medo de uma possível demissão em caso de acidentes), veirifcamos que os itens 17 e 51 podem refletir a vulnerabilidade do trabalhador independente do tempo de experiência profissional.

Contudo, embora os efeitos teto e chão tenham sido observados, é importante salientar que alguns itens podem ser revistos em pesquisas futuras, principalmente aqueles que apresentaram efeito teto muito alto no presente estudo.

Procedeu-se então à análise fatorial exploratória, que permite conhecer a dimensionalidade do instrumento, ou melhor, quantos fatores do construto o instrumento mede na realidade. Essa análise produz para cada item uma carga fatorial, indicando a covariância entre o item e o fator sendo que, quanto mais próximo de $100 \%$ de covariância item-fator melhor será o item (Pasquali, 1998)

Em decorrência da análise fatorial, o Fator 8 "Estresse e conhecimento" e - Fator 9 "Efeito psicológico" foram eliminados pois apresentaram baixa consistência interna 0,405 e 0,520 respectivmente. O Fator 10 "Efeito da pressa" também foi eliminado pois apresentou carga fatorial associada a apenas 1 item.

Ao término da análise fatorial o instrumento contava com 27 itens divididos em 7 dimensões denominadas:

\section{Dimensão 1 - Causas dos acidentes}

Refere-se às causas dos acidentes de trabalho com fluido biológicos. Valores altos nesta dimensão, apontam crenças maiores com relação aos 5 itens: Q20 (O preenchimento da caixa coletora de materiais perfurocortantes além do limite recomendado favorece a ocorrência de acidentes), Q19 (O Descarte inadequado de materiais perfurocortantes favorece a ocorrência de acidentes), Q18 (A não 
utilização dos equipamentos de proteção individual pelos trabalhadores favorece a ocorrência do acidente), Q21 (A utilização de materiais e instrumentos inadequados para a realização dos procedimentos contribui para a exposição dos trabalhadores) e Q23 (Paciente agitado favorece a ocorrência do acidente);

Essa dimensão contempla o que é descrito na literatura referente ao contexto dos acidentes. Os estudos apontam o descarte inadequado dos materiais, principalmente no que se refere a caixa coletora de perfurocortante como um dos principais motivos para a ocorrência das exposições, a utilização inadequada de materiais e instrumentos e a não utilização dos equipamentos de proteção individual, também são apontados pelos autores como responsáveis pelas exposições (Arantes et al.,2017; Vieira et al.,2016).

Nesse sentido a identificação das crenças dos trabalhadores relacionadas à Dimensão 1 "Causas dos Acidentes" pode auxiliar as instituições de saúde no desenvolvimento de medidas de proteção específicas, voltadas para as crenças dos trabalhadores em relação as causas e que de alguma forma possam minimizar as situações que favorecem a ocorrência de acidentes no processo de trabalho da equipe de enfermagem.

Estudos apontam que trabalhadores acima de 40 anos executam mais tarefas administrativas e menos ações relacionadas a coleta de sangue ou outras situações associadas a risco mais elevado para exposições ocupacionais, por esse motivo menor a crença dos trabalhadores em relação as causas dos acidentes (Januário et al.,2017). Outros estudos apontam para a fatalidade, como principal causa apontada pelos trabalhadores como responsável pela ocorrência de acidente (Barbosa, Diogo, Silva, 2017).

Um estudo realizado na Escola de Enfermagem da Universidade de Barcelona demonstrou que estudantes sem treinamento prático anterior tiveram percepções mais fracas dos riscos de acidente em comparação com os alunos com treinamento prático, entretanto percebeu-se percepções mais fracas dos riscos de acidentes entre os estudantes com experiencia prévia de trabalho, logo os autores apontam para a influência do treinamento e a experiência de trabalho na percepção dos riscos de acidentes (Moreno-Arroyo et al.,2016). 


\section{Dimensão 2 - Uso de Equipamentos de Proteção}

Essa Dimensão diz respeito a um conjunto de itens que trazem em seus conteúdos o uso dos equipamentos de proteção individual, a importância do trabalho em equipe e o suporte da chefia após o acidente.Valores altos nesta dimensão, apontam crenças maiores com relação aos 6 itens: Q32 (Os Equipamentos de proteção individual devem ser utilizados em todas as situações onde há risco de exposição a material biológico), Q29 (A luva deve ser utilizada ao realizar uma punção venosa), Q31 (O uso de equipamentos de proteção individual favorece uma prática segura), Q33 (O Trabalho em equipe favorece o uso de Epi's), Q30 (Os óculos de proteção são importantes para o descarte de diurese) e Q50 (O suporte da chefia após o acidente é muito importante);

A Dimensão Uso dos Equipamentos de Proteção Individual" contém itens que vão de acordo com o descrito na literatura, no sentido em que apontam para situações onde se faz necessário o uso dos equipamentos de proteção individual, como durante uma punção venosa (item 29) ou descarte de diurese (item 30).

Essa dimensão traz crenças relevantes para o entendimento do contexto em que esse acidente ocorre e a importância do autocuidado do trabalhador no desenvolvimento de suas atividades durante o processo de trabalho, essas crenças apontam para o grau de vulnerabilidade do trabalhador quando da não utilização dos equipamentos de proteção.

Alguns autores apontam como fatores, as situações de desgastes e estresse no trabalho que levam ao descuidado de si, associados a falta de tempo para si em decorrência do trabalho, e a valorização do cuidar do outro muitas vezes em detrimento do cuidar de si (Tomaschewski-Barlem et al.,2016, Baggio, Monticelli, Erdmann, 2009).

Destaca-se que a organização do trabalho, o ambiente, sobrecarga de trabalho, exigências da chefia, conflitos, problemas nos relacionamentos entre os pares, baixa remuneração e as duplas jornadas de trabalho também contribuem significativamente para o descuidado impossibilitando o trabalhador de cuidar de si mesmo (Baggio, Formaggio, 2007, Baggio, Formaggio, 2008). 
Dessa forma, a negligencia do auto cuidado pode estar relacionada à carência de políticas setoriais que incentivem e apoiem o cuidado dos trabalhadores como ponto relevante para a melhoria das condições de saúde do trabalhador e diminuição dos acidentes de trabalho. Entre as estratégias para as ações de autocuidado ressalta-se a redução do ritmo e carga de trabalho, atividade física e capacitação em serviço, destacando como primordial o apoio dos gestores para que essas estratégias possam ser incorporadas ao ambiente de trabalho (Xavier et al., 2017).

\section{Dimensão 3 - Sobrecarga de Trabalho.}

Refere-se a sobrecarga de trabalho aos quais os trabalhadores estão expostos em sua rotina profissional e que favorece a ocorrência de acidentes. Valores altos nesta dimensão, apontam crenças maiores com relação aos 4 itens: Q27 (A dupla jornada favorece a ocorrência de acidentes), Q28 (Dobrar o plantão favorece o acidente), Q26 (A Escassez de recursos humanos é responsável pelos acidentes) e Q24 (O trabalho em turno noturno contribui para a ocorrência de acidentes);

Estão agrupados os itens relacionados as condições de trabalho da equipe de enfermagem. Diversas pesquisas apontam a escassez de recursos humanos, bem como dobrar o plantão na mesma instituição como responsáveis pela ocorrência de acidentes. Crenças fortes nessa dimensão refletem o contexto institucional e as condições de trabalho da enfermagem, lembrando que as condições de trabalho são apenas um fator no contexto de um acidente e podem ser responsáveis pelo aumento das exposições e adoecimento dos trabalhadores (Pereira et al.,2018).

\section{Dimensão 4 - Experiência pós acidente}

Composto por itens que se relacionam as condutas e procedimentos a serem realizados após a ocorrência de um acidente de trabalho.Valores altos nesta dimensão, apontam crenças maiores com relação aos 4 itens: Q40 (Os 
trabalhadores não sabem o que fazer caso sofram um acidente com fluido biológico), Q43 (A burocracia é muito grande após a ocorrência de um acidente), Q17 (Os trabalhadores mais inexperientes não se acidentam mais) e Q46 (O Atendimento médico após o acidente é importante, traz alívio e conforto);

Os itens contidos na Dimensão 4 corroboram com a literatura pois apresenta itens que relatam as crenças dos trabalhadores relacionadas ao pós acidente. A problemática da subnotificação dos acidentes é bastante descrita na literatura, enquanto que os itens 40 e 43 contemplam as principais dificuldades encontradas pelos trabalhadores após um acidente e podem fornecer indicadores válidos aos gestores, em relação ao fluxo pós acidente das instituições e o conhecimento destes pelos trabalhadores, ainda, crenças fortes nesses aspectos demonstram o quanto o trabalhador está alheio a notificação dos acidentes, o acompanhamento após o acidente bem como sua importância.

Pereira et al., (2018) identificaram motivações para mudanças nas ações dos trabalhadores após exposição ocupacional e demonstraram que a vivência do acidente de trabalho mostrou-se determinante para modificações nas práticas profissionais, mudanças essas motivadas principalmente pelo entendimento do risco em relação a mudança de comportamento frente aos cuidados necessários e adoção de medidas preventivas, destacando que este é o momento propício para discutir com os trabalhadores as causas e consequências dos acidentes de trabalho.

Outro estudo também apontou que os trabalhadores mostraram-se resilientes diante do acidente, afirmando que a experiência vivida contribuiu para adquirir experiência profissional, redobrar o cuidado durante a realização dos procedimentos, mais cautela no manejo de materiais perfurocortantes e reconhecer a importância ao uso dos Equipamentos de Proteção Individual (Rodrigues et al.,2017).

Gomes e Caldas (2017) apontaram que embora as notificações de acidentes de trabalho com fluido biológico apresentem crescimento anual no Brasil desde a implantação da ficha própria de notificação para esse tipo de acidente em 2006, não reflete a magnitude do problema pois apresenta dados incompletos principalmente em relação as variáveis: escolaridade, tempo de trabalho na 
ocupação, material orgânico envolvido, status sorológico do acidentado e do paciente-fonte, condutas adotadas, evolução do caso e emissão da CAT.Nesse sentido os autores apontam para a melhora urgente do preenchimento da ficha de investigação bem como a orientação aos trabalhadores sobre a obrigatoriedade das notificações dos acidentes de trabalho.

\section{Dimensão 5 - Medo}

Esta dimensao aponta para percepções individuais relacionadas ao acidente e os sentimentos desencadeados após essa experiência como o medo. Valores altos nesta dimensão, apontam crenças maiores com relação aos 3 itens: Q9 (Tenho medo de contaminar meus filhos após o acidente), Q8 (Tenho medo de me contaminar após um acidente) e Q2 (Tenho medo de sofrer acidente com fluido biológico no trabalho);

Contempla itens identificados em estudos que buscaram compreender a experiência do trabalhador que sofreu acidente e os sentimentos vivenciados. Essas crenças permitem discutir o impacto do acidente na vida do trabalhador, essas crenças podem apontar a necessidade de apoio psicológico aos acidentados, a importância do acolhimento e ajuda por parte da equipe e da chefia após o acidente, como forma de minimizar o medo da morte e do risco de adquirir uma doença infectocontagiosa (Bernardes, 2014; Magagnini, 2011).

\section{Dimensão 6 - Minimização dos riscos}

Esta dimensão aponta para o não seguimento das condutas indicadas para a proteção do trabalhador, antes do acidente e após a sua ocorrência por meio da abertura da CAT. Valores altos nesta dimensão, apontam crenças maiores com relação aos 3 itens: Q35 (Os trabalhadores não consideram importante utilizar Epi's), Q44 (A abertura da CAT não é importante), Q34 (Quando os trabalhadores conhecem o diagnóstico do paciente, não utilizam Epi's);

Em se tratando da dimensão 6 "Minimização dos Riscos" a Escala de Crenças contempla itens descritos na literatura e relacionados a vulnerabilidade do 
trabalhador diante do uso dos equipamentos de proteção individual, a abertura da Comunicação de Acidente de Trabalho (CAT) novamente reitera a questão da subnotificação mas acima de tudo demonstra o risco ao qual o trabalhador está exposto caso não notifique o acidente e no futuro venha adoecer em decorrência do acidente. A CAT traz segurança e amparo legal aos trabalhadores acidentados e deve ser realizada em todo acidente de trabalho.

Essa dimensão corrobora com o estudo de Barbosa, Diogo, Silva (2017) onde de um total de 46 acidentes subnotificados em um Hospital público do município de Bauru, São Paulo, 34,9\% dos trabalhadores consideram desnecessário reportar a ocorrência, 17,4\% não fizeram por excesso de burocracia e 15,2\% por falta de conhecimento. A crença de que não é necessário reportar a ocorrência é extremamente preocupante já que não garante os direitos legais ao trabalhador em caso de dano ou morte acidental.

\section{Dimensão 7 - Interferências}

Descreve questões que interferem na prática diária podendo ocasionar os acidentes. Valores altos nesta dimensão, apontam crenças maiores com relação aos 2 itens: Q16 (As Interferências externas levam ao acidente) e Q25 (O Desequilíbrio emocional favorece a ocorrência de acidentes);

Em relação a Dimensão 7 "Interferências" contempla as principais questões descritas em pesquisas como fatores que interferem na prática profissional e que favorecem a ocorrência do acidente, a crença no desequilíbrio emocional apresenta um trabalhador fragilizado e consciente do seu desgaste psíquico, enquanto que as interferências de colegas, acompanhantes e outros também são descritos como situações que favorecem as exposições (Xavier, 2017).

Assim, a Escala de Crenças dos Trabalhadores da Equipe de Enfermagem contempla todas as informações que são dadas na literatura em relação aos acidentes de trabalho com fluido biológico.

Em relação a análise da consistência interna, nessa pesquisa a Escala de Crenças dos Trabalhadores da Equipe de Enfermagem frente aos acidentes de 
trabalho com fluido biológico apresentou coeficiente com valor de 0,84. A confiabilidade refere-se ao grau de coerência ou precisão com que o instrumento mede o atributo que se propõe a medir, está relacionada o quão exato e estável ele é ao longo do tempo. A confiabilidade do instrumento pôde ser verificada através da medida da consistência interna.

A consistência interna diz respeito à análise dos itens separadamente, considerando-se sua respectiva dimensão (subescala) e o instrumento na sua totalidade. A consistência interna pode ser avaliada pelo Coeficiente Alfa de Cronbach, sendo que os itens devem ser altamente correlacionados uns com os outros, uma vez que o atributo avaliado, teoricamente, é o mesmo. Seu valor pode variar entre zero e um $(1,0)$, sendo que quanto maior for o valor, maior a consistência interna do instrumento ou maior a congruência entre os itens, indicando a homogeneidade na medida do mesmo fenômeno. Entretanto, quando o valor é muito elevado pode significar que há redundância entre os itens; assim, sugere-se que o valor do Alfa de Cronbach seja acima de 0,70 e no máximo 0,90 (McDowell, Neweel, 1996). 
Discussão 
A Escala de Crenças dos trabalhadores da equipe de enfermagem frente ao acidente de trabalho com fluido biológico elaborada na presente pesquisa, apresentou-se válida para identificar as crenças dos trabalhadores relacionadas as causas dos acidentes, uso dos equipamentos de proteção individual, experiência e pós acidente entre trabalhadores de enfermagem.

Os resultados obtidos demonstraram que a Escala de Crenças em sua versão final ficou com 27 itens, divididos em 7 dimensões e apresenta qualidades psicométricas satisfatórias para um instrumento em desenvolvimento, capaz de identificar as crenças dos trabalhadores com comprovada confiabilidade.

A escala contém itens relevantes e suficientes já que foi realizada uma varredura na Literatura e todas as questões pertinentes aos acidentes com fluido biológico foram contempladas na Escala de Crenças e esses mesmos itens já haviam sido validados pelo painel de juízes.

Diante dos resultados observados e por se tratar de um instrumento em sua primeira versão, a validade de construto é satisfatória e permite contribuir para a visibilidade do objeto de pesquisa proposto pela pesquisadora no cenário nacional, bem como para o desenvolvimento de novas pesquisas a partir do aprimoramento do instrumento aqui proposto.

Porém, recomenda-se a realização de novos estudos com vistas a confirmar a estrutura da Escala e para investigar sua sensibilidade e capacidade como instrumento de medida principalmente no que diz respeito aos efeitos teto e chão. É importante que a Escala seja aplicada em populações de diferentes cenários e instituições de saúde para que seja feita uma análise mais profunda e torne-se um instrumento com propriedades psicométricas mais robustas.

Nesse aspecto, o presente estudo avança uma vez que apresenta uma escala de crenças relacionada aos acidentes de trabalho com fluido biológico, desenvolvida no Brasil, capaz de identificar as crenças dos trabalhadores em diferentes cenários, poderá contribuir para o levantamento das características dessas crenças em território nacional que podem ser utilizadas como ferramentas estratégicas de intervenção significativas nas instituições de saúde, com vistas à redução dos acidentes de trabalho com fluido biológico. 
Abad IG, Reyes D,Delgado JAR, Calle JB, Ramón GPT,Arencibia MJ,et al. Exposición cutáneo-mucosa a sangre o material biológico en trabajadores sanitarios. Metas enferm. 2012; 15(5): 21-25.

Ajzen I, Fisbein M. Understanding attitudes and predicting social behavior. Englewood Cliffs, New Jersey: Prentice-Hall; 1980.

Amoran OE, Onwube OO. Infection control and practice of standard precautions among healthcare workers in northern Nigeria. J Glob Infect Dis. 2013; 5(4): 156-63.

Arantes MC, Haddad MCFL, Marcon SS, Rossaneis MA, Pissinati PSC, Oliveira SA. Acidentes de trabalho com material biológico em trabalhadores de serviços de saúde. Cogitare Enferm. 2017; 22(1): 01-08.

Baggio MA, Formaggio FM. Profissional de Enfermagem: compreendendo o autocuidado. Revista Gaúcha de Enfermagem. 2007;28(2):233-41.

Baggio MA, Formaggio FM. Trabalho, cotidiano e o professional de enfermagem: o significado do descuidado em si. Cogitare Enferm.2008; 13(1):67-74.

Baggio MA, Monticelli M, Erdmann AL. dmann AL. Cuidando de si, do outro e "do nós” na perspectiva da complexidade. Rev Bras Enferm, Brasília 2009; 62(4): 62731.

Bahadori M, Sadigh G. Occupational Exposure to Blood and Body Fluids. Int J Occup Environ Med. 2010; 1 (1):1-10.

Barbosa ASAA, Diogo SRAS, Silva SMUR. Subnotificação de acidente ocupacional com materiais biológicos entre profissionais de Enfermagem em um hospital público. Rev Bras Med Trab. 2017;15(1):12-7.

Bardin L. Análise de Conteúdo. Lisboa: Edições 70,2016.

Beaton DC, Bombardier C, Guilleman F, Ferraz M. Guidelines for the Processo f Cross- Cultural Adaptation of Self- Report Measures. Spine (Phila Pa 1976). 2000; 25 (24): 3186-91. 
Beltrame V, Engel R, Comandulli V, Steffani JA. Cuidado à saúde de quem cuida da saúde. Acidentes ocupacionais com exposição à materiais biológicos ocorridos em municípios da região sul do Brasil e notificados no SINAN nos anos de 2010 a 2012. Rev Bras Med. 2015; 72(8).

Bernardes $C L$. A vivência dos trabalhadores de enfermagem que sofreram acidente com fluido biológico: um olhar fenomenológico- [Dissertação].São Paulo: Escola de Enfermagem, Universidade de São Paulo;2014.

Bernardes CL, Vasconcelos LHS, Silva SM, Baptista PCP, Felli VEA, Pustiglione M etal. Agravos á saúde dos trabalhadores de Enfermagem em uma instituição pública deensino.Rev Esc Enferm USP.2014; 48(4):676-82.

Borges FRFS, Ribeiro LA, Oliveira LCM. Occupational exposures to body fluids and behaviors regarding their prevention and post-exposure among medical and nursing students at a Brazilian public university. Rev. Inst. Med. Trop.2014; 56(2): 157-63.

Brasil. Ministério do Trabalho e Emprego (BR). Portaria no 25 de 29 de Dezembro de 1994. NR09 - Programa de Prevenção de Riscos Ambientais. Disponível em: http://portal.mte.gov.br/legislacao/normas-regulamentadoras-1.htm.

Brasil. Ministério da Saúde. "Recomendações para Atendimento e Acompanhamento de Exposição Ocupacional a Material Biológico: HIV e Hepatites B e C. Brasília; 2004. Disponível em http://www.aids.gov.br/sites/default/files/manual_acidentes_final_0.pdf.

Brasil. Ministério da Saúde. Secretaria de Atenção à Saúde. Departamento de Ações Programáticas. Exposição a materiais biológicos. 2006.

Brevidelli MM, Cianciarullo TI. Aplicação do modelo de crenças em saúde na prevenção dos acidentes com agulha. Rev Saúde Pública .2001; 35(2):193-201.

Butsashvili M, Kamkamidze G, Kajaia M, Morse DL, Triner W, DeHovitz J, et al. Occupational exposure to body fluids among health care workers in Georgia. Occupational Medicine. 2012; 62:620-626. 
Centers for disease Control and Prevention.Guidelines for the Management of Occupational Exposures to HBV, HCV, and HIV and Recommendations for Postexposure Prophylaxis. Estados Unidos da América. 2001. Disponível em: http://www.cdc.gov.

Centers for disease Control and Prevention. Guidelines for the Management of Occupational Exposures to HIV and Recommendations for Postexposure Prophylaxis. Estados Unidos da América. 2005. Disponível em: http://www.cdc.gov.

Costa LP, Santos PR, Lapa AT, Spindola T. Acidentes de trabalho com enfermeiros de clínica médica envolvendo material biológico. Rev Enferm UERJ. 2015; 23(3):355-61.

Chaiwarith R, Ngamsrikam T, Fupinwong S, Sirisanthana T.Occupational Exposure to Blood and Body Fluids among Healthcare Workers in a Teaching Hospital: an Experience from Northern Thailand. Jpn. J. Infect. Dis 2013;66:121-125.

Cronbach L. Fundamentos da testagem psicológica. Porto Alegre: Artes Médicas; 1996.

DavhanaMaselesele LMM. Knowledge and uptake of occupational post-exposure prophylaxis amongst nurses caring for people living with HIV. AOSIS.2016; 22236279 .

Davis LL. Instrument review: getting the most from a panel of experts. Appl Nurs Res. 1992;5(4):194-197.

Denic LM, Maksimovic N, Marusic V, Vucicevi J, Ostric I, Duric D. Occupational Exposure to Blood and Body Fluids among Health-Care Workers in Serbia. Med Princ Pract .2015;24:36-41.

Departamento Intersindical de Estatística e Estudos Socioeconômicos. Anuário da saúde do trabalhador / Departamento Intersindical de Estatística e Estudos Socioeconômicos.2016; São Paulo: DIEESE.

Diaz CP, Calixto OJ, Martínez AAF, Ojeda JSB, García CAB, Pardo EU et al. Occupational exposure to blood borne pathogens among healthcare workers: a cross-sectional study of a registry in Colombia. Journal of Occupational Medicine and Toxicology. 2015;10(45):1-7. 
Dunn OJ. Multiple comparisons using rank sums. Technometrics. 1964;6: 241-252.

Egro FM, Nwaiwu CA, Smith S, Harper JD, Spiess AM. Seroconversion rates among health care workers exposed to hepatitis $C$ virus-contaminated body fluids: The University of Pittsburgh 13-year experience. Am J Infect Control. 2017;45(9):1001-1005.

Felli VEA, Peduzzi M. O trabalho gerencial em Enfermagem. In: Kurcgant $P$, organizadora. Gerenciamento em enfermagem. Rio de Janeiro: Guanabara Koogan; 2016.p 85-103.

Fitzpatrick R, Davey C, Buxton MJ, Jones DR. Evaluating patient-based outcome measures for use in clinical trials. Health Technology Assessment 1998;2:3-63.

Freitas IA, Borges-Andrade JE. Construção e validação de escala de crenças sobre sistema de treinamento. Estudos de Psicologia. 2004;9(3):479-488.

Galdino A, Santana VS, Ferrite S. Os Centros de Referência em Saúde do Trabalhador e a notificação de acidentes de trabalho no Brasil. Cad. Saúde Pública. 2012; 28(1):145-159.

Galindo EBG, Ruíz CR, Sánchez NAC, Cabal VEE, Pardo MIS, Roselli JML et al. Caracterización del accidente con riesgo biológico en estudiantes de pregrado en facultades de salud en una institución de educación superior de Bogotá 2009-2010. Revista Colombiana de Enfermería. 2011;6(6):90-101.

Gessner R, Larocca LM, Chaves MMN, Moreira SD, Wistuba ES, Souza SJP. As notificações de acidentes de trabalho com material biológico em um hospital de ensino de Curitiba/PR. Saúde em Debate.2013;37(99):619-627.

Giancotti GM, Haeffner R, Solheid NLS, Miranda FMA, Sarquis LMM. Caracterização das vítimas e dos acidentes de trabalho com material biológico atendidas em um hospital público do Paraná, 2012. Epidemiol. Serv. Saúde. 2014;23(2):337-346.

Gomes SCS, Caldas AJM. Qualidade dos dados do sistema de informação sobre acidentes de trabalho com exposição a material biológico no Brasil, 2010 a 2015. Rev Bras Med Trab. 2017;15(3):200-8. 
Hair JF, Anderson RE, Tatham RL, Black WC. Análise multivariada de dados. 6ed. Bookman: Porto Alegre; 2009.

Hays RD, Anderson R, Revicki D. Psychometric considerations in evaluating healthrelated quality of life measures. Qual Life Res. 1993; 2(6): 441-9.

Jain M, Sabharwal ER, Srivastawa D. Practices of Health Care Personnel Regarding Occupational Exposure. Journal of Clinical and Diagnostic Research. 2016;10(11): 14-17.

Januário GC, Carvalho PCF, Lemos GC, Gir E, Toffano SEM. Acidentes ocupacionais com material potencialmente contaminado envolvendo trabalhadores de Enfermagem. Cogitare Enferm. 2017;22(1):01-09

Jaramillo RM, Maldonado MB, Guerra DD, Tetamantti D. Accidentes laborales con exposición a material biológico y grupo más sensible a los mismos (ALEMB), hospitales "Luis Vernaza", maternidad "Enrique C. Sotomayor", maternidad "Mariana de Jesús", del niño "Francisco de Ycaza Bustamante" y "Abel Gilbert Pontón" de Guayaquil. Rev. "Medicina. 2010;16(1).

Julio RS, Filardi MBS, Marziale MHP. Acidentes de trabalho com material biológico ocorridos em municípios de Minas Gerais. Rev Bras Enferm. 2014;67(1):119-26.

Lages SMR, Santos AF, Junior FFS, Costa JG. Formação em Odontologia: O Papel das Instituições de Ensino na Prevenção do Acidente com Exposição a Material Biológico. Cienc. Trab. 2015;17(54):182-187.

Laurell AC, Noriega M.O processo de produção e saúde: trabalho e desgaste operário. São Paulo: Hucitec,1989.

Leow JJ, Groen RS, Bae JY, Adisa CA, Kingham P, Kushner AL. Scarcity of healthcare worker protection in eight LMICs. 2012;17(3):397-401.

Makhado, L. Davhana- Maselesele M. Knowledge and uptake of occupational postexposure prophylaxis amongst nurses caring for people living with HIV. Curationis. 2016; 39(1). 
Magagnini MAM, Rocha SA, Ayres JA. O significado do acidente de trabalho com material biológico para os profissionais de enfermagem. Rev Gaúcha Enferm. 2011; 32(2):302-8.

Magnini MAM, Honori VM, Takiguchi OMY, Silva PMG, Magagnini MMM, Sanches M. Exposição a fluidos biológicos e acidentes com graduandos de medicina e enfermagem. CuidArte, Enferm. 2015;9(1):71-77.

Malka E, Streinu-Cercel A, Piţigoi D, Bacruban. Management of accidental exposure to HCV, HBV and HIV in healthcare workers in Romania. GERMS. 2012;2(4).

Manisha J, Sabharwal ER, Srivastava D. Prevalence and Practices of Needle Stick Injuries among Health Care Personnel. Journal of Clinical and Diagnostic Research. 2016;10(11):14-17.

Martins JCO, Aquino CAB, Sabóia IB, Pinheiro AAG. De Kairos a Kronos: metamorfoses do trabalho na linha do tempo. Cadernos de Psicologia Social do Trabalho. 2012;15(2):219-228.

Marx K. O capital: crítica da economia política. Rio de Janeiro: Bertrand; 1994. Cap 5.

Mashoto KO, Mubyasi GM, Mushi AK.Knowledge of occupational exposure to HIV: a cross sectional study of healthcare workwrs in Tumbi and Donoma Hospitals, Tanzania. BMC Health Services Research. 2015;15:(29).

Mbaisi EM, Ng'ang'a Z, Wanzala P, Omolo J.Prevalence and factors associated with percutaneous injuries and splash exposures among health-care workers in a provincial hospital, Kenya, 2010.Pan Afr Med J. 2013;14(10).

McDowell I, Neweel C. Measuring health: a guide to rating scales and questionnaires. 2end Ed. New York: Oxford University Press; 1996.

Mehrdad R, Atkins EH, Sharifian SA, Pouryaghoub G. Psychosocial Factors and Blood Borne Exposure among nurses. ljoem. 2014;5(1):32-39.

Melo FMS, Oliveira BSB, Oliveira RKL, Bezerra JC, Silva MJN, Joventino ES. Conhecimento de enfermeiros sobre acidentes de trabalho. Rev Rene. 2017; 18(2):173-80. 
Moreno-Arroyo MC, Puig-LLobet M, Falco-Pegueroles A, Lluch-Canut MT, Casas I, Roldan-Merino J. What is the perception of biological risk by undergraduate nursing students? Rev. Latino-Am. Enfermagem. 2016;24:e2715.

Neves HCC, Souza ACS, Medeiros M, Munari DB, Ribeiro LCM, Tipple AFV. Segurança dos trabalhadores de enfermagem e fatores determinantes para adesão aos equipamentos de proteção individual. Rev. Latino-Am. Enfermagem. 2011; 19(2):[08 telas].

Occupational Safety and Health Administration. Bloodborne Pathogens Standard. 2011. Disponível em:

https://www.osha.gov/OshDoc/data_BloodborneFacts/bbfact01.pdf.

Occupational Health and Surveillance Program. Massachusetts Department of Public Health.Massachusetts Sharps Injury Surveillance System 2015; disponível em: www.mass.gov/dph/ohsp.

Paiva MHRS, Oliveira AC. Fatores determinantes e condutas pós-acidente com material biológico entre profisisonais do atentimento pré-hospitalar. Rev Bras Enferm. 2011;64(2):268-73.

Pasquali, L; Princípios de elaboração de escalas psicológicas.Rev. Psiq. Clin.1998; 25(5):206-213.

Pasquali, L. Psicometria: teoria dos testes na psicologia e na educação. Petrópolis. RJ, editora vozes,2003.

Pasquali, L. Psicometria. Rev.Esc Enferm USP. 2009; 43 (Esp): 992-9.

Pereira EAA, Velasco AR, Hanzelmann RS, Gimenez S, Silva JF, Passos JP. Motivações para mudança nas ações dos profissionais de enfermagem após exposição acidental a material biológico. J. res.: fundam. care. online 2018;10(2):534541.

Polit DF, Beck CT. The content validity index: are you sure you know what's being reported? Critique and recomendationas. Res Nurs Health 2006;29:489-497. 
Quan M, Xuyao W, Hualian W, Xiaoli Y, Dan L, Zhixia J et al. Influencing factors on use of standard precautions against occupational exposures to blood and body fluids among nurses in China. Int J Clin Exp Med. 2015;8(12):22450-22459.

Rice BD, Tomkins SE, Ncube FM. Sharp truth: health care workers remain at risk of bloodborne infection. Occupational Medicine. 2015;65:210-214.

Rodrigues PS, Sousa AFL, Magro MCS, Andrade D, Hermann PRS. Acidente ocupacional entre profissionais de enfermagem atuantes em setores críticos de um pronto-socorro. Esc Anna Nery 2017;21(2).

Rosenstock IM. The health belief model: explaining health behavior through expectancies. In: Glanz K, Lewis FM, Rimer BK. Health behavior and health education: theory, research and practice. San Francisco: Jossey-Bass Publishers; 1990. p. 39-62.

Sailer GC, Marziale MHP. Vivência dos trabalhadores de enfermagem frente ao uso dos antirretrovirais após exposição ocupacional a material biológico.Texto Contexto Enferm. 2007;16(1):55-62.

Samargandy SA, Bukhari LM, Samargandy AS, Bahlas RS, Aldigs EK, Alawi MM et al. Epidemiology and clinical consequences of occupational exposure to blood and other body fluids in a university hospital in Saudi Arabia. 2016; Saudi Med J 37 (7).

Silva SM, Baptista PCP, Felli VEA, Martins AC, Sarquis LMM, Mininel VA. Estratégias de intervenção relativas à saúde dos trabalhadores de enfermagem de hospitais universitários no Brasil Rev. Latino-Am. Enfermagem. 2013; 21(1):[09 telas].

Sireci SG. The construct of content validity. Soc Indic Res. 1998;45:83-117.

Sven H. Principles of test theories. Hillsdate: Lawrence Erlbaum; 1990.

Terwee CB, Bot SDM, Boer MR, van der DAWM, Knol DL, Dekker J, et al. Quality criteria were proposed for measurement properties status questionnaires. J Clin Epidemiol. 2007;60:34-42.

Texas Department of State Health Services. Contaminated Sharps Injuries Among Healthcare Workers in Texas: 2013. Infectious Disease Control Unit 2016. 
Tomaschewski-Barlem JG; Piexak DR; Barlem ELD; et al. Produção científica da enfermagem acerca do cuidado de si: uma revisão integrativa. Rev Fund Care Online. 2016;8(3):4629-4635.

Valim MD, Marziale MHP. Notification of work accidents with exposure to biological material: cross study. Online braz. j. nurs.2012;11(1).

Vieira DB, Lima RO, Santana EB, Miranda GL, Cerqueira EM. Acidentes de trabalho com exposição a material biológico: ocorrências em profissionais de saúde em um hospital geral. Revista Baiana de Saúde Pública. 2016;40(4):821-831.

Xavier AP, Barreto DM, Alóchio KV, Sá SPC, Júnior DIS. Ressignificando o cuidado de si na enfermagem: percepções de uma equipe. Rev enferm UFPE on line. 2017;11(3):1179-88.

Wall ML, Miranda FMAM, Sarquis LMM, Labronici LM, Cruz EDA.As crenças dos trabalhadores de saúde nos acidentes de trabalho com exposição a fluido biológico: pesquisa descritiva. Online braz.j.nrs.2011;10 (1).

Weiss HM. Deconstruting job satisfaction separating evaluations, beliefs and affective experiences.Human Resource Management. 2002; Review 12:173-194.

Wynd CA, Schmidt B, Schaefer MA. Two quantitative approaches for estimating content validity. West J Nurs Res 2003; 25(5):508-518. 
Apêndice 1. Escala de crenças dos trabalhadores da equipe de enfermagem frente ao acidente de trabalho com fluido biológico.

\begin{tabular}{|c|c|c|c|c|c|}
\hline ITENS & $\begin{array}{l}\text { Discordo } \\
\text { Totalmente } \\
\text { (1) }\end{array}$ & $\begin{array}{l}\text { Discordo } \\
\text { (2) }\end{array}$ & $\begin{array}{c}\text { Não } \\
\text { discordo } \\
\text { nem } \\
\text { concordo } \\
\text { (3) }\end{array}$ & $\begin{array}{l}\text { Concordo } \\
\text { (4) }\end{array}$ & $\begin{array}{l}\text { Concordo } \\
\text { Totalmente } \\
\text { (5) }\end{array}$ \\
\hline $\begin{array}{l}\text { 1. Pensar sobre o acidente me causa } \\
\text { angústia. }\end{array}$ & & & & & \\
\hline $\begin{array}{l}\text { 2. Tenho medo de sofrer acidente com } \\
\text { fluido biológico no trabalho. }\end{array}$ & & & & & \\
\hline $\begin{array}{l}\text { 3. Considero que o trabalhador que } \\
\text { sofre acidente não tem capacidade } \\
\text { para trabalhar na enfermagem }\end{array}$ & & & & & \\
\hline $\begin{array}{l}\text { 4. Penso que o trabalhador que sofre } \\
\text { acidente com fluido biológico } \\
\text { poderá ter conflitos familiares. }\end{array}$ & & & & & \\
\hline $\begin{array}{l}\text { 5. Acredito que a falta de } \\
\text { conhecimento contribui para o } \\
\text { acidente. }\end{array}$ & & & & & \\
\hline $\begin{array}{l}\text { 6. Penso que o acidente com fluido } \\
\text { biológico pode trazer graves } \\
\text { consequências para a vida. }\end{array}$ & & & & & \\
\hline $\begin{array}{l}\text { 7. Acredito que o casamento pode } \\
\text { acabar se o trabalhador sofrer um } \\
\text { acidente com um paciente portador } \\
\text { de HIVIAIDS. }\end{array}$ & & & & & \\
\hline $\begin{array}{l}\text { 8. Tenho medo de me contaminar } \\
\text { após um acidente. }\end{array}$ & & & & & \\
\hline $\begin{array}{l}\text { 9. Tenho medo de contaminar meus } \\
\text { filhos após o acidente }\end{array}$ & & & & & \\
\hline $\begin{array}{l}\text { 10. Acredito que os acidentes não } \\
\text { acontecem quando temos } \\
\text { autoconfiança. }\end{array}$ & & & & & \\
\hline $\begin{array}{l}\text { 11. Penso que o acidente pode fazer } 0 \\
\text { trabalhador repensar sobre a } \\
\text { própria vida. }\end{array}$ & & & & & \\
\hline $\begin{array}{l}\text { 12. Vejo que os trabalhadores que } \\
\text { sofrem acidente de trabalho com } \\
\text { fluido biológico passam a repensar } \\
\text { suas práticas de trabalho. }\end{array}$ & & & & & \\
\hline $\begin{array}{l}\text { 13. A falta de conhecimento contribui } \\
\text { para o acidente. }\end{array}$ & & & & & \\
\hline 14. O Estresse influencia a ocorrência & & & & & \\
\hline
\end{tabular}




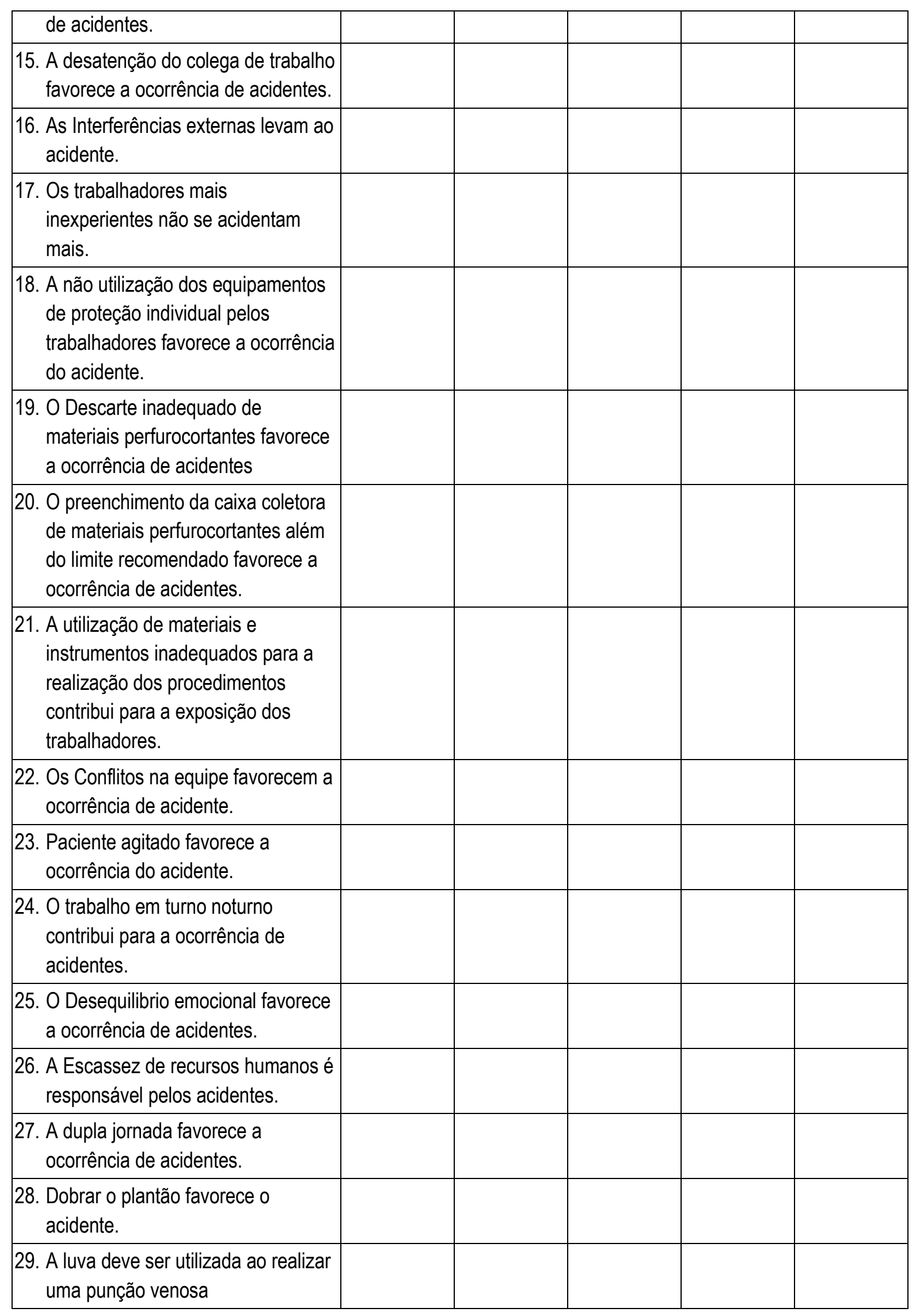




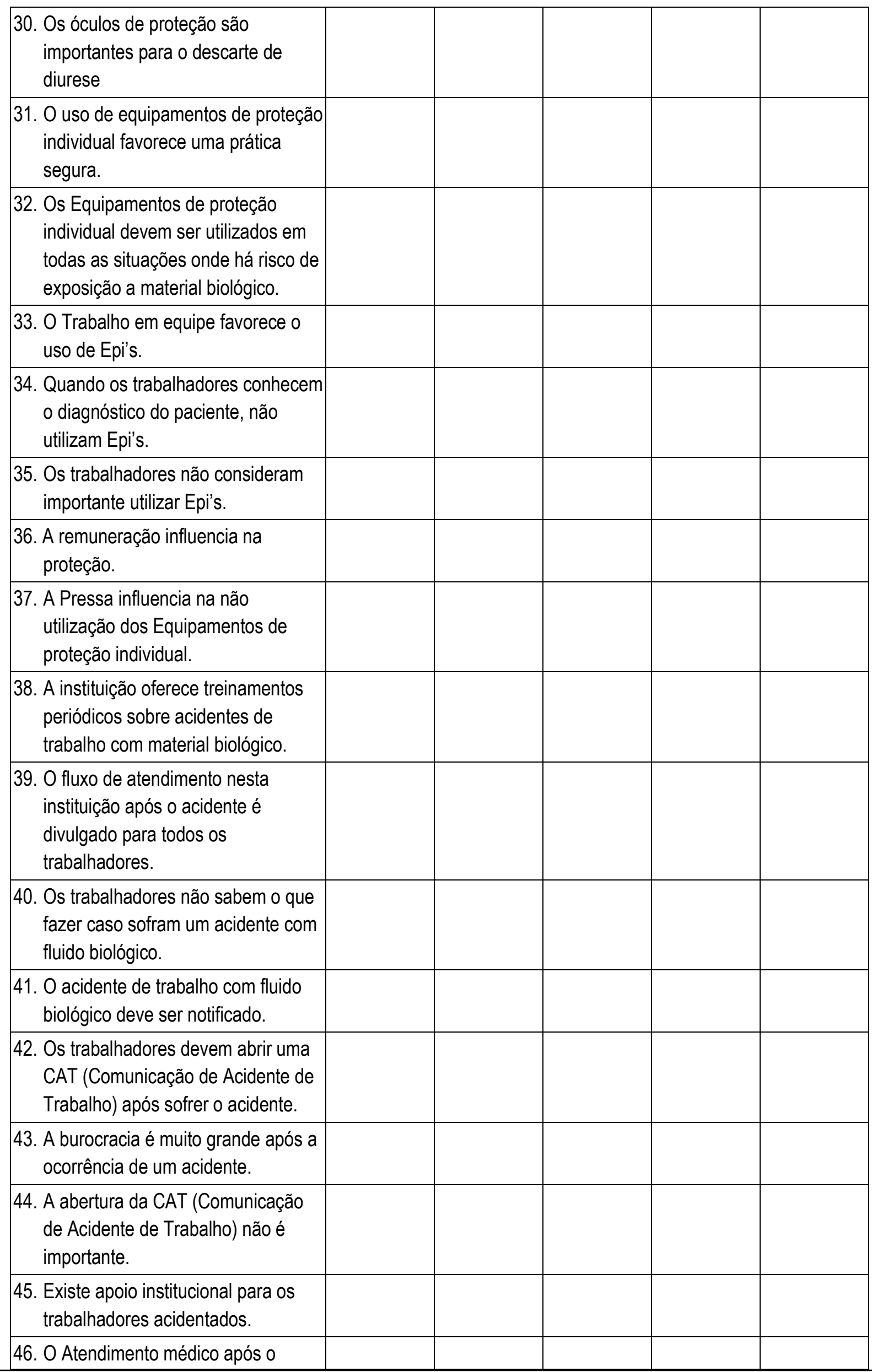




\begin{tabular}{|l|l|l|l|l|l|}
\hline $\begin{array}{l}\text { acidente é importante, traz alívio e } \\
\text { conforto. }\end{array}$ & & & & & \\
\hline $\begin{array}{l}\text { 47. A equipe tem preconceito com } \\
\text { quem sofre acidente. }\end{array}$ & & & & & \\
\hline $\begin{array}{l}\text { 48. Os trabalhadores conhecem o } \\
\text { acompanhamento clínico e } \\
\text { laboratorial após o acidente. }\end{array}$ & & & & \\
\hline $\begin{array}{l}\text { 49. O Atendimento psicológico é muito } \\
\text { importante para o trabalhador } \\
\text { acidentado. }\end{array}$ & & & & & \\
\hline $\begin{array}{l}\text { 50. O suporte da chefia após o acidente } \\
\text { é muito importante. }\end{array}$ & & & & & \\
\hline $\begin{array}{l}\text { 51. Os trabalhadores tem medo de uma } \\
\text { possível demissão em caso de } \\
\text { acidente. }\end{array}$ & & & & & \\
\hline
\end{tabular}


Apêndice 2. Carta Convite aos juízes

Prezado (a) Prof.(a) Dr.(a) :

Temos a grata satisfação de convidá-lo(a) para participar como membro do grupo de juízes validadores da Construção de uma Escala de Crenças dos trabalhadores da equipe de enfermagem relacionadas ao acidente de trabalho com fluidos biológicos,trabalho este que será desenvolvido durante o Curso de Doutorado.

Este estudo, tem como objetivo elaborar uma escala de medida de crenças dos trabalhadores de enfermagem frente ao acidente de trabalho com fluido biológico. A elaboração de um instrumento que possa identificar e mensurar especificamente as crenças dos trabalhadores justifica-se ressaltando que, a aplicação deste instrumento poderá fornecer indicadores reais e válidos acerca das atitudes dos trabalhadores em relação aos fluidos biológicos e ser ainda utilizada na avaliação periódica dos acidentes ocorridos nas instituições.

A indicação de Vossa Senhoria para o referido papel de Juiz, deve-se ao fato de ser pessoa inserida no meio acadêmico e envolvida com a pesquisa cientifica, critérios esses compatíveis com nosso trabalho e com a certeza de que sua experiência profissional e acadêmica contribuirá de forma significativa para este trabalho.

Estima-se um tempo de aproximadamente quatro dias dispendido para sua participação, considerando a data do recebimento do material, contendo as orientações, sua análise e devolutiva.

Em anexo encaminhamos um exemplar do Projeto de Pesquisa.

Antecipamos agradecimentos pela sua participação nesta pesquisa.

Atenciosamente,

\section{Carolina Luiza Bernardes}

Doutoranda do Programa de Pós-Graduação em Gerenciamento em Enfermagem- PPGEn da Escola de Enfermagem da Universidade de São Paulo 
Apêndice 3. Instrumento enviado aos juízes

\section{Instruções aos juízes}

Após contato prévio estamos enviando o material sobre a escala de crenças dos trabahadores da equipe de enfermagem frente ao acidente de trabalho com fluido biológico, que engloba temas referentes aos acidentes, equipamentos de proteção, causas das exposições ocupacionais. Cabe dizer que o instrumento será aplicado na equipe de enfermagem de um Hospital Universitário.

A indicação de vossa senhoria para o referido papel de juiz, deve-se ao fato de ser pessoa inserida no meio acadêmico e envolvida em pesquisa científica, critérios esses compatíveis com de nosso trabalho e também com a certeza de que sua experiência profissional nos ajudará.

A seguir, listamos algumas instruções que deverão ser respeitadas para que a função de juiz seja exercida de maneira mais fidedigna possível.

1. O juiz necessita ter o desempenho de um pesquisador ao analisar este instrumento, avaliando sua pertinência e importância.

2. Verificar também o aspecto semântico dos itens da escala, se os conteúdos estão claros, se as expressões estão corretas, se a regência dos verbos está adequada, se os termos utilizados são compressíveis.

3. Caso ache necessário, poderá incluir itens e conteúdos pertinentes, que contribuirão para a elaboração final do instrumento.

4. Para cada uma das afirmativas assinale se Discorda totalmente, Discorda, Não discorda nem concorda, concorda ou concorda totalmente quanto à Relevância, precisão, clareza e objetividade.

\section{Caracterização do juíz}

Idade:

Formação Acadêmica:

Nível de Formação:

Tempo de Formação:

Vínculo institucional:

Linhas de Pesquisa: 
1. Pensar sobre 0 acidente me causa angústia.

\begin{tabular}{|c|c|c|c|c|c|c|}
\hline Itens & $\begin{array}{l}\text { Discordo } \\
\text { Totalmente } \\
\text { (1) }\end{array}$ & $\begin{array}{l}\text { Discordo } \\
\text { (2) }\end{array}$ & $\begin{array}{c}\text { Não } \\
\text { discordo } \\
\text { nem } \\
\text { concordo } \\
\text { (3) }\end{array}$ & $\begin{array}{c}\text { Concordo } \\
\text { (4) }\end{array}$ & $\begin{array}{c}\text { Concordo } \\
\text { Totalmente } \\
\text { (5) }\end{array}$ & Observação \\
\hline \multicolumn{6}{|l|}{ Relevância } & \\
\hline \multicolumn{6}{|l|}{ Precisão } & \\
\hline \multicolumn{6}{|l|}{ Clareza } & \\
\hline Objetividade & & & & & & \\
\hline
\end{tabular}

2. Tenho medo de sofrer acidente com fluido biológico no trabalho.

\begin{tabular}{|c|c|c|c|c|c|c|}
\hline Itens & $\begin{array}{l}\text { Discordo } \\
\text { Totalmente } \\
\text { (1) }\end{array}$ & $\begin{array}{l}\text { Discordo } \\
\text { (2) }\end{array}$ & $\begin{array}{c}\text { Não } \\
\text { discordo } \\
\text { nem } \\
\text { concordo } \\
\text { (3) }\end{array}$ & $\begin{array}{c}\text { Concordo } \\
\text { (4) }\end{array}$ & $\begin{array}{c}\text { Concordo } \\
\text { Totalmente } \\
\text { (5) }\end{array}$ & Observação \\
\hline \multicolumn{6}{|l|}{ Relevância } & \\
\hline \multicolumn{6}{|l|}{ Precisão } & \\
\hline \multicolumn{6}{|l|}{ Clareza } & \\
\hline Objetividade & & & & & & \\
\hline
\end{tabular}

3. Considero que o trabalhador que sofre acidente não tem capacidade para trabalhar na enfermagem.

\begin{tabular}{|c|c|c|c|c|c|c|}
\hline Itens & $\begin{array}{c}\text { Discordo } \\
\text { Totalmente } \\
\text { (1) }\end{array}$ & $\begin{array}{c}\text { Discordo } \\
\text { (2) }\end{array}$ & $\begin{array}{c}\text { Não } \\
\text { discordo } \\
\text { nem } \\
\text { concordo } \\
\text { (3) }\end{array}$ & $\begin{array}{c}\text { Concordo } \\
\text { (4) }\end{array}$ & $\begin{array}{c}\text { Concordo } \\
\text { Totalmente } \\
\text { (5) }\end{array}$ & Observação \\
\hline \multicolumn{6}{|l|}{ Relevância } & \\
\hline \multicolumn{6}{|l|}{ Precisão } & \\
\hline \multicolumn{6}{|l|}{ Clareza } & \\
\hline Objetividade & & & & & & \\
\hline
\end{tabular}

4. Penso que o trabalhador que sofre acidente com fluido biológico poderá ter conflitos familiares.

\begin{tabular}{|c|c|c|c|c|c|c|}
\hline & $\begin{array}{l}\text { Discordo } \\
\text { Totalmente } \\
\text { (1) }\end{array}$ & $\begin{array}{l}\text { Discordo } \\
\text { (2) }\end{array}$ & $\begin{array}{c}\text { Não } \\
\text { discordo } \\
\text { nem } \\
\text { concordo } \\
(3)\end{array}$ & $\begin{array}{c}\text { Concordo } \\
\text { (4) }\end{array}$ & $\begin{array}{c}\text { Concordo } \\
\text { Totalmente } \\
\text { (5) }\end{array}$ & Observação \\
\hline \multicolumn{6}{|l|}{ Relevância } & \\
\hline \multicolumn{6}{|l|}{ Precisão } & \\
\hline \multicolumn{6}{|l|}{ Clareza } & \\
\hline Objetividade & & & & & & \\
\hline
\end{tabular}


5. Acredito que a falta de conhecimento contribui para o acidente.

\begin{tabular}{|c|c|c|c|c|c|c|}
\hline & $\begin{array}{c}\text { Discordo } \\
\text { Totalmente } \\
\text { (1) }\end{array}$ & $\begin{array}{l}\text { Discordo } \\
\text { (2) }\end{array}$ & $\begin{array}{c}\text { Não } \\
\text { discordo } \\
\text { nem } \\
\text { concordo } \\
\text { (3) }\end{array}$ & $\begin{array}{c}\text { Concordo } \\
\text { (4) }\end{array}$ & $\begin{array}{c}\text { Concordo } \\
\text { Totalmente } \\
\text { (5) }\end{array}$ & Observação \\
\hline \multicolumn{6}{|l|}{ Relevância } & \\
\hline \multicolumn{6}{|l|}{ Precisão } & \\
\hline \multicolumn{6}{|l|}{ Clareza } & \\
\hline Objetividade & & & & & & \\
\hline
\end{tabular}

6. Penso que o acidente com fluido biológico pode trazer graves consequências para a vida.

\begin{tabular}{|c|c|c|c|c|c|c|}
\hline & $\begin{array}{l}\text { Discordo } \\
\text { Totalmente } \\
\text { (1) }\end{array}$ & $\begin{array}{l}\text { Discordo } \\
\text { (2) }\end{array}$ & $\begin{array}{c}\text { Não } \\
\text { discordo } \\
\text { nem } \\
\text { concordo } \\
\text { (3) }\end{array}$ & $\begin{array}{c}\text { Concordo } \\
\text { (4) }\end{array}$ & $\begin{array}{c}\text { Concordo } \\
\text { Totalmente } \\
\text { (5) }\end{array}$ & Observação \\
\hline \multicolumn{6}{|l|}{ Relevância } & \\
\hline \multicolumn{6}{|l|}{ Precisão } & \\
\hline \multicolumn{6}{|l|}{ Clareza } & \\
\hline Objetividade & & & & & & \\
\hline
\end{tabular}

7. Acredito que o casamento pode acabar se o trabalhador sofrer um acidente com um paciente portador de HIV/AIDS.

\begin{tabular}{|l|c|c|c|c|c|c|}
\hline & $\begin{array}{c}\text { Discordo } \\
\text { Totalmente } \\
\text { (1) }\end{array}$ & $\begin{array}{c}\text { Discordo } \\
\text { (2) }\end{array}$ & $\begin{array}{c}\text { discordo } \\
\text { nem } \\
\text { concordo } \\
\text { (3) }\end{array}$ & $\begin{array}{c}\text { Concordo } \\
\text { (4) }\end{array}$ & $\begin{array}{c}\text { Concordo } \\
\text { Totalmente } \\
\text { (5) }\end{array}$ & \multirow{2}{*}{ Observação } \\
\hline Relevância & & & & & & \\
\cline { 1 - 5 } Precisão & & & & & & \\
\hline Clareza & & & & & & \\
\hline Objetividade & & & & & & \\
\hline
\end{tabular}

8. Tenho medo de me contaminar após um acidente.

\begin{tabular}{|c|c|c|c|c|c|c|}
\hline & $\begin{array}{l}\text { Discordo } \\
\text { Totalmente } \\
\text { (1) }\end{array}$ & $\begin{array}{c}\text { Discordo } \\
\text { (2) }\end{array}$ & $\begin{array}{c}\text { Não } \\
\text { discordo } \\
\text { nem } \\
\text { concordo } \\
\text { (3) }\end{array}$ & $\begin{array}{c}\text { Concordo } \\
\text { (4) }\end{array}$ & $\begin{array}{c}\text { Concordo } \\
\text { Totalmente } \\
\text { (5) }\end{array}$ & Observação \\
\hline \multicolumn{6}{|l|}{ Relevância } & \\
\hline \multicolumn{6}{|l|}{ Precisão } & \\
\hline \multicolumn{6}{|l|}{ Clareza } & \\
\hline Objetividade & & & & & & \\
\hline
\end{tabular}


9. Tenho medo de contaminar meus filhos após o acidente.

\begin{tabular}{|l|c|c|c|c|c|c|}
\hline & $\begin{array}{c}\text { Discordo } \\
\text { Totalmente } \\
\text { (1) }\end{array}$ & $\begin{array}{c}\text { Não } \\
\text { Discordo } \\
\text { nem } \\
\text { (2) }\end{array}$ & $\begin{array}{c}\text { (3) } \\
\text { concordo }\end{array}$ & $\begin{array}{c}\text { Concordo } \\
\text { (4) }\end{array}$ & $\begin{array}{c}\text { Concordo } \\
\text { Totalmente } \\
\text { (5) }\end{array}$ & \multirow{2}{*}{ Observação } \\
\hline Relevância & & & & & & \\
\cline { 1 - 5 } Precisão & & & & & & \\
\hline Clareza & & & & & & \\
\hline Objetividade & & & & & & \\
\hline
\end{tabular}

10. Acredito que os acidentes não acontecem quando temos autoconfiança.

\begin{tabular}{|c|c|c|c|c|c|c|}
\hline & $\begin{array}{c}\text { Discordo } \\
\text { Totalmente } \\
\text { (1) }\end{array}$ & $\begin{array}{c}\text { Discordo } \\
\text { (2) }\end{array}$ & $\begin{array}{c}\text { Não } \\
\text { discordo } \\
\text { nem } \\
\text { concordo } \\
\text { (3) }\end{array}$ & $\begin{array}{c}\text { Concordo } \\
\text { (4) }\end{array}$ & $\begin{array}{c}\text { Concordo } \\
\text { Totalmente } \\
\text { (5) }\end{array}$ & Observação \\
\hline \multicolumn{6}{|l|}{ Relevância } & \\
\hline \multicolumn{6}{|l|}{ Precisão } & \\
\hline \multicolumn{6}{|l|}{ Clareza } & \\
\hline Objetividade & & & & & & \\
\hline
\end{tabular}

11. Penso que o acidente pode fazer o trabalhador repensar sobre a própria vida.

\begin{tabular}{|c|c|c|c|c|c|c|}
\hline & $\begin{array}{c}\text { Discordo } \\
\text { Totalmente } \\
\text { (1) }\end{array}$ & $\begin{array}{c}\text { Discordo } \\
(2)\end{array}$ & $\begin{array}{c}\text { Não } \\
\text { discordo } \\
\text { nem } \\
\text { concordo } \\
(3) \\
\end{array}$ & $\begin{array}{c}\text { Concordo } \\
\text { (4) }\end{array}$ & $\begin{array}{c}\text { Concordo } \\
\text { Totalmente } \\
\text { (5) }\end{array}$ & Observação \\
\hline \multicolumn{6}{|l|}{ Relevância } & \\
\hline \multicolumn{6}{|l|}{ Precisão } & \\
\hline \multicolumn{6}{|l|}{ Clareza } & \\
\hline Objetividade & & & & & & \\
\hline
\end{tabular}

12. Vejo que os trabalhadores que sofrem acidente de trabalho com fluido biológico passam a repensar suas práticas de trabalho.

\begin{tabular}{|c|c|c|c|c|c|c|}
\hline & $\begin{array}{l}\text { Discordo } \\
\text { Totalmente } \\
\text { (1) }\end{array}$ & $\begin{array}{c}\text { Discordo } \\
\text { (2) }\end{array}$ & $\begin{array}{c}\text { Não } \\
\text { discordo } \\
\text { nem } \\
\text { concordo } \\
\text { (3) }\end{array}$ & $\begin{array}{c}\text { Concordo } \\
\text { (4) }\end{array}$ & $\begin{array}{c}\text { Concordo } \\
\text { Totalmente } \\
\text { (5) }\end{array}$ & Observação \\
\hline \multicolumn{6}{|l|}{ Relevância } & \\
\hline \multicolumn{6}{|l|}{ Precisão } & \\
\hline \multicolumn{6}{|l|}{\begin{tabular}{|l|} 
Clareza \\
\end{tabular}} & \\
\hline Objetividade & & & & & & \\
\hline
\end{tabular}


13. A falta de conhecimento contribui para o acidente.

\begin{tabular}{|c|c|c|c|c|c|c|}
\hline & $\begin{array}{c}\text { Discordo } \\
\text { Totalmente } \\
\text { (1) }\end{array}$ & $\begin{array}{c}\text { Discordo } \\
(2)\end{array}$ & $\begin{array}{c}\text { Não } \\
\text { discordo } \\
\text { nem } \\
\text { concordo } \\
(3) \\
\end{array}$ & $\begin{array}{c}\text { Concordo } \\
(4)\end{array}$ & $\begin{array}{c}\text { Concordo } \\
\text { Totalmente } \\
\text { (5) }\end{array}$ & Observação \\
\hline \multicolumn{6}{|l|}{ Relevância } & \\
\hline \multicolumn{6}{|l|}{ Precisão } & \\
\hline \multicolumn{6}{|l|}{ Clareza } & \\
\hline Objetividade & & & & & & \\
\hline
\end{tabular}

14. O Estresse influencia a ocorrência de acidentes.

\begin{tabular}{|c|c|c|c|c|c|c|}
\hline & $\begin{array}{c}\text { Discordo } \\
\text { Totalmente } \\
\text { (1) }\end{array}$ & $\begin{array}{l}\text { Discordo } \\
\text { (2) }\end{array}$ & $\begin{array}{c}\text { Não } \\
\text { discordo } \\
\text { nem } \\
\text { concordo } \\
\text { (3) }\end{array}$ & $\begin{array}{c}\text { Concordo } \\
\text { (4) }\end{array}$ & $\begin{array}{c}\text { Concordo } \\
\text { Totalmente } \\
\text { (5) }\end{array}$ & Observação \\
\hline \multicolumn{6}{|l|}{ Relevância } & \\
\hline \multicolumn{6}{|l|}{ Precisão } & \\
\hline \multicolumn{6}{|l|}{ Clareza } & \\
\hline Objetividade & & & & & & \\
\hline
\end{tabular}

15. A desatenção do colega de trabalho favorece a ocorrência de acidentes.

\begin{tabular}{|c|c|c|c|c|c|c|}
\hline & $\begin{array}{l}\text { Discordo } \\
\text { Totalmente } \\
\text { (1) }\end{array}$ & $\begin{array}{l}\text { Discordo } \\
\text { (2) }\end{array}$ & $\begin{array}{c}\text { Não } \\
\text { discordo } \\
\text { nem } \\
\text { concordo } \\
\text { (3) }\end{array}$ & $\begin{array}{c}\text { Concordo } \\
\text { (4) }\end{array}$ & $\begin{array}{c}\text { Concordo } \\
\text { Totalmente } \\
\text { (5) }\end{array}$ & Observação \\
\hline \multicolumn{6}{|l|}{ Relevância } & \\
\hline \multicolumn{6}{|l|}{ Precisão } & \\
\hline \multicolumn{6}{|l|}{ Clareza } & \\
\hline Objetividade & & & & & & \\
\hline
\end{tabular}

16. As Interferências externas levam ao acidente.

\begin{tabular}{|c|c|c|c|c|c|c|}
\hline & $\begin{array}{c}\text { Discordo } \\
\text { Totalmente } \\
\text { (1) }\end{array}$ & $\begin{array}{c}\text { Discordo } \\
(2)\end{array}$ & $\begin{array}{c}\text { Não } \\
\text { discordo } \\
\text { nem } \\
\text { concordo } \\
(3) \\
\end{array}$ & $\begin{array}{c}\text { Concordo } \\
\text { (4) }\end{array}$ & $\begin{array}{c}\text { Concordo } \\
\text { Totalmente } \\
\text { (5) }\end{array}$ & Observação \\
\hline \multicolumn{6}{|l|}{ Relevância } & \\
\hline \multicolumn{6}{|l|}{ Precisão } & \\
\hline \multicolumn{6}{|l|}{ Clareza } & \\
\hline Objetividade & & & & & & \\
\hline
\end{tabular}


17. Os trabalhadores mais inexperientes não se acidentam mais.

\begin{tabular}{|c|c|c|c|c|c|c|}
\hline & $\begin{array}{c}\text { Discordo } \\
\text { Totalmente } \\
\text { (1) }\end{array}$ & $\begin{array}{c}\text { Discordo } \\
(2)\end{array}$ & $\begin{array}{c}\text { Não } \\
\text { discordo } \\
\text { nem } \\
\text { concordo } \\
(3)\end{array}$ & $\begin{array}{c}\text { Concordo } \\
\text { (4) }\end{array}$ & $\begin{array}{c}\text { Concordo } \\
\text { Totalmente } \\
(5)\end{array}$ & Observação \\
\hline \multicolumn{6}{|l|}{ Relevância } & \\
\hline \multicolumn{6}{|l|}{ Precisão } & \\
\hline \multicolumn{6}{|l|}{ Clareza } & \\
\hline Objetividade & & & & & & \\
\hline
\end{tabular}

18. A não utilização dos equipamentos de proteção individual pelos trabalhadores favorece a ocorrência do acidente.

\begin{tabular}{|c|c|c|c|c|c|c|}
\hline & $\begin{array}{c}\text { Discordo } \\
\text { Totalmente } \\
\text { (1) }\end{array}$ & $\begin{array}{c}\text { Discordo } \\
\text { (2) }\end{array}$ & $\begin{array}{c}\text { Não } \\
\text { discordo } \\
\text { nem } \\
\text { concordo } \\
\text { (3) }\end{array}$ & $\begin{array}{c}\text { Concordo } \\
\text { (4) }\end{array}$ & $\begin{array}{c}\text { Concordo } \\
\text { Totalmente } \\
(5)\end{array}$ & Observação \\
\hline \multicolumn{6}{|l|}{ Relevância } & \\
\hline \multicolumn{6}{|l|}{ Precisão } & \\
\hline \multicolumn{6}{|l|}{ Clareza } & \\
\hline Objetividade & & & & & & \\
\hline
\end{tabular}

19. O Descarte inadequado de materiais perfurocortantes favorece a ocorrência de acidentes

\begin{tabular}{|c|c|c|c|c|c|c|}
\hline & $\begin{array}{c}\text { Discordo } \\
\text { Totalmente } \\
\text { (1) }\end{array}$ & $\begin{array}{c}\text { Discordo } \\
(2)\end{array}$ & $\begin{array}{c}\text { Não } \\
\text { discordo } \\
\text { nem } \\
\text { concordo } \\
(3) \\
\end{array}$ & $\begin{array}{c}\text { Concordo } \\
\text { (4) }\end{array}$ & $\begin{array}{c}\text { Concordo } \\
\text { Totalmente } \\
\text { (5) }\end{array}$ & Observação \\
\hline \multicolumn{6}{|l|}{ Relevância } & \\
\hline \multicolumn{6}{|l|}{ Precisão } & \\
\hline \multicolumn{6}{|l|}{ Clareza } & \\
\hline Objetividade & & & & & & \\
\hline
\end{tabular}

20. O preenchimento da caixa coletora de materiais perfurocortantes além do limite recomendado favorece a ocorrência de acidentes.

\begin{tabular}{|c|c|c|c|c|c|c|}
\hline & $\begin{array}{c}\text { Discordo } \\
\text { Totalmente } \\
\text { (1) }\end{array}$ & $\begin{array}{c}\text { Discordo } \\
\text { (2) }\end{array}$ & $\begin{array}{c}\text { Não } \\
\text { discordo } \\
\text { nem } \\
\text { concordo } \\
\text { (3) }\end{array}$ & $\begin{array}{c}\text { Concordo } \\
\text { (4) }\end{array}$ & $\begin{array}{c}\text { Concordo } \\
\text { Totalmente } \\
\text { (5) }\end{array}$ & Observação \\
\hline \multicolumn{6}{|l|}{ Relevância } & \\
\hline \multicolumn{6}{|l|}{ Precisão } & \\
\hline \multicolumn{6}{|l|}{ Clareza } & \\
\hline Objetividade & & & & & & \\
\hline
\end{tabular}


21. A utilização de materiais e instrumentos inadequados para a realização dos procedimentos contribui para a exposição dos trabalhadores.

\begin{tabular}{|c|c|c|c|c|c|c|}
\hline & $\begin{array}{l}\text { Discordo } \\
\text { Totalmente } \\
\text { (1) }\end{array}$ & $\begin{array}{l}\text { Discordo } \\
\text { (2) }\end{array}$ & $\begin{array}{c}\text { Não } \\
\text { discordo } \\
\text { nem } \\
\text { concordo } \\
\text { (3) }\end{array}$ & $\begin{array}{c}\text { Concordo } \\
\text { (4) }\end{array}$ & $\begin{array}{c}\text { Concordo } \\
\text { Totalmente } \\
\text { (5) }\end{array}$ & Observação \\
\hline \multicolumn{6}{|l|}{ Relevância } & \\
\hline \multicolumn{6}{|l|}{ Precisão } & \\
\hline \multicolumn{6}{|l|}{ Clareza } & \\
\hline Objetividade & & & & & & \\
\hline
\end{tabular}

22. Os Conflitos na equipe favorecem a ocorrência de acidente.

\begin{tabular}{|c|c|c|c|c|c|c|}
\hline & \begin{tabular}{|c|} 
Discordo \\
Totalmente \\
(1)
\end{tabular} & $\begin{array}{l}\text { Discordo } \\
\text { (2) }\end{array}$ & $\begin{array}{c}\text { Não } \\
\text { discordo } \\
\text { nem } \\
\text { concordo } \\
\text { (3) }\end{array}$ & $\begin{array}{c}\text { Concordo } \\
\text { (4) }\end{array}$ & $\begin{array}{c}\text { Concordo } \\
\text { Totalmente } \\
\text { (5) }\end{array}$ & Observação \\
\hline \multicolumn{6}{|l|}{ Relevância } & \\
\hline \multicolumn{6}{|l|}{ Precisão } & \\
\hline \multicolumn{6}{|l|}{ Clareza } & \\
\hline Objetividade & & & & & & \\
\hline
\end{tabular}

23. Paciente agitado favorece a ocorrência do acidente.

\begin{tabular}{|c|c|c|c|c|c|c|}
\hline & $\begin{array}{l}\text { Discordo } \\
\text { Totalmente } \\
\text { (1) }\end{array}$ & $\begin{array}{c}\text { Discordo } \\
\text { (2) }\end{array}$ & $\begin{array}{c}\text { Não } \\
\text { discordo } \\
\text { nem } \\
\text { concordo } \\
\text { (3) }\end{array}$ & $\begin{array}{c}\text { Concordo } \\
\text { (4) }\end{array}$ & $\begin{array}{c}\text { Concordo } \\
\text { Totalmente } \\
\text { (5) }\end{array}$ & Observação \\
\hline \multicolumn{6}{|l|}{ Relevância } & \\
\hline \multicolumn{6}{|l|}{ Precisão } & \\
\hline \multicolumn{6}{|l|}{ Clareza } & \\
\hline Objetividade & & & & & & \\
\hline
\end{tabular}

24. O trabalho em turno noturno contribui para a ocorrência de acidentes.

\begin{tabular}{|c|c|c|c|c|c|c|}
\hline & $\begin{array}{c}\text { Discordo } \\
\text { Totalmente } \\
\text { (1) }\end{array}$ & $\begin{array}{c}\text { Discordo } \\
(2)\end{array}$ & $\begin{array}{c}\text { Não } \\
\text { discordo } \\
\text { nem } \\
\text { concordo } \\
(3) \\
\end{array}$ & $\begin{array}{c}\text { Concordo } \\
\text { (4) }\end{array}$ & $\begin{array}{c}\text { Concordo } \\
\text { Totalmente } \\
(5)\end{array}$ & Observação \\
\hline \multicolumn{6}{|l|}{ Relevância } & \\
\hline \multicolumn{6}{|l|}{ Precisão } & \\
\hline \multicolumn{6}{|l|}{ Clareza } & \\
\hline Objetividade & & & & & & \\
\hline
\end{tabular}


25. O Desequilibrio emocional favorece a ocorrência de acidentes.

\begin{tabular}{|c|c|c|c|c|c|c|}
\hline & $\begin{array}{c}\text { Discordo } \\
\text { Totalmente } \\
\text { (1) }\end{array}$ & $\begin{array}{c}\text { Discordo } \\
\text { (2) }\end{array}$ & $\begin{array}{c}\text { Não } \\
\text { discordo } \\
\text { nem } \\
\text { concordo } \\
\text { (3) }\end{array}$ & $\begin{array}{c}\text { Concordo } \\
\text { (4) }\end{array}$ & $\begin{array}{c}\text { Concordo } \\
\text { Totalmente } \\
\text { (5) }\end{array}$ & Observação \\
\hline \multicolumn{6}{|l|}{ Relevância } & \\
\hline \multicolumn{6}{|l|}{ Precisão } & \\
\hline \multicolumn{6}{|l|}{ Clareza } & \\
\hline Objetividade & & & & & & \\
\hline
\end{tabular}

26. A Escassez de recursos humanos é responsável pelos acidentes.

\begin{tabular}{|c|c|c|c|c|c|c|}
\hline & $\begin{array}{l}\text { Discordo } \\
\text { Totalmente } \\
\text { (1) }\end{array}$ & $\begin{array}{l}\text { Discordo } \\
\text { (2) }\end{array}$ & $\begin{array}{c}\text { Não } \\
\text { discordo } \\
\text { nem } \\
\text { concordo } \\
\text { (3) }\end{array}$ & $\begin{array}{c}\text { Concordo } \\
\text { (4) }\end{array}$ & $\begin{array}{c}\text { Concordo } \\
\text { Totalmente } \\
\text { (5) }\end{array}$ & Observação \\
\hline \multicolumn{6}{|l|}{ Relevância } & \\
\hline \multicolumn{6}{|l|}{ Precisão } & \\
\hline \multicolumn{6}{|l|}{ Clareza } & \\
\hline Objetividade & & & & & & \\
\hline
\end{tabular}

27. A dupla jornada favorece a ocorrência de acidentes.

\begin{tabular}{|c|c|c|c|c|c|c|}
\hline & $\begin{array}{c}\text { Discordo } \\
\text { Totalmente } \\
\text { (1) }\end{array}$ & $\begin{array}{c}\text { Discordo } \\
\text { (2) }\end{array}$ & $\begin{array}{c}\text { Não } \\
\text { discordo } \\
\text { nem } \\
\text { concordo } \\
\text { (3) }\end{array}$ & $\begin{array}{c}\text { Concordo } \\
\text { (4) }\end{array}$ & $\begin{array}{c}\text { Concordo } \\
\text { Totalmente } \\
\text { (5) }\end{array}$ & Observação \\
\hline \multicolumn{6}{|l|}{ Relevância } & \\
\hline \multicolumn{6}{|l|}{ Precisão } & \\
\hline \multicolumn{6}{|l|}{ Clareza } & \\
\hline Objetividade & & & & & & \\
\hline
\end{tabular}

28. Dobrar o plantão favorece o acidente.

\begin{tabular}{|c|c|c|c|c|c|c|}
\hline & $\begin{array}{c}\text { Discordo } \\
\text { Totalmente } \\
\text { (1) }\end{array}$ & $\begin{array}{c}\text { Discordo } \\
(2)\end{array}$ & $\begin{array}{c}\text { Não } \\
\text { discordo } \\
\text { nem } \\
\text { concordo } \\
(3) \\
\end{array}$ & $\begin{array}{c}\text { Concordo } \\
\text { (4) }\end{array}$ & $\begin{array}{c}\text { Concordo } \\
\text { Totalmente } \\
(5)\end{array}$ & Observação \\
\hline \multicolumn{6}{|l|}{ Relevância } & \\
\hline \multicolumn{6}{|l|}{ Precisão } & \\
\hline \multicolumn{6}{|l|}{ Clareza } & \\
\hline Objetividade & & & & & & \\
\hline
\end{tabular}


29. A luva deve ser utilizada ao realizar uma punção venosa.

\begin{tabular}{|c|c|c|c|c|c|c|}
\hline & $\begin{array}{c}\text { Discordo } \\
\text { Totalmente } \\
\text { (1) }\end{array}$ & $\begin{array}{c}\text { Discordo } \\
(2)\end{array}$ & $\begin{array}{c}\text { Não } \\
\text { discordo } \\
\text { nem } \\
\text { concordo } \\
\text { (3) }\end{array}$ & $\begin{array}{c}\text { Concordo } \\
\text { (4) }\end{array}$ & $\begin{array}{c}\text { Concordo } \\
\text { Totalmente } \\
\text { (5) }\end{array}$ & Observação \\
\hline \multicolumn{6}{|l|}{ Relevância } & \\
\hline \multicolumn{6}{|l|}{ Precisão } & \\
\hline \multicolumn{6}{|l|}{ Clareza } & \\
\hline Objetividade & & & & & & \\
\hline
\end{tabular}

30. O óculos de proteção são importantes para o descarte de diurese

\begin{tabular}{|c|c|c|c|c|c|c|}
\hline & $\begin{array}{c}\text { Discordo } \\
\text { Totalmente } \\
\text { (1) }\end{array}$ & $\begin{array}{c}\text { Discordo } \\
\text { (2) }\end{array}$ & $\begin{array}{c}\text { Não } \\
\text { discordo } \\
\text { nem } \\
\text { concordo } \\
\text { (3) }\end{array}$ & $\begin{array}{c}\text { Concordo } \\
\text { (4) }\end{array}$ & $\begin{array}{c}\text { Concordo } \\
\text { Totalmente } \\
\text { (5) }\end{array}$ & Observação \\
\hline \multicolumn{6}{|l|}{ Relevância } & \\
\hline \multicolumn{6}{|l|}{ Precisão } & \\
\hline \multicolumn{6}{|l|}{ Clareza } & \\
\hline Objetividade & & & & & & \\
\hline
\end{tabular}

31. O uso de equipamentos de proteção individual favorece uma prática segura.

\begin{tabular}{|c|c|c|c|c|c|c|}
\hline & $\begin{array}{c}\text { Discordo } \\
\text { Totalmente } \\
\text { (1) }\end{array}$ & $\begin{array}{c}\text { Discordo } \\
\text { (2) }\end{array}$ & $\begin{array}{c}\text { Não } \\
\text { discordo } \\
\text { nem } \\
\text { concordo } \\
\text { (3) }\end{array}$ & $\begin{array}{c}\text { Concordo } \\
\text { (4) }\end{array}$ & $\begin{array}{c}\text { Concordo } \\
\text { Totalmente } \\
\text { (5) }\end{array}$ & Observação \\
\hline \multicolumn{6}{|l|}{ Relevância } & \\
\hline \multicolumn{6}{|l|}{ Precisão } & \\
\hline \multicolumn{6}{|l|}{ Clareza } & \\
\hline Objetividade & & & & & & \\
\hline
\end{tabular}

32. Os Equipamentos de proteção individual devem ser utilizados em todas as situações onde há risco de exposição a amterial biológico.

\begin{tabular}{|c|c|c|c|c|c|c|}
\hline & $\begin{array}{l}\text { Discordo } \\
\text { Totalmente } \\
\text { (1) }\end{array}$ & $\begin{array}{c}\text { Discordo } \\
\text { (2) }\end{array}$ & $\begin{array}{c}\text { Não } \\
\text { discordo } \\
\text { nem } \\
\text { concordo } \\
\text { (3) }\end{array}$ & $\begin{array}{c}\text { Concordo } \\
\text { (4) }\end{array}$ & $\begin{array}{c}\text { Concordo } \\
\text { Totalmente } \\
\text { (5) }\end{array}$ & Observação \\
\hline \multicolumn{6}{|l|}{ Relevância } & \\
\hline \multicolumn{6}{|l|}{ Precisão } & \\
\hline \multicolumn{6}{|l|}{ Clareza } & \\
\hline \begin{tabular}{|l} 
Objetividade \\
\end{tabular} & & & & & & \\
\hline
\end{tabular}


33. O Trabalho em equipe favorece o uso de Epi's.

\begin{tabular}{|c|c|c|c|c|c|c|}
\hline & $\begin{array}{c}\text { Discordo } \\
\text { Totalmente } \\
\text { (1) }\end{array}$ & $\begin{array}{c}\text { Discordo } \\
\text { (2) }\end{array}$ & $\begin{array}{c}\text { Não } \\
\text { discordo } \\
\text { nem } \\
\text { concordo } \\
(3) \\
\end{array}$ & $\begin{array}{c}\text { Concordo } \\
\text { (4) }\end{array}$ & $\begin{array}{c}\text { Concordo } \\
\text { Totalmente } \\
\text { (5) }\end{array}$ & Observação \\
\hline \multicolumn{6}{|l|}{ Relevância } & \\
\hline \multicolumn{6}{|l|}{ Precisão } & \\
\hline \multicolumn{6}{|l|}{ Clareza } & \\
\hline Objetividade & & & & & & \\
\hline
\end{tabular}

34. Quando os trabalhadores conhecem o diagnóstico do paciente, não utilizam Epi's.

\begin{tabular}{|l|c|c|c|c|c|c|}
\hline & $\begin{array}{c}\text { Discordo } \\
\text { Totalmente } \\
\text { (1) }\end{array}$ & $\begin{array}{c}\text { Não } \\
\text { Discordo } \\
\text { (2) }\end{array}$ & $\begin{array}{c}\text { nem } \\
\text { concordo } \\
\text { (3) }\end{array}$ & $\begin{array}{c}\text { Concordo } \\
\text { (4) }\end{array}$ & $\begin{array}{c}\text { Concordo } \\
\text { Totalmente } \\
\text { (5) }\end{array}$ & \multirow{2}{*}{ Observação } \\
\hline Relevância & & & & & & \\
\cline { 1 - 5 } Precisão & & & & & & \\
\hline Clareza & & & & & & \\
\hline Objetividade & & & & & & \\
\hline
\end{tabular}

35. Os trabalhadores não consideram importante utilizar Epi's.

\begin{tabular}{|c|c|c|c|c|c|c|}
\hline & $\begin{array}{c}\text { Discordo } \\
\text { Totalmente } \\
\text { (1) }\end{array}$ & $\begin{array}{c}\text { Discordo } \\
\text { (2) }\end{array}$ & $\begin{array}{c}\text { Não } \\
\text { discordo } \\
\text { nem } \\
\text { concordo } \\
\text { (3) }\end{array}$ & $\begin{array}{c}\text { Concordo } \\
\text { (4) }\end{array}$ & $\begin{array}{c}\text { Concordo } \\
\text { Totalmente } \\
\text { (5) }\end{array}$ & Observação \\
\hline \multicolumn{6}{|l|}{ Relevância } & \\
\hline \multicolumn{6}{|l|}{ Precisão } & \\
\hline \multicolumn{6}{|l|}{ Clareza } & \\
\hline Objetividade & & & & & & \\
\hline
\end{tabular}

36. A remuneração influencia na proteção.

\begin{tabular}{|c|c|c|c|c|c|c|}
\hline & $\begin{array}{c}\text { Discordo } \\
\text { Totalmente } \\
\text { (1) }\end{array}$ & $\begin{array}{c}\text { Discordo } \\
\text { (2) }\end{array}$ & $\begin{array}{c}\text { Não } \\
\text { discordo } \\
\text { nem } \\
\text { concordo } \\
\text { (3) }\end{array}$ & $\begin{array}{c}\text { Concordo } \\
\text { (4) }\end{array}$ & $\begin{array}{c}\text { Concordo } \\
\text { Totalmente } \\
\text { (5) }\end{array}$ & Observação \\
\hline \multicolumn{6}{|l|}{ Relevância } & \\
\hline \multicolumn{6}{|l|}{ Precisão } & \\
\hline \multicolumn{6}{|l|}{ Clareza } & \\
\hline Objetividade & & & & & & \\
\hline
\end{tabular}


37. A Pressa influencia na não utilização dos Equipamentos de proteção individual.

\begin{tabular}{|c|c|c|c|c|c|c|}
\hline & $\begin{array}{c}\text { Discordo } \\
\text { Totalmente } \\
\text { (1) }\end{array}$ & $\begin{array}{l}\text { Discordo } \\
\text { (2) }\end{array}$ & $\begin{array}{c}\text { Não } \\
\text { discordo } \\
\text { nem } \\
\text { concordo } \\
\text { (3) }\end{array}$ & $\begin{array}{c}\text { Concordo } \\
\text { (4) }\end{array}$ & $\begin{array}{c}\text { Concordo } \\
\text { Totalmente } \\
\text { (5) }\end{array}$ & Observação \\
\hline \multicolumn{6}{|l|}{ Relevância } & \\
\hline \multicolumn{6}{|l|}{ Precisão } & \\
\hline \multicolumn{6}{|l|}{ Clareza } & \\
\hline Objetividade & & & & & & \\
\hline
\end{tabular}

38. A instituição oferece treinamentos periódicos sobre acidentes de trabalho com material biológico.

\begin{tabular}{|c|c|c|c|c|c|c|}
\hline & $\begin{array}{c}\text { Discordo } \\
\text { Totalmente } \\
\text { (1) }\end{array}$ & $\begin{array}{c}\text { Discordo } \\
\text { (2) }\end{array}$ & $\begin{array}{c}\text { Não } \\
\text { discordo } \\
\text { nem } \\
\text { concordo } \\
\text { (3) }\end{array}$ & $\begin{array}{c}\text { Concordo } \\
\text { (4) }\end{array}$ & $\begin{array}{c}\text { Concordo } \\
\text { Totalmente } \\
\text { (5) }\end{array}$ & Observação \\
\hline \multicolumn{6}{|l|}{ Relevância } & \\
\hline \multicolumn{6}{|l|}{ Precisão } & \\
\hline \multicolumn{6}{|l|}{ Clareza } & \\
\hline Objetividade & & & & & & \\
\hline
\end{tabular}

39. O fluxo de atendimento nesta instituição após o acidente é divulgado para todos os trabalhadores.

\begin{tabular}{|c|c|c|c|c|c|c|}
\hline & $\begin{array}{c}\text { Discordo } \\
\text { Totalmente } \\
\text { (1) }\end{array}$ & $\begin{array}{c}\text { Discordo } \\
(2)\end{array}$ & $\begin{array}{c}\text { Não } \\
\text { discordo } \\
\text { nem } \\
\text { concordo } \\
(3) \\
\end{array}$ & $\begin{array}{c}\text { Concordo } \\
(4)\end{array}$ & $\begin{array}{c}\text { Concordo } \\
\text { Totalmente } \\
\text { (5) }\end{array}$ & Observação \\
\hline \multicolumn{6}{|l|}{ Relevância } & \\
\hline \multicolumn{6}{|l|}{ Precisão } & \\
\hline \multicolumn{6}{|l|}{ Clareza } & \\
\hline Objetividade & & & & & & \\
\hline
\end{tabular}

40. Os trabalhadores não sabem o que fazer caso sofram um acidente com fluido biológico.

\begin{tabular}{|c|c|c|c|c|c|c|}
\hline & \begin{tabular}{|} 
Discordo \\
Totalmente \\
(1)
\end{tabular} & $\begin{array}{l}\text { Discordo } \\
\text { (2) }\end{array}$ & $\begin{array}{c}\text { Não } \\
\text { discordo } \\
\text { nem } \\
\text { concordo } \\
\text { (3) }\end{array}$ & $\begin{array}{c}\text { Concordo } \\
\text { (4) }\end{array}$ & $\begin{array}{c}\text { Concordo } \\
\text { Totalmente } \\
(5)\end{array}$ & Observação \\
\hline \multicolumn{6}{|l|}{ Relevância } & \\
\hline \multicolumn{6}{|l|}{ Precisão } & \\
\hline \multicolumn{6}{|l|}{ Clareza } & \\
\hline Objetividade & & & & & & \\
\hline
\end{tabular}


41. O acidente de trabalho com fluido biológico deve ser notificado.

\begin{tabular}{|c|c|c|c|c|c|c|}
\hline & $\begin{array}{l}\text { Discordo } \\
\text { Totalmente } \\
\text { (1) }\end{array}$ & $\begin{array}{l}\text { Discordo } \\
\text { (2) }\end{array}$ & $\begin{array}{c}\text { Não } \\
\text { discordo } \\
\text { nem } \\
\text { concordo } \\
\text { (3) }\end{array}$ & $\begin{array}{c}\text { Concordo } \\
\text { (4) }\end{array}$ & $\begin{array}{c}\text { Concordo } \\
\text { Totalmente } \\
\text { (5) }\end{array}$ & Observação \\
\hline \multicolumn{6}{|l|}{ Relevância } & \\
\hline \multicolumn{6}{|l|}{ Precisão } & \\
\hline \multicolumn{6}{|l|}{ Clareza } & \\
\hline Objetividade & & & & & & \\
\hline
\end{tabular}

42. Os trabalhadores devem abrir uma CAT (Comunicação de Acidente de Trabalho) após sofrer 0 acidente.

\begin{tabular}{|c|c|c|c|c|c|c|}
\hline & $\begin{array}{c}\text { Discordo } \\
\text { Totalmente } \\
\text { (1) }\end{array}$ & $\begin{array}{c}\text { Discordo } \\
\text { (2) }\end{array}$ & $\begin{array}{c}\text { Não } \\
\text { discordo } \\
\text { nem } \\
\text { concordo } \\
\text { (3) }\end{array}$ & $\begin{array}{c}\text { Concordo } \\
\text { (4) }\end{array}$ & $\begin{array}{c}\text { Concordo } \\
\text { Totalmente } \\
(5)\end{array}$ & Observação \\
\hline \multicolumn{6}{|l|}{ Relevância } & \\
\hline \multicolumn{6}{|l|}{ Precisão } & \\
\hline \multicolumn{6}{|l|}{ Clareza } & \\
\hline Objetividade & & & & & & \\
\hline
\end{tabular}

43. A burocracia é muito grande após a ocorrência de um acidente.

\begin{tabular}{|c|c|c|c|c|c|c|}
\hline & $\begin{array}{l}\text { Discordo } \\
\text { Totalmente } \\
\text { (1) }\end{array}$ & $\begin{array}{l}\text { Discordo } \\
\text { (2) }\end{array}$ & $\begin{array}{c}\text { Não } \\
\text { discordo } \\
\text { nem } \\
\text { concordo } \\
\text { (3) }\end{array}$ & $\begin{array}{c}\text { Concordo } \\
\text { (4) }\end{array}$ & $\begin{array}{c}\text { Concordo } \\
\text { Totalmente } \\
\text { (5) }\end{array}$ & Observação \\
\hline \multicolumn{6}{|l|}{ Relevância } & \\
\hline \multicolumn{6}{|l|}{ Precisão } & \\
\hline \multicolumn{6}{|l|}{ Clareza } & \\
\hline Objetividade & & & & & & \\
\hline
\end{tabular}

44. A abertura da CAT (Comunicação de Acidente de Trabalho) não é importante.

\begin{tabular}{|c|c|c|c|c|c|c|}
\hline & $\begin{array}{l}\text { Discordo } \\
\text { Totalmente } \\
\text { (1) }\end{array}$ & $\begin{array}{c}\text { Discordo } \\
\text { (2) }\end{array}$ & $\begin{array}{c}\text { Não } \\
\text { discordo } \\
\text { nem } \\
\text { concordo } \\
\text { (3) }\end{array}$ & $\begin{array}{c}\text { Concordo } \\
\text { (4) }\end{array}$ & $\begin{array}{c}\text { Concordo } \\
\text { Totalmente } \\
(5)\end{array}$ & Observação \\
\hline \multicolumn{6}{|l|}{ Relevância } & \\
\hline \multicolumn{6}{|l|}{ Precisão } & \\
\hline \multicolumn{6}{|l|}{ Clareza } & \\
\hline Objetividade & & & & & & \\
\hline
\end{tabular}


45. Existe apoio institucional para os trabalhadores acidentados.

\begin{tabular}{|c|c|c|c|c|c|c|}
\hline & $\begin{array}{c}\text { Discordo } \\
\text { Totalmente } \\
\text { (1) }\end{array}$ & $\begin{array}{c}\text { Discordo } \\
(2)\end{array}$ & $\begin{array}{c}\text { Não } \\
\text { discordo } \\
\text { nem } \\
\text { concordo } \\
(3) \\
\end{array}$ & $\begin{array}{c}\text { Concordo } \\
(4)\end{array}$ & $\begin{array}{c}\text { Concordo } \\
\text { Totalmente } \\
\text { (5) }\end{array}$ & Observação \\
\hline \multicolumn{6}{|l|}{ Relevância } & \\
\hline \multicolumn{6}{|l|}{ Precisão } & \\
\hline \multicolumn{6}{|l|}{ Clareza } & \\
\hline Objetividade & & & & & & \\
\hline
\end{tabular}

46. O Atendimento médico após o acidente é importante, traz alívio e conforto.

\begin{tabular}{|c|c|c|c|c|c|c|}
\hline & $\begin{array}{c}\text { Discordo } \\
\text { Totalmente } \\
\text { (1) }\end{array}$ & $\begin{array}{l}\text { Discordo } \\
\text { (2) }\end{array}$ & $\begin{array}{c}\text { Não } \\
\text { discordo } \\
\text { nem } \\
\text { concordo } \\
\text { (3) }\end{array}$ & $\begin{array}{c}\text { Concordo } \\
\text { (4) }\end{array}$ & $\begin{array}{c}\text { Concordo } \\
\text { Totalmente } \\
\text { (5) }\end{array}$ & Observação \\
\hline \multicolumn{6}{|l|}{ Relevância } & \\
\hline \multicolumn{6}{|l|}{ Precisão } & \\
\hline \multicolumn{6}{|l|}{ Clareza } & \\
\hline Objetividade & & & & & & \\
\hline
\end{tabular}

47. A equipe tem preconceito com quem sofre acidente.

\begin{tabular}{|c|c|c|c|c|c|c|}
\hline & $\begin{array}{l}\text { Discordo } \\
\text { Totalmente } \\
\text { (1) }\end{array}$ & $\begin{array}{c}\text { Discordo } \\
\text { (2) }\end{array}$ & $\begin{array}{c}\text { Não } \\
\text { discordo } \\
\text { nem } \\
\text { concordo } \\
\text { (3) }\end{array}$ & $\begin{array}{c}\text { Concordo } \\
\text { (4) }\end{array}$ & $\begin{array}{c}\text { Concordo } \\
\text { Totalmente } \\
\text { (5) }\end{array}$ & Observação \\
\hline \multicolumn{6}{|l|}{ Relevância } & \\
\hline \multicolumn{6}{|l|}{ Precisão } & \\
\hline \multicolumn{6}{|l|}{ Clareza } & \\
\hline Objetividade & & & & & & \\
\hline
\end{tabular}

48. Os trabalhadores conhecem o acompanhamento clínico e laboratorial após o acidente.

\begin{tabular}{|c|c|c|c|c|c|c|}
\hline & $\begin{array}{l}\text { Discordo } \\
\text { Totalmente } \\
\text { (1) }\end{array}$ & $\begin{array}{c}\text { Discordo } \\
\text { (2) }\end{array}$ & $\begin{array}{c}\text { Não } \\
\text { discordo } \\
\text { nem } \\
\text { concordo } \\
\text { (3) }\end{array}$ & $\begin{array}{c}\text { Concordo } \\
\text { (4) }\end{array}$ & $\begin{array}{c}\text { Concordo } \\
\text { Totalmente } \\
\text { (5) }\end{array}$ & Observação \\
\hline \multicolumn{6}{|l|}{ Relevância } & \\
\hline \multicolumn{6}{|l|}{ Precisão } & \\
\hline \multicolumn{6}{|l|}{ Clareza } & \\
\hline Objetividade & & & & & & \\
\hline
\end{tabular}


49. O Atendimento psicológico é muito importante para o trabalhador acidentado.

\begin{tabular}{|c|c|c|c|c|c|c|}
\hline & $\begin{array}{c}\text { Discordo } \\
\text { Totalmente } \\
\text { (1) }\end{array}$ & $\begin{array}{c}\text { Discordo } \\
\text { (2) }\end{array}$ & $\begin{array}{c}\text { Não } \\
\text { discordo } \\
\text { nem } \\
\text { concordo } \\
(3) \\
\end{array}$ & $\begin{array}{c}\text { Concordo } \\
\text { (4) }\end{array}$ & $\begin{array}{c}\text { Concordo } \\
\text { Totalmente } \\
\text { (5) }\end{array}$ & Observação \\
\hline \multicolumn{6}{|l|}{ Relevância } & \\
\hline \multicolumn{6}{|l|}{ Precisão } & \\
\hline \multicolumn{6}{|l|}{ Clareza } & \\
\hline Objetividade & & & & & & \\
\hline
\end{tabular}

50. O suporte da chefia após o acidente é muito importante.

\begin{tabular}{|c|c|c|c|c|c|c|}
\hline & $\begin{array}{l}\text { Discordo } \\
\text { Totalmente } \\
\text { (1) }\end{array}$ & $\begin{array}{l}\text { Discordo } \\
\text { (2) }\end{array}$ & $\begin{array}{c}\text { Não } \\
\text { discordo } \\
\text { nem } \\
\text { concordo } \\
\text { (3) }\end{array}$ & $\begin{array}{c}\text { Concordo } \\
\text { (4) }\end{array}$ & $\begin{array}{c}\text { Concordo } \\
\text { Totalmente } \\
\text { (5) }\end{array}$ & Observação \\
\hline \multicolumn{6}{|l|}{ Relevância } & \\
\hline \multicolumn{6}{|l|}{ Precisão } & \\
\hline \multicolumn{6}{|l|}{ Clareza } & \\
\hline Objetividade & & & & & & \\
\hline
\end{tabular}

51. Os trabalhadores tem medo de uma possível demissão em caso de acidente.

\begin{tabular}{|c|c|c|c|c|c|c|}
\hline & $\begin{array}{c}\text { Discordo } \\
\text { Totalmente } \\
\text { (1) }\end{array}$ & $\begin{array}{c}\text { Discordo } \\
\text { (2) }\end{array}$ & $\begin{array}{c}\text { Não } \\
\text { discordo } \\
\text { nem } \\
\text { concordo } \\
\text { (3) }\end{array}$ & $\begin{array}{c}\text { Concordo } \\
\text { (4) }\end{array}$ & $\begin{array}{c}\text { Concordo } \\
\text { Totalmente } \\
\text { (5) }\end{array}$ & Observação \\
\hline \multicolumn{6}{|l|}{ Relevância } & \\
\hline \multicolumn{6}{|l|}{ Precisão } & \\
\hline \multicolumn{6}{|l|}{ Clareza } & \\
\hline Objetividade & & & & & & \\
\hline
\end{tabular}


Apêndice 4. Termo de Consentimento Livre e Esclarecido

\section{TERMO DE CONSENTIMENTO LIVRE E ESCLARECIDO}

Convidamos o (a) Sr (a) para participar da pesquisa intitulada "Construção e Validação de uma Escala de Crenças dos trabalhadores da equipe de enfermagem frente ao acidente de trabalho com fluido biológico" desenvolvida pela Sra. Carolina Luiza Bernardes sob a orientação da Prof ${ }^{\underline{a}}$ Dr $\stackrel{\text { a }}{ }$ Patricia Campos Pavan Baptista.

Este estudo, do tipo metodológico, baseado na teoria de elaboração de instrumental psicológico, tem como objetivo: Elaborar uma escala de medida de crenças dos trabalhadores de enfermagem frente ao acidente de trabalho com fluido biológico, que possa direcionar as estratégias a serem desenvolvidas como prevenção dos acidentes, ser utilizada como ferramenta para a gestão de enfermagem frente ao panorama mundial de acidentes e possibilitar aos trabalhadores a reflexão acerca de suas práticas no trabalho. $E$, para que consiga atingir este objetivo, contamos com sua participação na segunda etapa desta pesquisa, desta pesquisa respondendo a um teste piloto com duração de aproximadamente 30 minutos que tem como objetivo testar o instrumento quanto a sua compreensão e clareza. Será realizado no próprio local de trabalho, em horário previamente agendado, e somente após a autorização da Instituição e aprovação do Comitê de Ética e Pesquisa

Declaramos que não haverá gastos por parte do participante, mas caso o senhor (a) tenha alguma despesa decorrente da sua participação na pesquisa, será realizado ressarcimento a partir de solicitação ao pesquisador responsável. É garantida a indenização diante de eventuais danos decorrentes de sua participação nesta pesquisa.

Os possíveis riscos decorrentes de sua participação nesta pesquisa podem ser de origem psicológica, intelectual ou/e emocional envolvendo a possibilidade de constrangimento, cansaço, desconforto e estresse durante a realização da entrevista. 
São garantidas, a plena liberdade de recusar-se a participar ou retirar seu consentimento, em qualquer fase da pesquisa, sem penalização alguma, a manutenção do anonimato e da sua privacidade durante todas as fases da pesquisa. Este Termo de Consentimento Livre e Esclarecido deve ser rubricado em todas as suas páginas e assinado nas duas vias e o $\mathrm{Sr}$ (a) receberá uma via do Termo assinada e rubricada pelo pesquisador.

Em qualquer etapa do estudo, você terá acesso ao pesquisador responsável pela investigação para esclarecimento de dúvidas. O principal pesquisador é a Sra. Carolina Luiza Bernardes que pode ser encontrada no endereço Av. General Valdomiro de Lima, 590 Bloco B Apto 104 Jabaquara, São Paulo/SP, CEP 04344-070 Telefone(s) (11) 27380816 e (11) 991812409 (atendimento 24 horas) e-mail: caluiza@usp.br.

Caso você tenha alguma consideração ou dúvida sobre a ética da pesquisa, entre em contato com o Comitê de Ética em Pesquisa (CEP) - Endereço - Av. Dr. Enéas de Carvalho Aguiar, 419 - Cerqueira Cesar - São Paulo/SP CEP - 05403-000 Telefone- (11) 30618858 e-mail - cepee@usp.br ou com o Comitê de Ética do Ética em Pesquisa do Hospital Universitário da Universidade de São Paulo: Av. Prof. Lineu Prestes no 2565- 3andar Cidade Universitária - CEP 05508-000 - São Paulo-SP. Tel: (11) 3091-9457 E-mail: cep@hu.usp.br .

Esta pesquisa atende todas as especificações da Resolução 466, de 12 de dezembro de 2012 que aprova as diretrizes e normas regulamentadoras de pesquisas envolvendo seres humanos.

Assinatura do pesquisador

Data: ../ $\ldots \ldots \ldots \ldots . . . . . . \ldots \ldots \ldots . . .$.

Data:

Assinatura do participante/representante legal 
Apêndice 5. Termo de Consentimento Livre e Esclarecido

\section{TERMO DE CONSENTIMENTO LIVRE E ESCLARECIDO}

Convidamos o (a) Sr (a) para participar da pesquisa intitulada "Construção e Validação de uma Escala de Crenças dos trabalhadores da equipe de enfermagem frente ao acidente de trabalho com fluido biológico" desenvolvida pela Sra. Carolina Luiza Bernardes sob a orientação da Prof ${ }^{a}$ Dr ${ }^{\underline{a}}$ Patricia Campos Pavan Baptista.

Este estudo, do tipo metodológico, baseado na teoria de elaboração de instrumental psicológico, tem como objetivos: Elaborar uma escala de medida de crenças dos trabalhadores de enfermagem frente ao acidente de trabalho com fluido biológico, que possa direcionar as estratégias a serem desenvolvidas como prevenção dos acidentes, ser utilizada como ferramenta para a gestão de enfermagem frente ao panorama mundial de acidentes e possibilitar aos trabalhadores a reflexão acerca de suas práticas no trabalho. E, para que consiga atingir este objetivo, contamos com sua participação na terceira etapa desta pesquisa respondendo a um instrumento com duração de aproximadamente 30 minutos com o objetivo de avaliar o comportamento das crenças, segundo a escala proposta, de trabalhadores de enfermagem frente ao acidente de trabalho com fluido biológico . Será relizado no próprio local de trabalho, em horário previamente agendado, e somente após a autorização da Instituição e aprovação do Comitê de Ética e Pesquisa.

Declaramos que não haverá gastos por parte do participante, mas caso o senhor (a) tenha alguma despesa decorrente da sua participação na pesquisa, será realizado ressarcimento a partir de solicitação ao pesquisador responsável. É garantida a indenização diante de eventuais danos decorrentes de sua participação nesta pesquisa.

Os possíveis riscos decorrentes de sua participação nesta pesquisa podem ser de origem psicológica, intelectual ou/e emocional envolvendo a possibilidade de constrangimento, cansaço, desconforto e estresse durante a realização do teste piloto. 
São garantidas, a plena liberdade de recusar-se a participar ou retirar seu consentimento, em qualquer fase da pesquisa, sem penalização alguma, a manutenção do anonimato e da sua privacidade durante todas as fases da pesquisa. Este Termo de Consentimento Livre e Esclarecido deve ser rubricado em todas as suas páginas e assinado nas duas vias e o $\mathrm{Sr}$ (a) receberá uma via do Termo assinada e rubricada pelo pesquisador.

Em qualquer etapa do estudo, você terá acesso ao pesquisador responsável pela investigação para esclarecimento de dúvidas. O principal pesquisador é a Sra. Carolina Luiza Bernardes que pode ser encontrada no endereço Av. General Valdomiro de Lima, 590 Bloco B Apto 104 Jabaquara, São Paulo/SP, CEP 04344-070 Telefone(s) (11) 27380816 e (11) 991812409 (atendimento 24 horas) e-mail: caluiza@usp.br.

Caso você tenha alguma consideração ou dúvida sobre a ética da pesquisa, entre em contato com o Comitê de Ética em Pesquisa (CEP) - Endereço - Av. Dr. Enéas de Carvalho Aguiar, 419 - Cerqueira Cesar - São Paulo/SP CEP - 05403-000 Telefone- (11) 30618858 e-mail - cepee@usp.br ou com o Comitê de Ética do Ética em Pesquisa do Hospital Universitário da Universidade de São Paulo: Av. Prof. Lineu Prestes no 2565- 3andar Cidade Universitária - CEP 05508-000 - São Paulo-SP. Tel: (11) 3091-9457 E-mail: cep@hu.usp.br .

Esta pesquisa atende todas as especificações da Resolução 466, de 12 de dezembro de 2012 que aprova as diretrizes e normas regulamentadoras de pesquisas envolvendo seres humanos.

Assinatura do pesquisador

Data: ../ $\ldots \ldots \ldots \ldots . . . . . . \ldots \ldots \ldots . . .$.

Data:

Assinatura do participante/representante legal 
Apêndice 6. Escala de Crenças dos trabalhadores da equipe de Enfermagem frente ao acidente de trabalho com fluido biológico

\section{Caracterização do trabalhador}

Idade:

Sexo:

Categoria Profissional:

Ano de ingresso na instituição:

Tempo na profissão:

Já sofreu acidente de trabalho com fluido biologico?

Sr (a) Trabalhador (a), leia as frases a seguir, e marque com um $\mathrm{X}$ em "Discordo Totalmente", "Discordo", "Não discordo nem concordo", "Concordo" ou "Concordo Totalmente" de acordo com as suas crenças relacionadas aos acidentes de trabalho com fluido biológico.

\begin{tabular}{|c|c|c|c|c|c|}
\hline & $\begin{array}{l}\text { Discordo } \\
\text { Totalmente }\end{array}$ & Discordo & $\begin{array}{c}\text { Não } \\
\text { discordo } \\
\text { nem } \\
\text { concordo }\end{array}$ & Concordo & $\begin{array}{l}\text { Concordo } \\
\text { Totalmente }\end{array}$ \\
\hline $\begin{array}{l}\text { 1. Pensar sobre o acidente me causa } \\
\text { angústia. }\end{array}$ & & & & & \\
\hline $\begin{array}{l}\text { 2. Tenho medo de sofrer acidente com } \\
\text { fluido biológico no trabalho. }\end{array}$ & & & & & \\
\hline $\begin{array}{l}\text { 4. Penso que o trabalhador que sofre } \\
\text { acidente com fluido biológico } \\
\text { poderá ter conflitos familiares. }\end{array}$ & & & & & \\
\hline $\begin{array}{l}\text { 5. Acredito que a falta de conhecimento } \\
\text { dos trabalhadores em relação aos } \\
\text { acidentes de trabalho com fluido } \\
\text { biológico contribui para o acidente. }\end{array}$ & & & & & \\
\hline $\begin{array}{l}\text { 6. Penso que o acidente com fluido } \\
\text { biológico pode trazer graves } \\
\text { consequências para a vida. }\end{array}$ & & & & & \\
\hline $\begin{array}{l}\text { 8. Tenho medo de me contaminar } \\
\text { após um acidente. }\end{array}$ & & & & & \\
\hline $\begin{array}{l}\text { 9. Tenho medo de contaminar meus } \\
\text { filhos após o acidente. }\end{array}$ & & & & & \\
\hline $\begin{array}{l}\text { 11. Penso que o acidente pode fazer o } \\
\text { trabalhador repensar sobre a } \\
\text { própria vida. }\end{array}$ & & & & & \\
\hline $\begin{array}{l}\text { 13. Vejo que os trabalhadores que } \\
\text { sofrem acidente de trabalho com } \\
\text { fluido biológico passam a repensar } \\
\text { suas práticas de trabalho. }\end{array}$ & & & & & \\
\hline 14. O Estresse influencia a ocorrência & & & & & \\
\hline
\end{tabular}




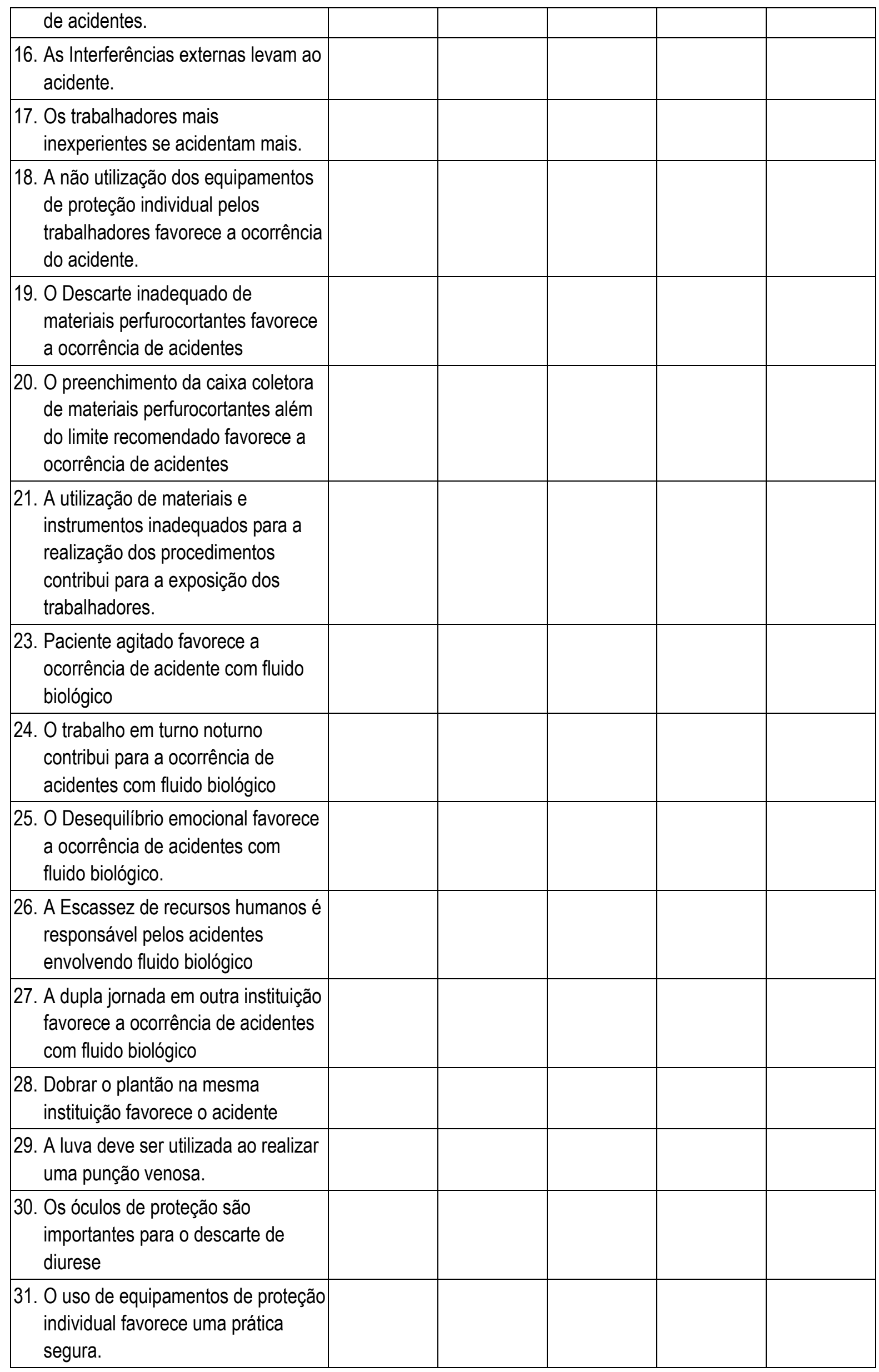




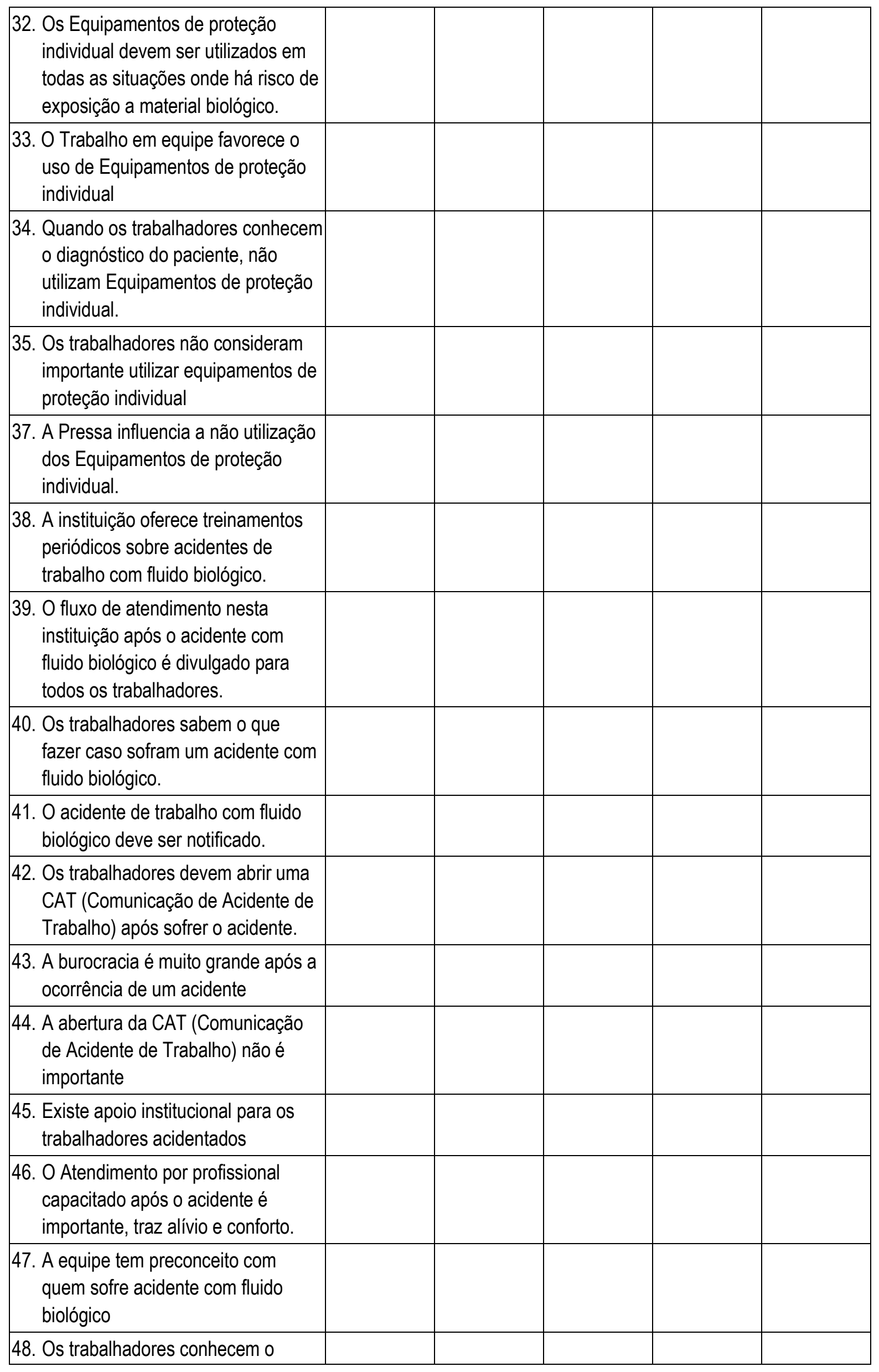




\begin{tabular}{|c|l|l|l|l|l|}
\hline $\begin{array}{l}\text { acompanhamento clínico e } \\
\text { laboratorial após o acidente. }\end{array}$ & & & & & \\
\hline $\begin{array}{c}\text { 49. O Atendimento psicológico é muito } \\
\text { importante para o trabalhador } \\
\text { acidentado. }\end{array}$ & & & & & \\
\hline $\begin{array}{c}\text { 50. O suporte da chefia após o acidente } \\
\text { é muito importante. }\end{array}$ & & & & & \\
\hline $\begin{array}{l}\text { 51. Os trabalhadores têm medo de uma } \\
\text { possível demissão em caso de } \\
\text { acidentes com fluido biológico. }\end{array}$ & & & & & \\
\hline
\end{tabular}


Anexo 1. Parecer Consubstanciado do CEP (No. 2286094)

\begin{tabular}{|c|c|c|} 
USP - ESCOLA DE \\
ENFERMAGEM DA \\
ENIVERSIDADE DE SÃO
\end{tabular}

PARECER CONSUBSTANCIADO DO CEP

\section{DADOS DO PROJETO DE PESQUISA}

Título da Pesquisa: Construção e Validação de uma Escala de Crenças dos trabalhadores da equipe de enfermagem frente ao acidente de trabalho com fluido biológico

Pesquisador: CAROLINA LUIZA BERNARDES

Área Temática:

Versão: 4

CAAE: 67648017.4 .0000 .5392

Instituição Proponente: Escola de Enfermagem da Universidade de São Paulo - EEUSP

Patrocinador Principal: Financiamento Próprio

\section{DADOS DO PARECER}

Número do Parecer: 2.286 .094

\section{Apresentação do Projeto:}

Trata-se de projeto de Doutorado, classificado como estudo metodológico, cujo método é baseado na teoria de elaboração de instrumental psicológico, composto por três focos: procedimentos teóricos, procedimentos empíricos ou experimentais e procedimentos analíticos.

O estudo parte da hipótese de que as crenças dos trabalhadores, construídas ao longo da vida profissional relacionadas aos acidentes de trabalho com fluidos biológicos bem como ao uso de equipamentos de proteção individual interferem nas práticas seguras, inclusive no seguimento clínico após a exposição e a recorrência do acidente.

A população do estudo será composta pelos trabalhadores da equipe de enfermagem (enfermeiros, técnicos e auxiliares de enfermagem) do Hospital Universitário da USP.

A elaboração e Validação da Escala de medida de Crenças envolverá as seguintes etapas:

Etapa I Procedimento teórico: Esta etapa envolve a construção do instrumento. Para a construção dos itens da escala, inicialmente será definido o constructo de interesse e suas dimensões por meio de pesquisa bilbiográfica. Os itens serão elaborados, os quais deverão ser valorados a partir de uma escala do tipo Likert, com 5 alternativas de resposta.

Posteriormente, a validação será feita por um grupo de seis juízes.

Etapa II: Análise Semântica: será aplicado o instrumento a um grupo heterogêneo de

\footnotetext{
Endereço: Av. Dr. Enéas de Carvalho Aguiar, 419

Bairro: Cerqueira Cesar

UF: SP Município: SAO PAULO

Telefone: (11)3061-8858

CEP: $05.403-000$

E-mail: cepee@usp.br
} 


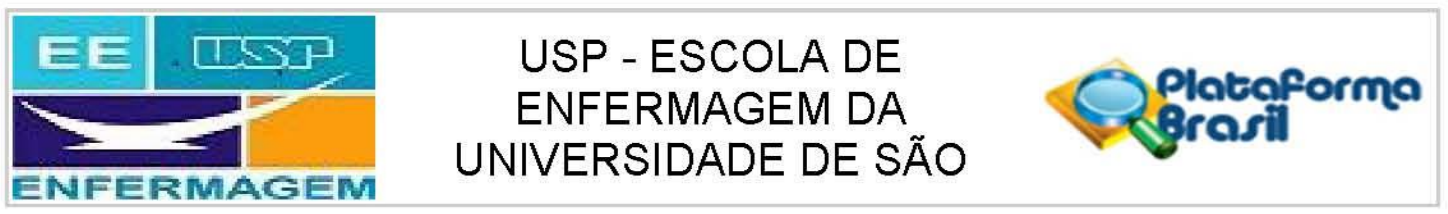

Continuação do Parecer: 2.286 .094

trabalhadores de enfermagem contendo as três categorias profissionais, enfermeiros, técnicos e auxiliares de enfermagem e em seguida serão discutidas as dúvidas que os itens suscitarem que deverão ser sanadas.

Etapa III: Aplicação do questionário na amostra de trabalhadores de enfermagem e avaliação das Propriedades de Medidas do Instrumento. Esta etapa envolve a verificação das propriedades psicométricas do instrumento por meio da avaliação da confiabilidade e validade.

\section{Objetivo da Pesquisa:}

Objetivo Geral

Elaborar uma escala de medida de crenças dos trabalhadores de enfermagem frente ao acidente de trabalho com fluido biológico.

\section{Objetivos Específicos}

- Validação da escala de medida de crenças de trabalhadores de enfermagem frente ao acidente de trabalho com fluido biológico.

- Avaliação das propriedades psicométricas da escala de crenças por meio de parâmetros estatísticos.

- Avaliar o comportamentos das crenças, segundo a escala proposta, de trabalhadores de enfermagem frente ao acidente de trabalho com fluido biológico.

\section{Avaliação dos Riscos e Benefícios:}

Riscos de origem psicológica, intelectual ou/e emocional envolvendo a possibilidade de constrangimento e cansaço ao responder as questões; desconforto e estresse, podendo haver interrupção a qualquer momento

Benefícios da pesquisa: a construção desta escala poderá ser relevante para a Enfermagem na medida em que possa direcionar as estratégias a serem desenvolvidas como prevenção dos acidentes, possa ser utilizada como ferramenta para a gestão de enfermagem frente ao panorama mundial de acidentes e possibilite aos trabalhadores a reflexão acerca de suas práticas no trabalho, além de fornecer subsídios para que novos estudos sejam realizados com o objetivo de

Endereço: Av. Dr. Enéas de Carvalho Aguiar, 419

Bairro: Cerqueira Cesar

CEP: $\quad 05.403-000$

UF: SP

Município: SAO PAULO

Telefone: (11)3061-8858

E-mail: cepee@usp.br 


\section{$\equiv \equiv$ USP $\quad$ USP - ESCOLA DE

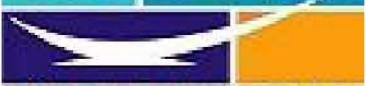

Continuação do Parecer: 2.286 .094

reduzir os acidentes de trabalho com fluidos biológicos na equipe de enfermagem.

Comentários e Considerações sobre a Pesquisa:

Pesquisa interessante, de valor para a área de atuação. O projeto foi apresentado com embasamento teórico sobre a questão dos acidentes de trabalho.

\section{Considerações sobre os Termos de apresentação obrigatória:}

A pesquisadora encaminhou novas versões do TCLE, do projeto e do Cadastro da Plataforma Brasil com as correções e modificações solicitadas, a saber:

- O item Metodologia Proposta, no Cadastro da Plataforma Brasil foi corrigido.

- A grafia da palavra "compreensão" foi corrigida no TCLE .

- Foi incluído no TCLE o objetivo da participação na terceira etapa.

- A pesquisadora afirmou que "a elaboração da escala de crenças dos trabalhadores da equipe de enfermagem frente ao acidente de trabalho com fluido biológico se encerra na análise fatorial do constructo." Portanto, não haverá mais a elaboração e análise do banco de dados.

\section{Recomendações:}

Sugere-se que o último objetivo específico seja re-escrito, uma vez que fica estranho "avaliar o comportamento das crenças dos trabalhadores...."

\section{Conclusões ou Pendências e Lista de Inadequações:}

Não há pendências.

\section{Considerações Finais a critério do CEP:}

- Este CEP informa a necessidade de registro dos resultados parciais e finais na Plataforma Brasil;

- Esta aprovação não substitui a autorização da instituição coparticipante, antes do início da coleta de dados.

Este parecer foi elaborado baseado nos documentos abaixo relacionados:

\begin{tabular}{|l|l|c|l|c|}
\hline \multicolumn{1}{|c|}{ Tipo Documento } & \multicolumn{1}{|c|}{ Arquivo } & Postagem & Autor & Situação \\
\hline Informações Básicas & PB_INFORMAÇŌES_BÁSICAS_DO_P & $02 / 09 / 2017$ & & Aceito \\
do Projeto & ROJETO 899213.pdf & $21: 40: 34$ & & \\
\hline Projeto Detalhado / & Projeto02_09.docx & $02 / 09 / 2017$ & $\begin{array}{l}\text { CAROLINA LUIZA } \\
\text { Brochura }\end{array}$ & Aceito \\
\hline
\end{tabular}

Endereço: Av. Dr. Enéas de Carvalho Aguiar, 419

Bairro: Cerqueira Cesar

CEP: $05.403-000$

UF: SP

Município: SAO PAULO

Telefone: (11)3061-8858

E-mail: cepee@usp.br 


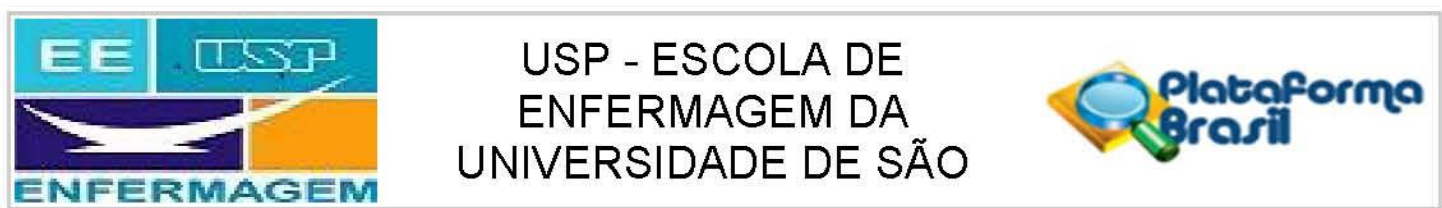

Continuação do Parecer: 2.286 .094

\begin{tabular}{|c|c|c|c|c|}
\hline Investigador & Projeto02_09.docx & $\begin{array}{c}02 / 09 / 2017 \\
21: 37: 26\end{array}$ & $\begin{array}{l}\text { CAROLINA LUIZA } \\
\text { BERNARDES }\end{array}$ & Aceito \\
\hline $\begin{array}{l}\text { TCLE / Termos de } \\
\text { Assentimento / } \\
\text { Justificativa de } \\
\text { Ausência }\end{array}$ & TCLE.docx & $\begin{array}{c}02 / 09 / 2017 \\
21: 35: 22\end{array}$ & $\begin{array}{l}\text { CAROLINA LUIZA } \\
\text { BERNARDES }\end{array}$ & Aceito \\
\hline Folha de Rosto & folha_rosto.pdf & $\begin{array}{c}07 / 08 / 2017 \\
20: 03: 12\end{array}$ & $\begin{array}{l}\text { CAROLINA LUIZA } \\
\text { BERNARDES }\end{array}$ & Aceito \\
\hline Outros & Declaracao_Compromisso.pdf & $\begin{array}{c}19 / 04 / 2017 \\
22: 44: 42\end{array}$ & $\begin{array}{l}\text { CAROLINA LUIZA } \\
\text { BERNARDES }\end{array}$ & Aceito \\
\hline Outros & Declaracao_Beneficios.pdf & $\begin{array}{c}19 / 04 / 2017 \\
22: 44: 11\end{array}$ & $\begin{array}{l}\text { CAROLINA LUIZA } \\
\text { BERNARDES }\end{array}$ & Aceito \\
\hline Outros & CartaAnuencia_Camara.pdf & $\begin{array}{c}19 / 04 / 2017 \\
22: 42: 29\end{array}$ & $\begin{array}{l}\text { CAROLINA LUIZA } \\
\text { BERNARDES }\end{array}$ & Aceito \\
\hline Outros & Carta_Anuencia_area.pdf & $\begin{array}{c}19 / 04 / 2017 \\
22: 41: 06\end{array}$ & $\begin{array}{l}\text { CAROLINA LUIZA } \\
\text { BERNARDES }\end{array}$ & Aceito \\
\hline Outros & Cadastro_Pesquisa.pdf & $\begin{array}{c}19 / 04 / 2017 \\
22: 40: 11\end{array}$ & $\begin{array}{l}\text { CAROLINA LUIZA } \\
\text { BERNARDES }\end{array}$ & Aceito \\
\hline Orçamento & Orcamento_Financeiro.pdf & $\begin{array}{c}19 / 04 / 2017 \\
22: 38: 02\end{array}$ & $\begin{array}{l}\text { CAROLINA LUIZA } \\
\text { BERNARDES }\end{array}$ & Aceito \\
\hline $\begin{array}{l}\text { Declaração de } \\
\text { Instituição e } \\
\text { Infraestrutura }\end{array}$ & Decl_Infraestrututa_Pesq_Carolina.pdf & $\begin{array}{l}19 / 04 / 2017 \\
22: 37: 12\end{array}$ & $\begin{array}{l}\text { CAROLINA LUIZA } \\
\text { BERNARDES }\end{array}$ & Aceito \\
\hline Cronograma & Cronograma_Execucao.pdf & $\begin{array}{c}19 / 04 / 2017 \\
22: 36: 44\end{array}$ & $\begin{array}{l}\text { CAROLINA LUIZA } \\
\text { BERNARDES }\end{array}$ & Aceito \\
\hline
\end{tabular}

Situação do Parecer:

Aprovado

Necessita Apreciação da CONEP:

Não

SAO PAULO, 20 de Setembro de 2017

Assinado por:

Marcelo José dos Santos

(Coordenador)

Endereço: Av. Dr. Enéas de Carvalho Aguiar, 419

Bairro: Cerqueira Cesar

UF: SP

Município: SAO PAULO

Telefone: (11)3061-8858

CEP: $05.403-000$

E-mail: cepee@usp.br

Página 04 de 04 
Anexo 2. Parecer Consubstanciado do CEP (No. 2352645)

USP - HOSPITAL
UNIVERSITÁRIO DA
UNIVERSIDADE DE SÃO

\section{PARECER CONSUBSTANCIADO DO CEP}

Elaborado pela Instituição Coparticipante

\section{DADOS DO PROJETO DE PESQUISA}

Título da Pesquisa: Construção e Validação de uma Escala de Crenças dos trabalhadores da equipe de enfermagem frente ao acidente de trabalho com fluido biológico

Pesquisador: CAROLINA LUIZA BERNARDES

Área Temática:

Versão: 1

CAAE: 67648017.4 .3001 .0076

Instituição Proponente: Hospital Universitário da Universidade de São Paulo

Patrocinador Principal: Financiamento Próprio

\section{DADOS DO PARECER}

\section{Número do Parecer: 2.352 .645}

\section{Apresentação do Projeto:}

Trata-se de tese de Doutorado do Programa de Pós-Graduação em Gerenciamento

em Enfermagem da EEUSP. Trata-se de estudo metodológico, cujo método é baseado na teoria de elaboração de instrumental psicológico, composto por três focos: procedimentos teóricos, que compreendem a teoria e a construção do instrumento, procedimentos experimentais e procedimentos analíticos, responsáveis por sua validação e normatização. A amostra será composta por 320 trabalhadores da equipe de enfermagem (enfermeiros, técnicos e auxiliares de enfermagem)do HU-USP, que em entrevista, testarão o instrumento quanto a sua compreensão e clareza, com o objetivo de avaliar o comportamento das crenças, segundo a escala proposta, de trabalhadores de enfermagem frente ao acidente de trabalho com fluido biológico .

Objetivo da Pesquisa:

- Objetivo Geral:

Elaborar uma escala de medida de crenças dos trabalhadores de enfermagem frente ao acidente de trabalho com fluido biológico.

- Objetivos Específicos:

Validação da escala de medida de crenças de trabalhadores de enfermagem frente ao acidente de trabalho com fluido biológico.

Avaliação das propriedades psicométricas da escala de crenças por meio de parâmetros

Endereço: Av. Profo Lineu Prestes, 2565

Bairro: Cidade Universitária

UF: SP Município: SAO PAULO

CEP: $05.508-000$

Telefone: (11)3091-9457

E-mail: cep@hu.usp.br 


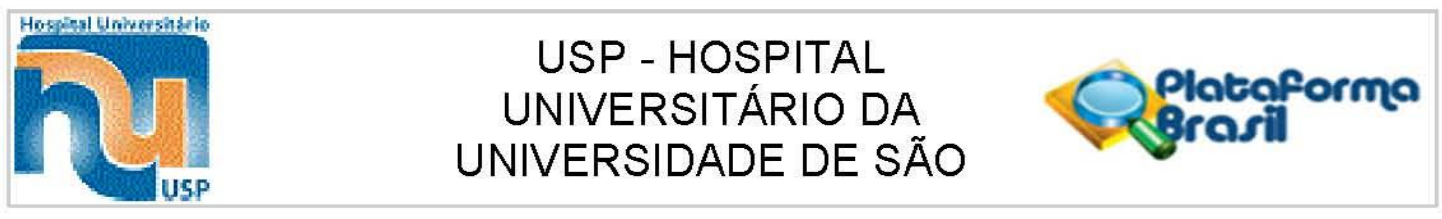

Continuação do Parecer: 2.352 .645

estatísticos.

- Avaliar o comportamentos das crenças, segundo a escala proposta, de trabalhadores de enfermagem frente ao acidente de trabalho com fluido biológico.

\section{Avaliação dos Riscos e Benefícios:}

Possíveis riscos referem-se a constrangimento, cansaço, desconforto e estresse durante a realização da entrevista, sendo assegurado a desistência a qualquer momento, garantia de anonimato e privacidade. Benefícios - o instrumento pode ser utilizado como ferramenta para a gestão de enfermagem frente ao panorama mundial de acidentes e possibilitar aos trabalhadores a reflexão acerca de suas práticas no trabalho.

\section{Comentários e Considerações sobre a Pesquisa:}

Pesquisa relevante para a gestão em enfermagem, com metodologia adequada.

\section{Considerações sobre os Termos de apresentação obrigatória:}

TCLE adequados, projeto aprovado pelo Comitê de Ética em Pesquisa da EEUSP.

\section{Recomendações:}

Não há.

Conclusões ou Pendências e Lista de Inadequações:

Não há.

\section{Considerações Finais a critério do CEP:}

O projeto já foi apresentado e aprovado no CEP da EEUSP em setembro de 2017. Hoje apresentado e tmbém aprovado em nossa reunião.Lembramos que cabe ao pesquisador elaborar e apresentar a este Comitê, relatórios parciais e final, de acordo com a Resolução n 466/2012 do Conselho Nacional de Saúde, inciso XI.2, letra "d".

Este parecer foi elaborado baseado nos documentos abaixo relacionados:

\begin{tabular}{|c|c|c|c|c|}
\hline Tipo Documento & Arquivo & Postagem & Autor & Situação \\
\hline $\begin{array}{l}\text { Informações Básicas } \\
\text { do Projeto }\end{array}$ & $\begin{array}{l}\text { PB_INFORMAÇŌES_BÁSICAS_DO_P } \\
\text { ROJETO 899213.pdf }\end{array}$ & $\begin{array}{l}02 / 09 / 2017 \\
21: 40: 34\end{array}$ & & Aceito \\
\hline $\begin{array}{l}\text { Projeto Detalhado / } \\
\text { Brochura } \\
\text { Investigador }\end{array}$ & Projeto02_09.docx & $\begin{array}{c}02 / 09 / 2017 \\
21: 37: 26\end{array}$ & $\begin{array}{l}\text { CAROLINA LUIZA } \\
\text { BERNARDES }\end{array}$ & Aceito \\
\hline
\end{tabular}

Endereço: Av. Prof Lineu Prestes, 2565

Bairro: Cidade Universitária

UF: SP Município: SAO PAULO

Telefone: (11)3091-9457

CEP: $05.508-000$

E-mail: cep@hu.usp.br 


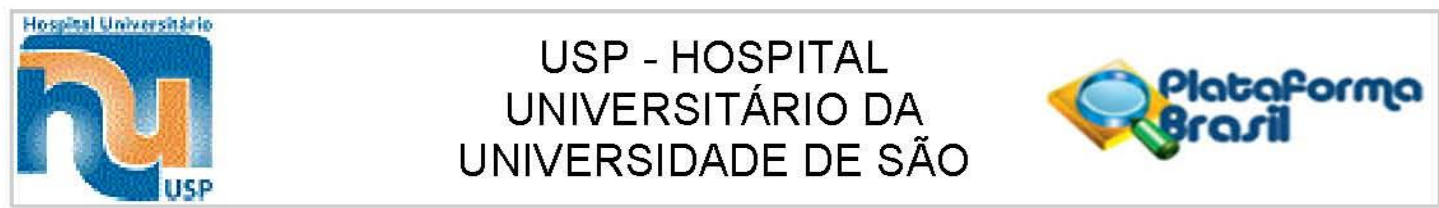

Continuação do Parecer: 2.352 .645

\begin{tabular}{|c|c|c|c|c|}
\hline $\begin{array}{l}\text { TCLE / Termos de } \\
\text { Assentimento / } \\
\text { Justificativa de } \\
\text { Ausência }\end{array}$ & TCLE.docx & $\begin{array}{l}02 / 09 / 2017 \\
21: 35: 22\end{array}$ & $\begin{array}{l}\text { CAROLINA LUIZA } \\
\text { BERNARDES }\end{array}$ & Aceito \\
\hline $\begin{array}{l}\text { Informações Básicas } \\
\text { do Projeto }\end{array}$ & $\begin{array}{l}\text { PB_INFORMAÇŌES_BÁSICAS_DO_P } \\
\text { ROJETO 899213.pdf }\end{array}$ & $\begin{array}{l}08 / 08 / 2017 \\
10: 34: 33\end{array}$ & & Aceito \\
\hline $\begin{array}{l}\text { Projeto Detalhado / } \\
\text { Brochura } \\
\text { Investiaador }\end{array}$ & Projeto08_08.docx & $\begin{array}{c}08 / 08 / 2017 \\
10: 33: 08\end{array}$ & $\begin{array}{l}\text { CAROLINA LUIZA } \\
\text { BERNARDES }\end{array}$ & Aceito \\
\hline $\begin{array}{l}\text { Informações Básicas } \\
\text { do Projeto }\end{array}$ & $\begin{array}{l}\text { PB_INFORMAÇŌES_BÁSICAS_DO_P } \\
\text { ROJETO 899213.pdf }\end{array}$ & $\begin{array}{l}07 / 08 / 2017 \\
20: 07: 12\end{array}$ & & Aceito \\
\hline $\begin{array}{l}\text { TCLE / Termos de } \\
\text { Assentimento / } \\
\text { Justificativa de } \\
\text { Ausência }\end{array}$ & TCLE.docx & $\begin{array}{l}07 / 08 / 2017 \\
20: 06: 24\end{array}$ & $\begin{array}{l}\text { CAROLINA LUIZA } \\
\text { BERNARDES }\end{array}$ & Aceito \\
\hline Folha de Rosto & folha_rosto.pdf & $\begin{array}{l}07 / 08 / 2017 \\
20: 03: 12\end{array}$ & $\begin{array}{l}\text { CAROLINA LUIZA } \\
\text { BERNARDES }\end{array}$ & Aceito \\
\hline $\begin{array}{l}\text { Informações Básicas } \\
\text { do Projeto }\end{array}$ & $\begin{array}{l}\text { PB_INFORMAÇÓES_BÁSICAS_DO_P } \\
\text { ROJETO 899213.pdf }\end{array}$ & $\begin{array}{c}25 / 05 / 2017 \\
15: 19: 27\end{array}$ & & Aceito \\
\hline $\begin{array}{l}\text { Projeto Detalhado / } \\
\text { Brochura } \\
\text { Investigador }\end{array}$ & Projeto.docx & $\begin{array}{c}25 / 05 / 2017 \\
15: 18: 47\end{array}$ & $\begin{array}{l}\text { CAROLINA LUIZA } \\
\text { BERNARDES }\end{array}$ & Aceito \\
\hline $\begin{array}{l}\text { TCLE / Termos de } \\
\text { Assentimento / } \\
\text { Justificativa de } \\
\text { Ausência }\end{array}$ & TCLE.docx & $\begin{array}{c}25 / 05 / 2017 \\
15: 13: 34\end{array}$ & $\begin{array}{l}\text { CAROLINA LUIZA } \\
\text { BERNARDES }\end{array}$ & Aceito \\
\hline $\begin{array}{l}\text { Informações Básicas } \\
\text { do Projeto }\end{array}$ & $\begin{array}{l}\text { PB_INFORMAÇŌES_BÁSICAS_DO_P } \\
\text { ROJETO 899213.pdf }\end{array}$ & $\begin{array}{c}25 / 04 / 2017 \\
19: 16: 28 \\
\end{array}$ & & Aceito \\
\hline $\begin{array}{l}\text { TCLE / Termos de } \\
\text { Assentimento / } \\
\text { Justificativa de } \\
\text { Ausência } \\
\end{array}$ & TCLE_.doc & $\begin{array}{c}25 / 04 / 2017 \\
19: 15: 54\end{array}$ & $\begin{array}{l}\text { CAROLINA LUIZA } \\
\text { BERNARDES }\end{array}$ & Aceito \\
\hline $\begin{array}{l}\text { Informações Básicas } \\
\text { do Projeto }\end{array}$ & $\begin{array}{l}\text { PB_INFORMAÇŌES_BÁSICAS_DO_P } \\
\text { ROJETO 899213.pdf }\end{array}$ & $\begin{array}{c}23 / 04 / 2017 \\
19: 38: 15 \\
\end{array}$ & & Aceito \\
\hline $\begin{array}{l}\text { Informações Básicas } \\
\text { do Projeto }\end{array}$ & $\begin{array}{l}\text { PB_INFORMAÇOES_BÁSICAS_DO_P } \\
\text { ROJETO 899213.pdf }\end{array}$ & $\begin{array}{l}19 / 04 / 2017 \\
22: 51: 55\end{array}$ & & Aceito \\
\hline $\begin{array}{l}\text { Projeto Detalhado / } \\
\text { Brochura } \\
\text { Investigador }\end{array}$ & Projeto.docx & $\begin{array}{l}19 / 04 / 2017 \\
22: 48: 06\end{array}$ & $\begin{array}{l}\text { CAROLINA LUIZA } \\
\text { BERNARDES }\end{array}$ & Aceito \\
\hline Outros & Declaracao_Compromisso.pdf & $\begin{array}{l}19 / 04 / 2017 \\
22: 44: 42\end{array}$ & $\begin{array}{l}\text { CAROLINA LUIZA } \\
\text { BERNARDES }\end{array}$ & Aceito \\
\hline Outros & Declaracao_Beneficios.pdf & $\begin{array}{c}19 / 04 / 2017 \\
22: 44: 11\end{array}$ & $\begin{array}{l}\text { CAROLINA LUIZA } \\
\text { BERNARDES }\end{array}$ & Aceito \\
\hline Outros & CartaAnuencia_Camara.pdf & $\begin{array}{c}19 / 04 / 2017 \\
22: 42: 29\end{array}$ & $\begin{array}{l}\text { CAROLINA LUIZA } \\
\text { BERNARDES }\end{array}$ & Aceito \\
\hline Outros & Carta_Anuencia_area.pdf & $\begin{array}{c}19 / 04 / 2017 \\
22: 41: 06\end{array}$ & $\begin{array}{l}\text { CAROLINA LUIZA } \\
\text { BERNARDES }\end{array}$ & Aceito \\
\hline
\end{tabular}

Endereço: Av. Prof Lineu Prestes, 2565

Bairro: Cidade Universitária

UF: SP

Município: SAO PAULO

Telefone: (11)3091-9457
CEP: $05.508-000$

E-mail: cep@hu.usp.br 


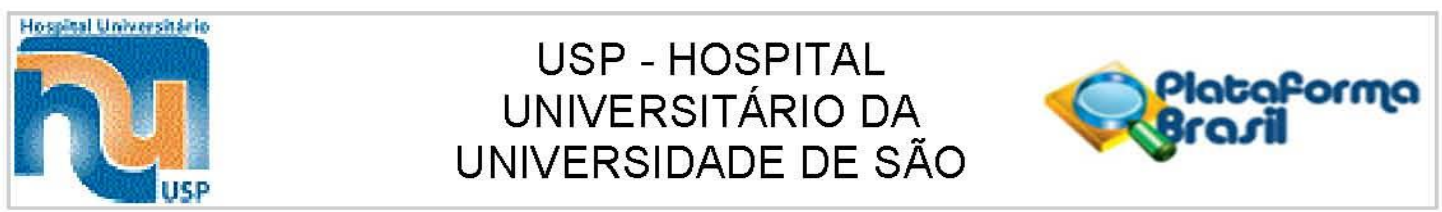

Continuação do Parecer: 2.352 .645

\begin{tabular}{|c|c|c|c|c|}
\hline Outros & Cadastro_Pesquisa.pdf & $\begin{array}{c}19 / 04 / 2017 \\
22: 40: 11\end{array}$ & $\begin{array}{l}\text { CAROLINA LUIZA } \\
\text { BERNARDES }\end{array}$ & Aceito \\
\hline Orçamento & Orcamento_Financeiro.pdf & $\begin{array}{c}19 / 04 / 2017 \\
22: 38: 02\end{array}$ & $\begin{array}{l}\text { CAROLINA LUIZA } \\
\text { BERNARDES }\end{array}$ & Aceito \\
\hline $\begin{array}{l}\text { Declaração de } \\
\text { Instituição e } \\
\text { Infraestrutura }\end{array}$ & Decl_Infraestrututa_Pesq_Carolina.pdf & $\begin{array}{c}19 / 04 / 2017 \\
22: 37: 12\end{array}$ & $\begin{array}{l}\text { CAROLINA LUIZA } \\
\text { BERNARDES }\end{array}$ & Aceito \\
\hline Cronograma & Cronograma_Execucao.pdf & $\begin{array}{c}19 / 04 / 2017 \\
22: 36: 44 \\
\end{array}$ & $\begin{array}{l}\text { CAROLINA LUIZA } \\
\text { BERNARDES }\end{array}$ & Aceito \\
\hline Folha de Rosto & Folha_Rosto.pdf & $\begin{array}{c}19 / 04 / 2017 \\
21: 10: 25\end{array}$ & $\begin{array}{l}\text { CAROLINA LUIZA } \\
\text { BERNARDES }\end{array}$ & Aceito \\
\hline
\end{tabular}

Situação do Parecer:

Aprovado

Necessita Apreciação da CONEP:

Não

SAO PAULO, 27 de Outubro de 2017

Assinado por:

(Coordenador)

Endereço: Av. Prof ${ }^{\circ}$ Lineu Prestes, 2565

Bairro: Cidade Universitária

UF: SP

Município: SAO PAULO

Telefone: (11)3091-9457
CEP: $05.508-000$

E-mail: cep@hu.usp.br 